IZA DP No. 10359

Labor Outcomes during the Transition from Adolescence to Adulthood: The Role of Personality, Cognition, and Shocks in Madagascar

David E. Sahn

Kira M. Villa

November 2016 


\title{
Labor Outcomes during the Transition from Adolescence to Adulthood: The Role of Personality, Cognition, and Shocks in Madagascar
}

\author{
David E. Sahn \\ Cornell University \\ and IZA \\ Kira M. Villa \\ University of New Mexico
}

Discussion Paper No. 10359

November 2016

\author{
IZA \\ P.O. Box 7240 \\ 53072 Bonn \\ Germany \\ Phone: +49-228-3894-0 \\ Fax: +49-228-3894-180 \\ E-mail: iza@iza.org
}

Any opinions expressed here are those of the author(s) and not those of IZA. Research published in this series may include views on policy, but the institute itself takes no institutional policy positions. The IZA research network is committed to the IZA Guiding Principles of Research Integrity.

The Institute for the Study of Labor (IZA) in Bonn is a local and virtual international research center and a place of communication between science, politics and business. IZA is an independent nonprofit organization supported by Deutsche Post Foundation. The center is associated with the University of Bonn and offers a stimulating research environment through its international network, workshops and conferences, data service, project support, research visits and doctoral program. IZA engages in (i) original and internationally competitive research in all fields of labor economics, (ii) development of policy concepts, and (iii) dissemination of research results and concepts to the interested public.

IZA Discussion Papers often represent preliminary work and are circulated to encourage discussion. Citation of such a paper should account for its provisional character. A revised version may be available directly from the author. 


\section{ABSTRACT \\ Labor Outcomes during the Transition from Adolescence to Adulthood: The Role of Personality, Cognition, and Shocks in Madagascar}

There is growing evidence that noncognitive skills affect economic, behavioral, and demographic outcomes in the developed world. However, little such evidence exists from developing countries. This paper estimates the joint effect of five specific personality traits and cognition on a sequence of labor market outcomes for a sample of Malagasy individuals as they transition from adolescence to young adulthood. Specifically we model these individuals' age of entry into the labor market, labor market sectoral selection, and within sector earnings. The personality traits we examine are the Big Five Personality Traits: Openness to Experience, Conscientiousness, Extraversion, Agreeableness, and Neuroticism. Additionally, we look at how these traits interact with household-level shocks in determining their labor market entry decisions. We find that personality, as well as cognitive test scores, affect these outcomes of interest, and that their impact on labor supply is, in part, a function of how individuals respond to exogenous shocks.

JEL Classification: $\quad 015,017, \mathrm{~J} 16, \mathrm{~J} 24, \mathrm{~J} 22$

Keywords: personality, cognitive, noncognitive, returns to skills, informal sector, formal sector, labor market entry, shocks, Madagascar

Corresponding author:

David E. Sahn

Cornell University

B16 MVR Hall

Ithaca, NY 14853

USA

E-mail: David.Sahn@cornell.edu

\footnotetext{
* The work was supported by the IZA/DFID GLM | LIC Program under Grant Agreement GA-C1-RA4067. This document is an output from a project funded by the UK Department for International Development (DFID) and the Institute for the Study of Labor (IZA) for the benefit of developing countries. The views expressed are not necessarily those of DFID or IZA. The authors would like to thank Marc Bellemare, Travis Lybbert and participants of the 2015 PAA and AAEA annual meetings for their comments and suggestions.
} 


\section{Introduction}

There is ample evidence from economics and psychology that cognitive ability is an important predictor of a number of economic, demographic, and social outcomes of interest. Recent research, albeit more limited, suggests that “noncognitive” skills ${ }^{1}$ are also important for economic success, affecting labor market participation and earnings, as well as a broad range of related outcomes, including school attainment, crime participation, earnings, and participation in risky behaviors (Dawson et al. 2000; Meany 2001; Blau and Currie 2006; Cunha et al. 2006; Knudsen et al. 2006; Heckman 2007; Marshall 2009; Curley et al. 2011). Recent views hold that noncognitive skills may be equally—or even more—important in determining economic success than cognition (Brunello and Schlotter 2011).

Research in psychology and sociology investigates the relationship between specific noncognitive traits and numerous outcomes of interest. One strand in this literature examines the importance of personality and what is referred to as the Big Five Personality Traits: Openness to Experience, Conscientiousness, Extraversion, Agreeableness, and Neuroticism. Findings from developed countries show that these five traits are important predictors of outcomes such as job performance, wages, academic achievement, occupational choice, and health (Barrick and Mount 1991; Hogan et al. 1996; Schmidt and Hunter 1998; Chamorro-Premuzic and Furnham 2003; Hogan and Holland 2003; Hampson et al. 2006; Robbins et al. 2006; Ones et al. 2007; Roberts et al. 2007).

Given the broad range of outcomes with which cognitive and noncognitive traits are associated, their influence on adult economic success likely represents a direct effect, in addition

\footnotetext{
${ }^{1}$ Noncognitive ability encompasses the socio-emotional status of an individual and includes an extensive set of skills and characteristics such as personality, motivation, perseverance, self-control, time preference, self-esteem, and the ability to work with others.
} 
to the cumulative impact of numerous indirect effects through mediating outcomes such as school achievement, occupational choice, and experience. In their pioneering study, Heckman et al. (2006) found that noncognitive skills not only directly raise wages, but also indirectly affect wages through schooling, occupational choice, and work experience.

The vast majority of research linking cognitive and noncognitive abilities to economic outcomes of the interest comes from a developed country context. In this analysis, we take these questions to a developing country context to examine how cognition and certain noncognitive traits directly and indirectly influence the labor market outcomes of a sample of young adults in Madagascar. In developing countries, there is limited but growing evidence that points to the importance of cognitive ability ${ }^{2}$ for educational attainment and economic success. However, to date, we are not aware of any empirical evidence linking personality and other noncognitive dimensions to labor market outcomes in poorer countries.

There are a number of reasons why understanding the importance of personality traits, in addition to cognitive ability, to economic success might have salience in a developing country context. In developing countries, schooling is not universal and school quality is generally lower, making traditional signals of human capital such as school attainment weaker. Further, evidence suggests that the economic importance of noncognitive skills exceeds that of cognition for poorer households in developed countries (Heckman et al. 2006; Lindqvist and Vestman 2011). Therefore, the importance of noncognitive traits and skills for success in life in poor countries

\footnotetext{
${ }^{2}$ For the remainder of the paper, we assume that cognitive skills can be measured using scholastic achievement tests. Cognitive skills are thus a direct measure of human capital and a function of "effective schooling," which is a function of actual years of schooling, as well as school characteristics and household characteristics, such as parental education and assets and unobserved individual ability.
} 
with generally weak school infrastructure may be even greater than is found in developed countries.

Additionally, cognitive ability and personality traits may influence the extent to which other determinants affect economic and social outcomes. For example, in developing countries, shocks to a household's health and economic well-being present a real threat to the household's ability to build the human capital of its members through schooling. ${ }^{3}$ A household's decision to cope with shocks by taking a child out of school may depend on that child's cognitive ability and personality, which affect both her returns to schooling, as well as her labor market returns. In this way, personality and ability interact with household shocks to jointly affect the child’s educational and economic outcomes.

In this paper, we explore how personality and cognition jointly determine a sequence of labor outcomes for individuals in our Malagasy sample, as they transition from adolescence to young adulthood. Namely, we investigate the role of cognitive skills and the Big Five Personality traits in determining age of entry into the labor market, selection into labor market sectors, and finally, within sector earnings. By looking at how these traits influence a sequence of labor market decisions, we are able to explore their direct and cumulative indirect effects on adult economic productivity. One important element of the indirect effects that we examine is the extent to which these traits and skills either mitigate or exacerbate the influence of householdlevel shocks on the decision to first enter the labor market.

Since individuals in our sample are still relatively young — most between 21 and 23 years of age - many have not yet entered the job market. We, therefore, model age of entry into the labor market as a continuous time hazard with right censored observations. In modeling

\footnotetext{
${ }^{3}$ See Glick et al. (2015) for a discussion of the role of shocks on education in Madagascar.
} 
employment sector selection, we use a multinomial approach to estimate selection into four categories: unemployed, informal sector employment, formal sector employment, and enrollment as a student. Then, correcting for sectoral selection in the manner of Dubin and McFadden (1984), we estimate the effect of these traits and skills on within-sector earnings.

In the following section, we discuss the Big Five Personality Traits and relevant research on the role of personality and noncognitive skills in determining labor outcomes. Section 3 describes our data, followed by a presentation of our empirical approach in Section 4. In Section 5, we discuss our results, which is followed by our conclusions in Section 6

\section{Background}

The importance of noncognitive skills first began to garner attention in the economics literature through a series of groundbreaking papers on the economic and behavioral outcomes of high school dropouts who completed the General Education Development (GED) Test in the United States. Cameron and Heckman (1993) observed that although GED recipients have what are supposed to be equivalent cognitive qualifications as regular high school graduates, they earn much lower wages. Heckman et al. (2000) further demonstrated that after controlling for cognitive ability, high school dropouts who subsequently earned GEDs actually earn less and have lower hourly wages than high school dropouts who did not complete the GED. They attributed the performance gap between these two groups to some unmeasured element of noncognitive ability.

Subsequent research in economics demonstrates that various noncognitive skills predict a variety of labor outcomes including work experience, occupation type, unemployment, and wages (Heckman et al. 2006; Carneiro et al. 2007; Lindqvist and Vestman 2011; Gill and Prowse 
2016). Some found that the effect of noncognitive traits on these outcomes can even exceed that of cognitive ability, particularly for individuals at the lower end of the earnings distribution (Heckman et al. 2006; Lindqvist and Vestman 2011). Gill and Prowse (2016) further found that marginal changes in cognitive ability mainly affect success in strategic game playing for high cognitive ability individuals, while marginal changes in what they call "character” skills mainly affect success for individuals with low cognitive ability.

The psychology and sociology literature points to the importance of personality to economic success. A widely accepted taxonomy of personality is the Five-Factor Model of Personality, also referred to as the Big Five Personality Traits. Most characteristics used to assess personality in the field of personality psychology can be mapped into one or more of these dimensions: Openness to Experience, Conscientiousness, Extraversion, Agreeableness, and Neuroticism (John et al. 2008; McCrae and Costa 2008; Brunello and Schlotter 2011). Openness to Experience is the degree to which a person is curious and needs intellectual stimulation, change, and variety. It describes the complexity, depth, and originality of an individual. Conscientiousness captures the attitude of being hardworking, organized, and dependable, as opposed to lazy, disorganized, and unreliable. People rated high in Conscientiousness tend to be able to delay gratification, follow the rules, adhere to norms, and think before acting. It describes the characteristics behind task- and goal-oriented behavior. Extraversion captures the preference for human contact, empathy, gregariousness, assertiveness, and a wish to inspire other people. Extraverted individuals have an energetic approach to social and material life. Agreeableness is the degree to which someone is cooperative, altruistic, modest, warm, and agreeable, in contrast to being cold, disagreeable, and antagonistic. Neuroticism is the extent to which an individual is 
insecure, anxious, depressed, and emotional rather than calm and self-confident (McCrae and Costa 2008).

Historically, researchers in personality psychology were beset by a wide-ranging array of personality scales with little guidance on how to choose between or use them. The Five-Factor Model of Personality first rose out of lexicographic studies describing personality (John et al. 2008). Since then, the use of this model has increased substantially, and the field of psychology has reached an initial consensus around the five-factor framework (John et al. 2008). This has given way to replication and consistent definitions, even though there remain variations in methodology and data sources. The model is also consistent for and argued to be relevant across different periods of the adult lifespan (McCrae and Costa 2008).

Evidence from the fields of sociology and psychology, which in fact is far greater and broader than economics, links the Big Five Personality Traits to job performance, occupational choice, earnings, and health. Studies demonstrate that Conscientiousness is an important predictor of grades, years of education, job performance in a wide range of jobs, and leadership ratings (Borghans et al. 2008; John et al. 2008; Brunello and Schlotter 2011). Furthermore, evidence shows that self-discipline (an aspect of Conscientiousness) accounts for more than twice as much of the variation in grades than does IQ (Brunello and Schlotter 2011). Research shows Openness to Experience is the best personality predictor of the number of years of education. Agreeableness and Neuroticism predict job performance positively and negatively, respectively, in situations where people work in groups. Openness predicts success in artistic jobs, and Neuroticism is an important predictor of job satisfaction (John et al. 2008; Brunello and Schlotter 2011). 
A number of studies investigate the role of the Big Five Personality Traits in explaining earnings in developed countries. Generally, Openness to Experience and Conscientiousness are associated with higher earnings and selection into white-collar or higher paying jobs (Mueller and Plug 2006; Ham et al. 2009; Cobb-Clark and Tan 2010; Heineck and Anger 2010; Gensowski 2014). However, Gensowski (2014) further investigated the role of these traits in determining earnings by decomposing their direct and indirect effects. She found suggestive evidence that although Openness to Experience has a positive indirect effect on male earnings through educational attainment, its direct effect is negative (although statistically insignificant). Neuroticism and Agreeableness tend to negatively affect earnings and selection into white-collar occupations (Mueller and Plug 2006; Ham et al. 2009; Cobb-Clark and Tan 2010; Heineck and Anger 2010; Gensowski 2014).

To date, the body of literature that we are aware of linking noncognitive skills, particularly personality, to labor outcomes comes entirely from developed countries. Exploring the role of skills and traits in labor market success in developing country contexts is clearly important. However, in poor countries it is also important to consider a closely related dimension, the role of exogenous shocks, in explaining labor market participation and sectoral choice. This is especially the case during the transition from adolescence to adulthood when individuals are selecting between continued schooling and work.

In that regard, ample evidence demonstrates that economic constraints and imperfect or incomplete credit markets still greatly hinder human capital accumulation and influence the choice of whether or not to enter the labor market for many children in poor countries. Due to these market imperfections, households in developing countries often cope with negative economic or health shocks by taking children out of school to either work in the household or 
enter the labor market (Jacoby and Skoufias 1997; Jensen 2000; Beegle et al. 2006; Glick et al. 2016). This, in turn, can likely limit the employment options that a child faces as an adult.

However, whether or not a household employs this coping strategy likely depends on the characteristics of the child. Since the child has some agency in this decision, its outcome depends, at least in part, on his or her preferences over school and labor. It also depends on the relative expected returns if the child stays in school as opposed to leaving school to enter the labor market. In turn, these preferences and returns likely depend on the child's skills and personality. For example, high Conscientiousness has been shown to improve school performance in developed countries and thus may positively affect a child's education in this developing country context if the household is experiencing robust income growth. However, in times of economic hardship, the more dutiful and conscientious child might be more likely to leave school in order to support the household. Similarly, one could easily envision that a child with greater cognitive ability would likely generate higher returns to education than a child with lower cognitive ability, thus delaying entry into the labor market in order to complete more education. However, if the local labor market is structured such that returns to higher levels of education are sufficiently low and the household's discount rate is sufficiently high, then an economically strained household might find greater value for those cognitive skills in the labor market than in the child completing further education.

An individual's traits or skills likely also determine his or her occupation type and earnings within that occupation. Labor markets in developing countries tend to be characterized by distinct formal and informal sectors, which differ by job quality, the nature of employment, job security, and earnings potential (Vijverberg 1986; De Beyer and Knight 1989; Khandker 1992; Vijverberg 1993; Glick and Sahn 1997; Mills and Sahn 1997; Nasir 2005). These sectors 
also likely differ in rewards to different skills sets and traits, in terms of the ease of job entry and remuneration. Existing studies that investigate determinants of labor market sectoral selection and within-sector earnings generally focus on the role of schooling in this process (Vijverberg 1986; De Beyer and Knight 1989; Gindling 1991; Khandker 1992; Vijverberg 1993). Empirical evidence suggests that greater educational attainment is associated with higher earnings, and that much of this effect is mediated through the important role that education plays in increasing the probability that individuals are employed as formal wage earners (Vijverberg 1986; De Beyer and Knight 1989; Gindling 1991; Khandker 1992; Vijverberg 1993; Glick and Sahn 1997). Although evidence in the literature from developing countries provides some understanding of the role of individual characteristics in the process of selecting into different labor market sectors and earnings, we find no literature that examines the role of cognitive ability and personality or other noncognitive skills in affecting these outcomes, as we examine in this paper. ${ }^{4}$

\section{Madagascar Life Course Transitions of Young Adults Survey}

The data used in this paper come from the Madagascar Life Course Transitions of Young Adults Survey. In 2011-12, the survey re-interviewed a cohort of 1,749 young adults between the ages of 21 and 24 years, who were originally surveyed in 2004. The surveys were specifically designed to capture the transition from adolescence to young adulthood and contain detailed information on household characteristics, family background, and health. Detailed community surveys were also conducted in 2004 and 2012, and the 2004 surveys also include a detailed module on local schools.

\footnotetext{
${ }^{4}$ Using the terminology of Behrman and Birdsall (1983), we are not interested solely in schooling as a measure of human capital, but, more specifically, in "effective schooling," which is a function of actual years of schooling, as well as school characteristics ("quality”) and household characteristics, such as parental education and assets and unobserved individual ability.
} 
Of the individuals surveyed in 2011-12, 1,733 were administered a personality questionnaire, and approximately 1,500 also took cognitive tests. The cognitive tests were designed to measure abilities in math and French and involved both written and oral components. For the purposes of this analysis, we aggregate the scores of the math and French tests together and then standardize this aggregate using the data's sample moments. ${ }^{5}$

The survey also measured household-level shocks using individual recall. The survey recorded whether or not a cohort member's parents were living and if not, the date of their death. In both the 2004 and 2011-12 surveys, all individuals in the household were asked if they had suffered an illness or injury that prevented them from working or performing normal activities and the year that this event occurred. Questions were also asked about unexpected losses or gains in crops and livestock, as well as non-farm revenues, both in 2004 and again, in 2012. We used this information to construct indicator variables for eight household-level shocks: whether or not the cohort member's mother or father died, whether or not the mother or father experienced an illness or injury that prevented him or her from working or conducting normal activities, and whether or not the household experienced a positive or negative income shock during three stages of the cohort member's childhood. These stages were divided into the periods before the cohort member turned 10 years old, was between the ages of 10 and 14, and was beyond age $14 .^{6}$

The 2012 questionnaire included a module to characterize individual personality traits. This module had 116 questions that were designed to capture how individuals behave and

\footnotetext{
${ }^{5}$ We also performed preliminary estimations using each cognitive test score individually, using separate math and French score aggregates, and using separate oral and write score aggregates. None of these specifications had any meaningful difference from our reported results.

${ }^{6}$ We also conducted analyses in which income shocks were disaggregated into different types of income shocks, but that provided no substantive difference in our results. We also specified the shock variables as a count variable that indicated the number of positive or negative income shocks. Again, this specification did not differ substantially from the results reported in this paper.
} 
respond to different situations. For each question in the personality module, individuals were asked to rate their response to a statement as 1-Strongly Disagree, 2-Somewhat Disagree, 3Neither Agree or Disagree, 4-Tend to Agree, or 5-Strongly Agree. Using confirmatory factor analysis on these questions, we generated an individual-level factor score for each of the five personality traits and then standardized those factor scores using the data's sample moments. A more detailed description of how the personality factor scores were generated can be found in Appendix A. Tables A.1-A.5 in Appendix A lists summary statistics for all the questions used to measure each personality trait. Tables A.6-A.10 report the estimated factor loadings of the relevant personality trait onto each question. Table A.11 gives the correlation matrix of each of the five personality traits and the standardized aggregate cognitive test score. Each of these variables is statistically significant, correlated at the 1 percent level. In particular, there is a high degree of correlation between Openness to Experience, Conscientiousness, and Extraversion. Of the five personality traits, the aggregate cognitive test score is most correlated with Openness to Experience.

In this paper we estimate three models: one predicting the age of entry into the labor market, one predicting labor market sectoral selection, and one predicting within-sector earnings. After accounting for missing variables at the individual and community levels, we are left with $1,175,1,156$, and 965 observations in each estimation sample, respectively. There is little to no difference in observed characteristics across the full sample, the job entry sample, and the sectoral selection sample. Indeed, there are no statistically significant differences between baseline characteristics across any two of these three samples. There are statistically significant differences on numerous characteristics between the earnings sample and the other three samples. The earnings sample is significantly lower in Openness to Experience, cognitive test 
scores, the 2004 asset index, parental education, highest grade achieved, ever employed, and percent living in an urban area. However, this sample is only made up of currently employed individuals and excludes students and the unemployed. Therefore, by construction, the earnings sample is a nonrandom subset of the other samples. These variables are all likely determinants of either working or being enrolled in school. To the best of our knowledge, then, any individual exclusion from our working samples is largely random and unlikely to affect our core results.

Table 1 reports sample summary statistics. ${ }^{7}$ Roughly 48 percent of our sample is male; approximately 26 percent live in an urban area; and the average age is around 22 years old. The mean level of education for individuals in the sample is around 8.3 years, and their mothers and fathers have attained an average of around 5 and 5.5 years of education, respectively.

In this paper we model selection into four current categories: unemployed, employment in the formal sector, employment in the informal sector, and enrollment as a student (Table 2). ${ }^{8}$ We consider an individual to be employed in the formal sector if she/he reports that her/his main employment activity is in public administration or in a formal private enterprise, or works in a nongovernmental organization (NGO). We also consider an individual to be working in the formal sector if she/he works in a family enterprise or does domestic work in another household and earns regular wages or salary for that work. We consider an individual to be employed in the informal sector if she/he reports her/his main occupation as working in a family-owned enterprise or domestic work in another household and remuneration status is listed as selfemployed or unpaid. We also consider an individual to be working in the informal sector if

\footnotetext{
${ }^{7}$ The reported descriptive statistics are from the sample used to estimate labor market sectoral selection. These statistics do not substantively change if we report them using the age of labor market entry sample or the full sample of individuals who took the cognitive tests and personality module.

${ }^{8}$ Very few individuals report that they are working and also enrolled in school. We categorize these individuals as students, assuming that their main occupation is being a student.
} 
she/he reports her/his main occupation is self-employment. Most of our sample (57 percent or 663 individuals) is employed in the informal sector. These workers are predominately selfemployed (mostly in agriculture or livestock) or are doing unpaid work in a family enterprise or as a caregiver or apprentice. Nineteen percent of our sample are working in the formal public or private sector and are largely working in skilled or semi-skilled jobs or in upper or middle management positions.

Approximately 81 percent of our sample was employed at least once by the time of the 2012 survey. Of those previously employed, the average age at which they began their first job was 16 years. Approximately 53 percent of those previously employed started their first job before the age of 16 .

Table 3 describes individual characteristics by employment sector. Comparing observed characteristics of individuals employed in the informal sector to the mean levels in the other three categories, we see that these individuals had lower cognitive test scores, lower grade attainment, entered the labor market at a younger age, were less likely to live in an urban area, and their parents had lower levels of education than the averages of all these characteristics in the sample. They also exhibited lower levels of Conscientiousness, Extraversion, Openness, and Agreeableness and higher levels of Neuroticism. Individuals employed in the informal sector earn almost three times less than individuals employed in the formal sector. Average hourly earnings in the informal sector are 143.47 Malagasy Ariary, compared to 390.96 in the formal sector. However, it is important to note that these earnings roughly translate to approximately 0.07 and 0.18 USD per hour, respectively. Thus, regardless of sector of employment, this population is quite poor. 
Individuals found in the other three sectors, on the other hand, had higher cognitive test scores, were more likely to live in an urban area, had more education, and had better educated parents. Individuals employed in the formal sector were older than the sample average when they entered the labor market, while students were younger. However, it is important to note that only 10 percent of students in the sample were ever employed before.

\section{Estimation Strategy}

In this section we discuss our estimation strategy used to model the age an individual first enters the labor market, selection into different labor market sectors, and earnings within these sectors. In modeling these outcomes, we first address some methodological challenges that revolve around concerns over endogeneity, especially, of schooling and cognition. Also, we must deal with sector selection when estimating the within-sector earnings model.

\subsection{Endogeneity of Schooling and Cognition}

When investigating the role of education and cognitive ability in determining labor outcomes, the endogeneity of these covariates is of particular concern. For example, we know that labor market choices affect schooling, and that in fact these decisions are often made jointly. Likewise, there is certainly unobserved heterogeneity whereby individual preferences over school and work simultaneously determine education and labor decisions. Therefore, in each of our labor models, we instrument for grade attainment and aggregate cognitive test scores using rich information on local schools, collected in a separate survey of schools conducted in 2004 in the same communities where our sample of young adults were teenage children. 
To amplify, we model the grade attainment, $G_{i j r}$, and cognitive test scores, $\theta_{i j r}^{C}$ of individual $i$ in community $j$ and region $r,{ }^{9}$ as a function of the individual's personality, $\theta_{i j r}^{P}$, household, $X_{i j r}$, and community, $C_{i j r}$ controls, household-level shocks, $S_{i j r}$, and local schoollevel characteristics in the village where the child resided in 2004, $S C H_{j r}$. These school-level variables effectively serve as instruments for grade attainment and cognitive test scores in our labor market models.

$$
\begin{aligned}
& G_{i j r}=\beta_{0}^{S}+\beta_{1}^{S} S C H_{j r}+\beta_{2}^{S} \theta_{i j r}^{P}+\beta_{3}^{S} S_{i j r}+\beta_{4}^{S} X_{i j r}+\beta_{5}^{S} C_{j r}+\beta_{6}^{S} r_{r}^{S}+u_{i j r}^{S} \\
& \theta_{i j r}^{C}=\beta_{0}^{C}+\beta_{1}^{C} S C H_{j r}+\beta_{2}^{C} \theta_{i j r}^{P}+\beta_{3}^{C} S_{i j r}+\beta_{4}^{C} X_{i j r}+\beta_{5}^{C} C_{j r}+\beta_{6}^{C} r_{r}^{S}+u_{i j r}^{C}
\end{aligned}
$$

The 2004 survey collected detailed information on up to three primary schools in the communities in which our survey participants resided as children in $2004 .{ }^{10}$ School-level instruments that we include from the 2004 school survey are from the school with the highest attendance in the village. They include: distance between the center of town and this primary school, whether or not this primary school participated in a government-sponsored nutrition program, and a school facilities quality index computed using factor analysis on indicators of the availability of electricity, medicine, toilets, separate toilets for boys and girls, recreation grounds, and clean water in the school. Finally, we also include an indicator for whether or not there is a private school in the community.

\footnotetext{
${ }^{9}$ Region $r_{r}$ in the model is thus a regional fixed effect.

${ }^{10}$ For a significant portion, $50 \%$ percent, of communities, there was only one public school in the community attended by the children in the villages and communes. $88 \%$ have only one or two primary schools in the commune.
} 
Our estimating equations show the strength of these instruments in affecting schooling outcomes. Results from our first-stage equation can be found in Table B.1 in Appendix B. An Ftest on the joint significance of our instruments is statistically significant at the 1 percent level, with F-Statistics values of 9.72 and 17.13 for the grade and cognition first-stage equations, respectively. The main concern about our identification is therefore the validity of the exclusion restriction. For example, if the parents of young adults in our sample chose to settle in particular communities, or selected a particular school to send their child to within the community they lived, in consideration of the quality of local schools, then our school-level instruments would fail to meet the necessary exclusion restriction. However, the primary school conditions measured by our instruments are not necessarily measuring the conditions of the primary school attended by the sample individual. We instead use as instruments the characteristics and conditions of the primary school most frequently attended in the community, so as to avoid the issue of school choice. Furthermore, migration in our sample is quite low. Almost 90 percent of our sample households had always resided in the community in which they were surveyed. This mitigates concerns that households migrate for the purpose of gaining access to higher quality schools.

We are still left with the possibility that local school characteristics correlate with local labor market conditions. This concern is lessened by the fact that the school survey used was conducted nearly a decade prior to examining labor market outcomes. Nonetheless, to address this concern we include an extensive set of community controls in both our instrumenting equations and each of our labor models. These controls include information on a remoteness index that we calculate from a large set of community characteristics from yet another separate community census conducted in 2001, as well as more detailed community information from 
2004 and 2012 on health, physical and financial infrastructure. The specific community controls we employ will be discussed further below.

\subsection{Exogeneity of Personality}

In contrast to our treatment of schooling and cognition, we treat the Big Five Personality Traits as exogenous. Currently, the empirical evidence as to how personality is formed in an individual is sparse. A growing body of evidence points to the interaction between environment and inherited genetics in producing individual characteristics (Committee 2000). However, there is no empirical evidence in the literature that we are aware of that empirically demonstrates the effects of childhood experiences and circumstances on the formation of adult personality. ${ }^{11}$ Likewise, there is little evidence on the relationship between personality traits or the temperament in children and those characteristics upon reaching adulthood. There is evidence, however, that the Big Five Personality Traits remain generally stable over adulthood (Costa and McCrae 1988). Consequently, the literature estimating the effect of personality on economic outcomes largely treats personality as exogenous, a convention we follow in this paper. And although the literature's treatment of personality traits as exogenous is, in part, based on no clear evidence to the contrary, we cannot exclude the possibility that there may be unobserved variables that affect both our outcome variables of interest and the personality traits we measure in adulthood. Like other researchers, there is little we can do to address this possibility other than checking the robustness of our results to the inclusion and exclusion of numerous control variables in each of our models. We find that incrementally adding an extensive set of

\footnotetext{
${ }^{11}$ Limited research finds that parental investment can be influential in forming 'noncognitive' skills (e.g., Cunha and Heckman 2008), however, none of this work investigates the formation of personality. Personality is thought to be much less malleable (and possibly not at all malleable) than other noncognitive traits.
} 
individual-, household-, and community-level controls has little to no effect on the point estimates of the coefficients on personality traits. ${ }^{12}$ Therefore, if there is some unobserved factor impacting both personality and our dependent variables, it is largely uncorrelated with our controls. Although this helps to alleviate concerns that unobserved characteristics bias our estimates of interest, the possibility that these traits are nonetheless endogenous still exists.

\subsection{Age of Entry into the Labor Market}

We estimate entry into a first job using a Cox Proportional Hazard Model (Cox 1972). Specifically, the hazard of an individual, $i$, in community, $j$, and region, $r$, entering the labor market at age, $a$, is:

$$
\begin{aligned}
& h_{i j r}(a)=h_{o}(a) * \exp \left(\gamma_{1} \theta_{i j r}+\gamma_{2} S_{i j r}^{I}+\gamma_{3} \text { Male }_{i j r}+\gamma_{4} \theta_{i j r} \times S_{i j r}^{I}+\gamma_{5} \theta_{i j r} \times \text { Male }_{i j r}+\right. \\
& \gamma_{6} S_{i j r}^{I} \times \text { Male }_{i j r}+\gamma_{7} \theta_{i j r} \times S_{i j r}^{I} \times \text { Male }_{i j r}+\gamma_{8} S_{i j r}^{P}+\gamma_{9} X_{i j r}^{l}+\gamma_{10} G_{i j r}+\gamma_{11} \hat{u}_{i j r}^{S} \\
& \left.+\gamma_{12} \hat{u}_{i j r}^{C}+\gamma_{13} C_{j r}+\gamma_{14} r_{r}+u_{i j r}^{l}\right)
\end{aligned}
$$

where $h_{o}(a)$ represents the baseline hazard function for leaving the state of not working at age

a. $\theta_{i j r}=\left[\theta_{i j r}^{O}, \theta_{i j r}^{C}, \theta_{i j r}^{E}, \theta_{i j r}^{A}, \theta_{i j r}^{N}, \theta_{i j r}^{\operatorname{Cog}}\right]$ is a vector that includes the individual standardized factor scores for each of the Big Five Personality Traits and the standardized aggregate cognitive test score. $S_{i r j}^{I}$ is a vector containing the six income-related shock indicator variables: whether a positive or negative income shock occurred before the cohort members were 10 years old, whether it occurred between ages 10 and 14, and whether these shocks occurred after they were

\footnotetext{
12 These results are available in the web appendix.
} 
14. The effects of an adolescent's personality and cognition might differ by gender. Personality type and cognitive ability and gender might also influence labor-entry response to shocks. Therefore, we allow for differential labor responses across gender, personality type and cognition, and shock realizations. Accordingly, we include pairwise interactions between the personality factor and cognitive test scores, gender and the six household income shock variables, and a triple interaction between personality and cognition, gender, and the income shock variables.

$S_{i j r}^{P}$ is a vector of the four parental shock variables: whether or not the individual's father or mother died and whether or not the father or mother suffered an illness or injury preventing work and the ability to conduct normal activities. Interacting parental shocks with gender, personality, or cognitive ability did not yield substantively different results than excluding these interactions. Therefore, we exclude these interactions in order to preserve degrees of freedom.

$X_{i j r}^{l}$ is a matrix of individual-level controls and includes gender, 2004 and 2012 household-level non-labor income in the form of transfers, ${ }^{13}$ the highest grade attained by both an individual's mother and father, 2004 household size and number of children in the household under the age of 17 in 2004. Following Sahn and Stifel (2003), we include a 2004 household asset index constructed using factor analysis, so as to reduce the potential for reverse causality if we used a contemporaneous measure of wealth. $G_{i j r}$ is highest grade attained by the 2012 survey.

\footnotetext{
${ }^{13}$ Non-labor income includes the value of in-kind and monetary transfers into the household, both from individuals outside the household and from the government.
} 
$C_{j r}$ is a vector of 2004 and 2012 community-level controls for community $j$. Given the large number of potential community controls, we create a number of indices related to community quality and infrastructure using factor analysis. We include a 2004 community health index using indicators of whether or not there was a hospital or health center in the community, whether family planning services and contraception were available in the community, and whether or not maternal health information was accessible in the community. We include a 2004 and 2012 community infrastructure index generated from variables indicating the availability of electricity, pumped water, and daily and weekly markets in the community. We include a 2004 remoteness index, using information on distance to health services, banks, post offices, schools, taxis, courts, markets, inputs, extension services, veterinarians, and access to national and provincial roads, utilities, media, and transportation. We also include variables that indicate whether or not, in 2004, one of the top three methods of savings in the community was with a formal account and whether one of the top three sources of a large loan in the community was a bank. Finally, we include a 2012 urban indicator and an indicator for whether or not there was a secondary school present in the community in 2012.

As described above, we instrument school attainment and cognition, since a child's decision to enter the labor market is partially determined by the decision to leave school. A traditional instrumental variable approach, in which grade and cognitive test scores are replaced by their first-stage predicted value, will not yield a consistent estimate of $\gamma_{4}$ and $\gamma_{10}$ due to the nonlinearity of the hazard function. Therefore, we employ a control function approach (also referred to as two-stage residual inclusion method), which remains consistent in the nonlinear hazard (Terza et al. 2008). The term, $\hat{u}_{i j r}^{S}$, is the predicted residual from Equation (1), and $\hat{u}_{i j r}^{C}$ is the predicted first-stage residual from instrumenting for cognitive skills. 


\subsection{Selection into Labor Market Sectors}

Our model of selection into different labor market sectors has four categories: unemployed, informal sector employment, formal sector employment, and student. We use a multinomial logistic model to estimate the probabilities that an individual will be found in each employment sector.

$$
\begin{aligned}
& V_{i j r k}=\mu_{k}+\delta_{1 k} \theta_{i j r}+\delta_{2 k} \text { Male }_{i j r}+\delta_{3 k} \text { Male }_{i j r} \times \theta_{i j r}+\delta_{4 k} G_{i j r}+\delta_{5 k} E_{i j r} \times A_{i j r}+ \\
& \delta_{6 k} X_{i j r}^{m}+\delta_{7 k} C_{j r}+\delta_{8 k} \hat{u}_{i j r}^{S}+\delta_{9 k} \hat{u}_{i j r}^{C}+\delta_{10 k} r_{r}+u_{i j r}^{m k}
\end{aligned}
$$

$V_{i j r k}$ is the utility received by individual $i$, in community $j$ and region $r$, by being employed in market sector alternative $k$. $\theta_{i j r}$ is, again, a vector of the standardized factor scores for the five personality traits and cognitive test scores. $G_{i j r}$ is the highest grade attained. $E_{i j r}$ is a dummy variable indicating whether or not the individual has ever been employed, and $A_{i j r}$ is the age at which the individual first entered the labor market. Thus, for individuals previously employed, $\delta_{5 k}$ captures the effect of the age when the individual first began work. Because the effects of an individual's personality and cognitive ability might differ by gender, we also include interactions between gender and each of these variables. ${ }^{14} X_{i}^{m}$ is a vector of individual-level controls that includes the same individual controls described in Equation (3), excluding the number of

\footnotetext{
${ }^{14}$ Interactions of gender with grade and age of labor market entry did not produce substantively different results. We therefore excluded these interactions to preserve degrees of freedom.
} 
children under age 17 in the household in 2004. We also include individual age as an additional control. $C_{j r}$ is the same vector of 2004 and 2012 community controls, as described for Equation (3). Again, $r_{r}$ is a regional fixed effect. We instrument for grade and cognitive test scores, using the same specification described for Equation (3), employing the control function approach, which remains consistent in this framework.

Under the multinomial framework, an individual is assumed to select into the employment sector $k \in\{1,2,3,4\}$ for which he receives the highest utility. Thus, the probability that individual $i$ selects into sector $k$ is:

$$
P_{i k}=\operatorname{Pr}\left(V_{i k}>V_{i l}\right) \text {, for all } k \neq l \text {. }
$$

Since the formulation of Equation (5) is a function of differences in utilities derived from choosing each sector, some normalization is required. We therefore consider working in the formal sector as the base category in our estimation. The estimated coefficients can, therefore, be interpreted as the effects of a variable on the utility of being in employment alternative $k$, relative to the utility derived from the base category of working in the formal sector.

\subsection{Within-Sector Earnings}

While much of the limited literature evaluating the effects of cognitive and noncognitive skills on earnings in some way controls for occupation type, it does not explicitly correct for selection into different occupations or sectors, or then estimate the effects of these characteristics on within-sector earnings. However, different labor market sectors likely value the signaling of school attainment, skills, and other related considerations, such as experience, differently, and 
therefore, it is important to account and correct for the selection into these sectors when evaluating the effect of skills and traits on earnings. To correct for the selection process, we follow Dubin and McFadden (1984). Using the probability of being employed in employment sector, $k$, predicted from Equations (4) and (5), we calculate the selection correction term $\lambda_{i j r}^{k}$, such that:

$$
\lambda_{i j r}^{k}=\sum_{j \neq k} \varphi_{j}\left[\frac{\hat{P}_{j} \ln \left(\hat{P}_{j}\right)}{1-\hat{P}_{j}}+\ln \left(\hat{P}_{k}\right)\right] .
$$

We then model within-sector earnings as follows:

$$
\ln \left(W_{i j r}^{k}\right)=\mu^{k}+\omega_{1}^{k} T_{i j r}+\omega_{2}^{k} \text { Male }+\omega_{3}^{k} \text { Male } \times T_{i j r}+\omega_{4}^{k} X_{i j r}+\omega_{5}^{k} C_{j r}+\omega_{6}^{k} r_{r}+\omega_{7}^{k} \lambda_{i j r}^{k}+u_{i j y}^{w k}
$$

where $\ln \left(W_{i j r}^{k}\right)$ is the log of hourly earnings of individual, $i$, in community, $j$, and region, $r$, who is employed in labor market sector, $k . T_{i j r}=\left[\theta_{i j r}^{P}, \hat{\theta}_{i j r}^{C o g}, \hat{G}_{i j r}, A_{i j r},\right]$ is a vector of traits that includes the five personality traits, instrumented cognitive test score, instrumented grade attainment, and the age at first job. These variables are all interacted with an indicator variable for male to allow for differential returns to skills, traits, and experience by gender. $X_{i j r}$ includes the same individual controls described for Equation (3). $C_{j r}$ are the same community controls included in Equation (4). ${ }^{15}$

\footnotetext{
${ }^{15}$ We bootstrap the standard errors in Equations (3). (4), and (7) to account for the fact that each of these equations include at least one predicted variable.
} 


\section{Results}

\subsection{Hazard of Entry into the Labor Market}

Table B.2 in Appendix B reports the estimated coefficients in the Cox Proportional Hazard Model predicting the age a child first enters the labor market. The first column of Table B.2 reports the estimated coefficients without instrumenting for grade and cognitive test scores, and the second column reports them with instrumenting for these characteristics. The estimated coefficients can be interpreted as the marginal effect of the explanatory variable on the log of the relative hazard of entering the labor market at a younger age. Once we instrument for grade attainment and cognitive test score, the coefficient on cognitive ability goes from significantly negative to significantly positive and that of grade attainment becomes statistically insignificant. ${ }^{16}$ In other words, after accounting for the simultaneity that exists between grade attainment and labor market entry, grade attainment no longer has a statistically significant impact on the relative hazard of entering the labor market at a younger age. However, if we control for grade attainment, we find that increasing cognitive test scores increases the hazard of entering at a younger age. This indicates that although completing more grades necessarily delays entry into the labor market and develops cognitive skills, once grade is controlled for, adolescents with high cognitive ability are entering the labor market at a younger age than their counterparts with low cognitive ability and with the same school attainment. Therefore, these

\footnotetext{
${ }^{16}$ When we do not instrument for grade and cognitive ability, both of their coefficients are statistically significant and negative. This result is fairly intuitive, because, by construction, completing one more grade requires at least one year of education. Thus increasing a child's education and subsequent cognitive ability delays his entry into the labor market, as the adolescent completes more grades.
} 
individuals with high cognitive ability are likely starting school earlier and progressing through grades more rapidly, thus allowing them to enter the labor market at a younger age. ${ }^{17}$ Further, adolescents with higher cognitive ability are likely to be better able to find employment sooner, and higher paying jobs when they do enter. They are, therefore, likely to receive greater returns to entering the labor market and thus have higher opportunity costs of delaying entry. Indeed, as discussed below, we find that individuals with high cognitive ability are more likely to select into the higher paying formal sector than the lower paying informal sector.

In Equation (3), the five personality traits and instrumented cognitive test score are each interacted with gender and household-level income shocks to allow for differential personality effects across shock realizations and gender. Figures 1-9 plot the estimated hazard curves for males and females in our sample across varying trait levels and shock realizations. Figure 1 plots the hazard curves of males and females who have experienced a positive or negative income shock between the ages 10 and 14, and after 14, at mean trait levels. ${ }^{18}$ Figure 2, on the other hand, plots the hazard curves of males and females at high and low trait levels in the event of no shock realizations. Finally, Figures 3-9 plot the hazard functions of males and females with high and low levels of cognitive ability, Openness to Experience, Neuroticism, and Conscientiousness across shock realizations. In order to conserve space, we do not report hazard curves across trait levels and shock realizations for all traits and all measured shocks in the main text. Rather, we focus on those that garner the most insight to discuss in the text. All hazard curves not included in the main text can be found in Appendix C. Table B.3 in the Appendix B reports the $\chi^{2}$ test

\footnotetext{
${ }^{17}$ For this same sample of adolescents in Madagascar, Aubery and Sahn (2014) found that those with higher grade progression score better on cognitive achievement tests.

${ }^{18}$ Income shocks experienced before age 10 displayed a similar pattern to those experienced after 10 but with a much less pronounced effect. Those plots are reported in Figure C.1 in Appendix C.
} 
statistics on the joint significance of the coefficients on each personality trait and cognition and their interactions.

As we see in Figure 1, males generally enter the labor market at earlier ages than females, and negative income shocks after age 14 increase the hazard of entering the labor market at younger ages for both males and females. The effect of a negative shock is particularly pronounced for males. Conversely, a positive economic shock after age 14 allows female adolescents to delay their entry into the labor market, although the magnitude of the effect is small. In the face of unexpected economic pressure, older adolescents are likely to be expected to help support the household financially. A male adolescent's entry decision is additionally influenced by his economic circumstances during younger adolescence when he is between the ages of 10 and 14; a negative income shock during this period increases his hazard of beginning work at a younger age, while a positive income shock reduces this hazard. This may be explained by the possibility that males receive higher returns to entering the labor market at younger ages than females, and that households are more reluctant to send their young girls off to work for reasons related to social norms and concern over the well-being of young girls and their vulnerability to physical harm, violence, and stigma when they enter the labor market as a preteen.

Looking at Figures 2-9, what is immediately striking is that the effects of a number of personality traits and cognitive skills on the hazard of labor market entry are much stronger than those of the shocks themselves. ${ }^{19}$ Further, an individual's personality type and cognitive ability can either exacerbate the effects of shocks or act as a buffer against them. Figure 2 reports the

\footnotetext{
${ }^{19}$ Figures 2-9 exclude the hazard curves across levels of Extraversion and Agreeableness, because they appear to be less important determinants of entry overall. The corresponding plots for these traits across all shock realizations are provided in Appendix C
} 
hazard curves of males and females at high and low levels of Conscientiousness, Neuroticism, Openness to Experience, and cognitive ability in the event of no household income shock. Here we see that Openness and cognitive ability have strikingly strong, although opposite effects on the hazard of labor market entry for both males and females. Males and females with high levels of Openness have a substantially lower hazard of entering the labor market at a younger age than those with low levels of this trait. Conversely, males and females with high cognitive ability have substantially higher hazard rates than their counterparts with low cognitive ability. In terms of other traits, we note that more neurotic males and females have higher hazards rates than those with lower levels of Neuroticism. This higher hazard also applies to more Conscientious males, but not females.

Figures 3 and 4 plot the hazard curves of males and females, respectively, with high and low cognitive ability in the event of a shock after age $10 .^{20}$ As noted, the effect of cognitive test scores on the hazard of labor market entry is positive. This effect is large in magnitude and statistically significant for both sexes and across all shock realizations. For both males and females, across all shock realizations, individuals with high cognitive ability have dramatically higher hazard rates than individuals with low cognitive ability, all else being equal. In other words, adolescents with high cognitive ability are at much higher risk of entering the labor market at a younger age. Again, these individuals with high cognitive ability likely complete more grades by a younger age, are better able to get more desirable employment offers, receive higher returns to their labor, and spend less time searching for employment—all resulting in a higher likelihood of entering the labor market at a younger age. The effect of cognitive ability on the hazard of entering the labor market at a younger age is considerably larger than that of any of

\footnotetext{
${ }^{20}$ The corresponding plots for shocks occurring before age 10 can be found in Table C.3 in Appendix C.
} 
the personality traits examined, as well as being larger than the effects of the shocks themselves. It is also noteworthy that in several of the cases, negative shocks further accelerate the hazard of labor market entry among males and females of high cognitive ability, and the opposite is the case for positive shocks when they occur between 10 and 14 years of age.

After cognitive ability, Openness to Experience has the largest effect on the hazard of labor market entry (Figure 5). Openness generally reduces the hazard of entering the labor market for both sexes, and its effect is substantial and statistically significant across most shock realizations. ${ }^{21}$ There is little difference between the hazard rates of individuals high in Openness regardless of shock experience. The effect of being high in Openness largely dominates the effect of household shocks. Thus, while a negative income shock after the age of 10 generally increases the hazard of males and females entering the labor market, those higher in Openness are largely buffered from the entry effects of this shock.

On the other hand, in Figure 6 we see that males and females with high levels of Neuroticism generally have a higher hazard of entry at a younger age than those with low Neuroticism, and this effect is generally consistent across shock realizations. While it is clear that some shocks have larger effects than others, the effect of high or low Neuroticism dominates that of household income shocks in almost all cases. Further, the effect of this trait can even exacerbate the effect of a shock. For example, the difference between the hazard of adolescents that do or do not experience a negative income shock after 14 is larger for those with high Neuroticism than with low. The only exceptions are that a positive income shock between the ages 10 and 14 lowers the entry hazard for males of either high or low Neuroticism to the level of that of males of low Neuroticism in the event of no shock (Figure 7). Also, there is no

\footnotetext{
${ }^{21}$ The corresponding plots for shocks occurring before age 14 can be found in Tables C.4-C.5 in Appendix C.
} 
substantive difference in the hazard rates of females with high or low Neuroticism in the event of a positive shock after age 14. Therefore, it appears that a positive shock can buffer adolescents against the entry effects of Neuroticism.

Finally, in Figures 8 and 9 we can see that the effect of Conscientiousness on the hazard of labor market entry varies by shock realization and gender. Across most shock realizations, higher Conscientiousness in females generally reduces their hazard of entering the labor market at a younger age. Further, females with low Conscientiousness appear more vulnerable to the effect of some income shocks than females with high Conscientiousness. Negative shocks before age 14 and positive shocks after age 14 increase the hazard of labor market entry for females with low Conscientiousness but have little to no effect on females with high Conscientiousness. In the event of a negative income shock after age 14, however, females high in Conscientiousness face an increased hazard of entering the labor market at a younger age than those with low Conscientiousness.

Unlike females, higher Conscientiousness in males tends to increase their hazard of entering the labor market at a younger age across all shock realizations. For males, the effect on their entry hazard of moving from a low to high level of Conscientiousness is generally larger than the effect of a number of the household shocks. Some interesting exceptions are that if a male's household experience negative shocks between the ages 10 and 14, then there is no difference in the relative entry hazards between males with low or high levels of Conscientiousness. Similarly, if positive shocks occur in a male's household between the ages 10 and 14, then the effect of this shock is to lower the hazard of entry for both high and low Conscientiousness males to levels similar to that of males with low Conscientiousness in the no shock scenario. Thus the effects of household shocks between the ages of 10 and 14 appear to 
dominate the effect of Conscientiousness for males. We also see that if households experience a negative shock when males are over age 14, then males of either high or low Conscientiousness have similar hazard rates, whereas if there is not a shock, the males with high Conscientiousness have much higher hazard rates than their counterparts with low Conscientiousness.

Highly conscientious individuals tend to be hardworking, responsible, organized, and dutiful. It therefore appears that the more dutiful and responsible males high in Conscientiousness tend to begin working at younger ages, while their female counterparts with high Conscientiousness tend to delay their entry. The exception to this tendency is if there is a negative income shock after age 14, in which case highly conscientious females enter earlier, as do males with both high and low Conscientiousness.

\subsection{Labor Market Sectoral Selection}

Table 4 reports the estimated average marginal effects of each of the five personality traits, instrumented cognitive test score, instrumented grade attainment, and age of labor market entry on the probability of being employed in each of the four sectors of interest: the formal sector, the informal sector, student, and unemployed. Included interactions with gender allow the average marginal effects of the five personality traits and cognitive test scores to vary by gender. Including gender interactions with grade and age of entry did not substantively change our results and were thus excluded. The estimated coefficients for the multinomial logit model of selection into labor market sectors are found in Table B.4 in Appendix B. Given the limited sample size for this four-sector model, we highlight some results that do not meet standard levels of significance, and thus some caution is required in interpreting some of the findings. 
In Table 4 we see that, of the five personality traits, Agreeableness is a significant determinant of female sectoral selection, while Extraversion is a significant determinant of male sectoral selection. Increasing Agreeableness by one standard deviation increases the probability that a female is a student or works in the informal sector by 2.3 or 3.2 percent, respectively, and decreases the probability of females being employed in the formal sector by 3.5 percent. Increasing Extraversion in males by one standard deviation increases their likelihood of being employed in the informal sector by 6.2 percent and reduces their likelihood of formal sector employment by 5.4 percent. In addition to Extraversion, Openness to Experience also influences the probability of being employed in the formal sector. Increasing Openness by one standard deviation increases the probability of formal sector employment by 5.7 percent.

Intuitively, increasing grade attainment increases the likelihood that both males and females are still students at the time of the survey. Higher school attainment also decreases the likelihood of being unemployed at the time of the 2012 survey. Increasing grade attainment by one grade reduces the likelihood of being unemployed by 4.5 percent. Although the signal of grade attainment appears to influence whether or not an individual is employed, it does not significantly influence the sector of employment for those individuals who are employed. Grade does not significantly impact male or female selection into the formal or informal sectors of employment. Cognitive ability, on the other hand, does significantly influence selection into the formal and informal sectors for both males and females. For females and males, increasing cognitive ability by one standard deviation increases the likelihood of working in the formal sector by 9 percent and 7 percent, respectively, and reduces the likelihood of informal sector employment by 11 percent and 9 percent, respectively. Therefore, the skill set signal of grade 
attainment does not appear to be as important for formal or informal sector selection as cognitive ability, or the realized skill set, does.

We note that there are also indirect effects of personality and cognitive ability on sectoral selection, as mediated by their influence on age of labor market entry. Increasing the age an individual begins their first job by one year increases the likelihood of working in the formal sector by 2.4 percent and reduces the likelihood of informal sector employment by 2 percent, respectively. Thus, all of the personality trait effects on the timing of entry indirectly play a role in terms of sector selection.

\subsection{Within-Sector Earnings}

Table 5 reports the marginal effects of personality, cognitive test scores, grade, and age at first job on wages. We do so for the informal and formal sectors pooled (columns 1-2 of the top panel), the informal sector alone (columns 3-6 of the top panel), and the formal sector alone (bottom panel).

Similar to other studies estimating the effect of particular traits or skills on earnings, the pooled model includes an occupational dummy variable indicating employment in the formal sector. The main result to note in the pooled model is that there is a large earnings premium for working in the formal sector. Working in the formal sector, instead of the informal sector, is associated with approximately a 75 percent earnings premium for females and 140 percent premium for males. Since selection into the formal sector is endogenous, this result cannot be interpreted causally. However, it is worth keeping this in mind as we analyze the within-sector earnings. The other point to note in the pooled model is that the estimated coefficients differ 
from those estimated for each sector individually, indicating both that individual characteristics are differentially valued across the two sectors and that selection likely matters.

Looking at the sector-specific models, although cognitive ability, Agreeableness, and Extraversion all significantly determine male selection into the formal and informal sectors, after accounting for sectoral selection, none of the five personality traits, cognitive ability, or grade significantly affect male hourly earnings within the formal sector. Only Agreeableness significantly affects male informal sector earnings: a one standard deviation increase is associated with a decline in male informal sector earnings by approximately 37 percent. This is consistent with findings from developed countries, which also show Agreeableness to be negatively associated with male earnings (Mueller and Plug 2006; Gensowski 2014). Therefore, the effects of personality and cognitive ability on male hourly earnings are largely indirect through their effects on age of entry and subsequent sectoral selection. Given the large earnings premium for formal sector work, these indirect effects are nonetheless substantial.

For females, comparing the estimated marginal effects of traits and skills on within-sector earnings, with and without formally modeling selection, we see that estimated effects do not differ substantially in regard to informal sector earnings, although some do slightly increase in magnitude. However, estimated marginal effects on female formal sector earnings do change in both magnitude and statistical significance once selection is formally accounted for. If selection into the formal sector is not corrected for, none of the five personality traits or cognitive ability have statistically significant effects on earnings. However, after correcting for selection, the estimated marginal effects of Conscientiousness, Openness, and Neuroticism increase in magnitude and statistical significance for females in the formal sector. This is further evidence that formally correcting for sectoral selection is important for capturing labor market returns to 
skills and traits. When doing so, we find that increasing Openness and Neuroticism by one standard deviation each reduces female formal sector earnings by approximately 8.1 percent. Gensowski (2014) also found evidence that Openness might have a positive indirect effect on earnings but a negative direct effect. In contrast, increased Conscientiousness yields substantial returns for females working in the formal sector: a one standard deviation increase raises female formal sector earnings by 114 percent. This result is quite intuitive in that more responsible, dependable, and hardworking individuals are also likely to be more productive in their jobs. Numerous studies from developed countries also find Conscientiousness to be positively associated with job performance and earnings (Hogan and Holland 2003; Mueller and Plug 2006; Borghans et al. 2008). It is interesting, however, that for earnings in this sample from Madagascar, Conscientiousness is rewarded in females, but not males.

Similar to the story with males, none of the five personality traits, cognitive ability, or grade attainment significantly affects female hourly earnings in the informal sector. Increasing the age at first job by one year increases female informal sector earnings by 13 percent. Therefore, the effects of personality and cognitive ability on female informal sector hourly earnings are largely indirect, through their effect on age of entry and sectoral selection, as is the case with males.

\section{Conclusion}

In recent years there has been an increasing interest in the effect of "noncognitive" dimensions of human capital on economic outcomes. Numerous studies from industrialized countries find that noncognitive skills can be as an important predictor of economic outcomes as cognition. In developing countries, it is reasonable to think that certain noncognitive skills may 
prove to be even more important to economic success than schooling and cognition since school quality and school enrollment rates are generally lower in these countries than in industrialized ones. Moreover, noncognitive traits may also affect how individuals and households respond to economic and health shocks, which are persistent threats to households' economic well-being in this context.

For a sample of young adults in Madagascar, we estimate the effect of cognition and the Big Five Personality Traits, as well as economic shocks, on the age of labor market entry, employment sectoral selection, and within-sector hourly earnings. We find that personality and cognitive ability directly impact each of the labor outcomes we investigate and that these impacts differ for males and females. Moreover, we find that the importance of these skills to adult hourly earnings lies mainly in their indirect effect through the age of labor market entry and subsequent selection into labor sectors of employment, rather than through direct effects on productivity, as measured by earnings.

Like other studies, we find that household economic shocks affect the labor market entry decision for adolescents, and that those effects vary by gender. Particularly noteworthy is that negative income shocks increase the hazard for both males and females entering the labor market at a younger age, although among those under 14 years of age, this applies largely to males. We suspect this gender difference is explained by the possibility that boys receive higher returns to entering the labor market than girls, and that households are more reluctant to send their young girls off to work.

However, among the most salient of our findings is that personality and cognition appear to be even more influential determinants of the age an adolescent first enters the labor market than are shocks. Moreover, the effect of household shocks on that first entry decision varies 
substantially not only by gender (as other studies have also found), but also by an adolescent's personality type and cognitive ability. For example, while a negative household income shock during adolescence increases the hazard of a male child entering the labor market at a younger age, the effect of this shock is greatly exacerbated if the male is high in Conscientiousness and mitigated if he is low in Conscientiousness. Among all the personality traits, the one that generally appears to be most important in affecting timing of labor market entry is Openness to Experience, which reduces the hazard of adolescents entering the labor market and even buffers them from the effects of negative income shocks.

Our interest in understanding the determinants of the first labor market entry decision is motivated, in part, by another result of our research that shows that the timing of entry has important long-term welfare implications. The younger an adolescent is when she first begins work increases the likelihood she will be working in the informal sector as a young adult, rather than the formal sector where earnings are substantially higher. Delaying entry by one year increases the likelihood of formal sector employment by 2.5 percent and decreases the likelihood of informal sector employment by 2 percent. Delaying entry by one year further increases hourly earnings for females selected into the informal sector by over 13 percent.

High cognitive ability among adolescents is associated with delayed entry into the labor market since these individuals are completing more schooling (as indicated by the uninstrumented hazard model estimates). However, once these individuals complete their education, they enter at younger ages than those with low cognitive ability and the same school attainment. This is likely due to their ability to complete more grades by a younger age and be more successful in searching for quality jobs. While entering at a younger age decreases the likelihood of formal versus informal employment, this effect is dominated by the substantial 
influence that cognitive skills have on sectoral selection. Increasing cognitive ability by one standard deviation enhances the likelihood of formal sector employment by 8.5 percent for females and 7 percent for males, and reduces the probability of informal sector employment by 11 and 9 percent for females and males, respectively.

As with the entry hazard, our sector selection model also indicates the importance of personality traits. For example, among males, Extraversion increases their likelihood of being employed in the informal sector, while Openness to Experience increases their likelihood of being employed in the formal sector. However, the magnitude of the impact of traits tends to be smaller in sorting individuals into sector of work than in determining the timing of their entry.

Although our research shows that cognition and personality traits primarily affect the timing of labor market entry and the sector of employment, there are a few notable exceptions. Most prominent is the finding that Conscientiousness has substantial direct returns to earnings for females working in the formal sector. Agreeableness is associated with a decline in male informal sector earnings. Other traits have smaller effects on earnings, such as the finding that increasing Openness and Neuroticism reduce female formal sector earnings. We note that the directions of these findings are consistent with the evidence, albeit limited, from developed countries, despite the large differences in the nature of the labor market. However, we also need to interpret with caution the far smaller impact of personality, and lack of direct effect of cognition, on earnings for several reasons. First, it is unclear whether the labor market in a country like Madagascar will reward, or is even able to measure, productivity that is associated with greater skills, whether they be cognitive or noncognitive abilities. Second, our focus is on young adults that are new entrants to the labor market. Thus, while their skills and traits have strong impacts on the timing of entry and nature of the job they take, their brief experience in the 
labor market may not have yet allowed for a differentiation of productivity, or rewards associated with higher productivity.

As research continues to evaluate the role of human capital in economic success and development, we need to consider more carefully not just schooling, but the role of skills, as well as the noncognitive dimensions of human capital such as personality and elements of psychosocial well-being. As discussed earlier, little is known at this point about how personality is formed and thus how we can impact personality trait formation through policy. While little is known about how and if policy can affect its formation, understanding the role of personality in determining labor outcomes is nonetheless important. Although the research on the formation of the traits is in its infancy and will largely be taken up by psychologists, there is much economists can contribute to the understanding of the role of personality in determining a range of social and economic outcomes. And this is particularly true to the extent that personality interacts with skills, shocks, and other characteristics, including gender, for which we already have (although still need more) evidence on how to effectuate. Understanding these complex dynamics will better allow policymakers to recognize who might be vulnerable to adverse outcomes and target programs accordingly, regardless of whether or not these traits can be directly impacted themselves. 


\section{References}

Aubery, F. and D. Sahn (2014). Cognitive Achievement Production in Madagascar: A ValueAdded Model Approach, Cornell University, Centre d'Etude et de Recherche sur le Développement International (CERDI).

Barrick, M. R., and M. K. Mount (1991). The Big Five Personality Dimensions and Job Performance: A Meta-Analysis. Personnel Psychology 44(1): 1-26.

Beegle, K., R. H. Dehejia, and Roberta Gatti (2006). Child Labor and Agricultural Shocks. Journal of Development Economics 81(1): 80-96.

Behrman, J. R. and N. Birdsall (1983). "The Quality of Schooling: Quantity Alone is Misleading." American Economic Review 73(5): 928-946.

Blau, D., and J. Currie (2006). Daycare and Afterschool Care: Who's Minding the Kids? In E. Hanushek and F. Welch (eds.), Handbook of the Economics of Education. Amsterdam, North-Holland.

Borghans, L., A. L. Duckworth, J. Heckman, and B. T. Weel (2008). The Economics and Psychology of Personality Traits. Journal of Human Resources 43(4): 972-1059.

Brunello, G., and M. Schlotter (2011). Non Cognitive Skills and Personality Traits: Labour Market Relevance and their Development in Education and Training Systems. IZA Discussion Paper No. 5743, Institute for the Study of Labor (IZA), Bonn.

Cameron, S., and J. Heckman (1993). The Nonequivalence of High School Equivalents. Journal of Labor Economics 11(1): 1-47.

Carneiro, P., C. Crawford, and A. Goodman (2007). The Impact of Early Cognitive and NonCognitive Skills on Later Outcomes. CPP Discussion Paper No. 92, Centre for the Economics of Education, London School of Economics. 
Chamorro-Premuzic, T., and A. Furnham (2003). Personality Predicts Academic Performance:

Evidence from Two Longitudinal University Samples. Journal of Research in Personality 37(4): 319-338.

Cobb-Clark, D., and M. Tan (2010). Noncognitive Skills, Occupational Attainment, and Relative Wages. IZA Discussion Papers 4289, Institute for the Study of Labor (IZA), Bonn.

Committee on Integrating the Science of Early Childhood Development (2000). From Neurons to Neighborhoods: The Science of Early Childhood Development. Washington, DC: National Academy Press.

Costa, P. T., and R. R. McCrae (1988). Personality in Adulthood: A Six-Year Longitudinal Study of Self-Reports and Spouse Ratings on the NEO Personality Inventory. Journal of Personality and Social Psychology 54(5): 853-863.

Cunha, F., J. Heckman, L. Lochner, and D. Masterov (2006). Interpreting the Evidence on Life Cycle Skill Formation. In E. Hanushek and F. Welch (eds.), Handbook of the Economics of Education, pp. 697-812. Amsterdam: North-Holland: Elsevier.

Curley, J. P., C. L. Jensen, R. Mashoodh, and F. A. Champagne (2011). Social influences on neurobiology and behavior: Epigenetic effects during development. Psychoneuroendocrinology 36(3): 352-371.

Dawson, G., S. Ashman, and L. Carver (2000). The Role of Early Experience in Shaping Behavioral and Brain Development and Its Implications for Social Policy. Development and Psychopathology 12(4): 695-712.

De Beyer, J., and J. B. Knight (1989). The Role of Occupation in the Determination of Wages. Oxford Economic Papers 41(3): 525-618. 
Dubin, J. A., and D. L. McFadden (1984). An Econometric Analysis of Residential Electric Appliance Holdings and Consumption. Econometrica 52(2): 345-362.

Gensowski, M. (2014). Personality, IQ, and Lifetime Earnings. IZA Discussion Paper No. 8535, Institute for the Study of Labor (IZA), Bonn.

Gill, D., and V. L. Prowse (2016). Cognitive Ability, Character Skills, and Learning to Play Equilibrium: A Level-k Analysis. Journal of Political Economy, forthcoming.

Gindling, T. H. (1991). Labor Market Segmentation and the Determination of Wages in the Public, Private-Formal, and Informal Sectors in San Jose, Costa Rica. Economic Development and Cultural Chang, 39(3): 584-605.

Glick, P., and D. Sahn (1997). Gender and Education Impacts on Employment and Earnings in West Africa: Evidence from Guinea. Economic Development and Cultural Change 45(4): 793-823.

Glick, Peter, Chris Handy, and David E. Sahn (2015). Schooling, Marriage and Age at First Birth in Madagascar._Population Studies 69(2): 219-236.

Glick, P. Sahn, D., and T. Walker (2016). Household Shocks and Education Investment in Madagascar. Oxford Bulletin of Economics and Statistics, forthcoming.

Ham, R., P. N. Junankar, and R. Wells (2009). Occupational Choice: Personality Matters. IZA Discussion Paper No 4105, Institute for the Study of Labor (IZA), Bonn.

Hampson, S. E., L. R. Goldberg, T. M. Voght, and J. P. Dubanoski (2006). Forty Years On: Teachers' Assessments of Children's Personality Traits Predict Self-Reported Health Behaviors and Outcomes in Midlife. Health Psychology 25(1): 57-64.

Heckman, J. (2007). The Economics, Technology and Neuroscience of Human Capability Formation. Proceedings of the National Academy of Sciences 104(33): 13250-13255. 
Heckman, J. J., J. Stixrud, and S. Urzua (2006). The Effects of Cognitive and Noncognitive Abilities on Labor Market Outcomes and Social Behavior. Journal of Labor Economics 24(3): 411-482.

Heckman, James J., Jingjing Hsee, and Yona Rubinstein (2000) The GED is a `mixed signal': The effect of cognitive and non-cognitive skills on human capital and labor market outcomes. University of Chicago.

Heineck, G., and S. Anger (2010). The Returns to Cognitive Abilities and Personality Traits in Germany. Labor Economics 17(3): 535-546.

Hogan, J., and B. Holland (2003). Using Theory to Evaluate Personality and Job-Performance Relations: A Socioanalytic Perspective. Journal of Applied Psychology 88(1): 100-112. Hogan, R., J. Hogan, and B. W. Roberts (1996). Personality Measurement and Employment Decisions: Questions and Answers. American Psychologist 51(5): 469-477.

Jacoby, H. G., and E. Skoufias (1997). Risk, Financial Markets and Human Capital in a Developing Country. Review of Economic Studies 64(3): 311-335.

Jensen, R. (2000). Agricultural Volatility and Investments in Children. American Economic Review 90(2): 399-404.

John, O. P., L. P. Naumann, and C. J. Soto (2008). Paradihm Shift to the Integrative Big Five Trait Taxonomy. In O. P. John, R. W. Robins, and L. A. Pervin (eds.), Handbook of Personality: Theory and Research. New York, NY: The Guilford Press.

Khandker, S. (1992). Earnings, Occupational Choice, and Mobility in Segmented Labor Markets of India. World Bank Discussion Papers 154, World Bank, Washington, DC. 
Knudsen, E., J. Heckman, J. Cameron, and J. Shonkoff (2006). Economic, Neurobiological, and Behavioral Perspectives on Building America's Future Workforce. Proceedings of the National Academy of Sciences 103(27): 10155-10162.

Lindqvist, E., and R. Vestman (2011). The Labor Market Returns to Cognitive and Noncognitive Ability: Evidence from Swedish Enlistment. American Economic Journal: Applied Economics 3(1): 101-128.

Marshall, P. (2009). Biological perspectives on the effects of early psychosocial experience. Developmental Review 29(2): 96-119.

McCrae, R. R., and P. T. Costa (2008). The Five-Factor Theory of Personality. In O. P. John, R. W. Robbins, and L. A. Pervin (eds.), Handbook of Personality: Theory and Research. New York, NY: The Guildford Press.

Meany, M. (2001). Maternal Care, Gene Expression, and the Transmission of Indiviudal Differences in Stress Reactivity across Generations. Annual Review of Neuroscience 24(1): 11161-11192.

Mills, B., and D. E. Sahn (1997). Labor Market Segmentation and the Implication for Public Sector Retrenchment Programs. Journal of Comparative Economics 25(3): 385-402. Mueller, G., and E. J. S. Plug (2006). Estimating the Effect of Personality on Male and Female Earnings. Cornell ILR Review 60(1): 1-22.

Nasir, Z. M. (2005). An Analysis of Occupational Choice in Pakistan: A Multinomial Logit Approach. The Pakistan Development Review 44(1): 57-79.

Ones, D. S., S. Dilchert, C. Viswesvaran, and T. A. Judge (2007). In Support of Personality Assessment in Organizational Settings. Personnel Psychology 64(4): 995-1027. 
Robbins, S. B., J. Allen, A. Casillas, C. H. Peterson, and H. Le (2006). Unraveling the Differential Effects of Motivational and Skills, Social, and Self-Management Measures from Traditional Predictors of College Outcomes. Journal of Educational Psychology 98(3): 598-616.

Roberts, B. W., N. R. Kuncel, R. Shiner, A. Caspi, and L. R. Goldberg (2007). The Power of Personality: THe Comparative Validity of Personality Traits, Socioeconomic Status, and Cognitive Ability for Predicting Important Life Outcomes. Perspectives on Psychological Science 2(4): 313-345.

Sahn, D., and D. Stifel (2003). Exploring Alternative Measures of Welfare in the Absence of Expenditure Data. Review of Income and Wealth, 49(4): 463-489.

Schmidt, F. L., and J. E. Hunter (1998). The Validity and Utility of Selection Methods in Personnel Psychology: Practical and Theoretical Implications of 85 Years of Research Findings. Psychological Bulletin 124(2): 262-274.

Terza, J. V., A. Basu, and P. J. Rathouz (2008). Two-Stage Residual Inclusion Estimation: Addressing Endogeneity in Health Econometric Modeling. Journal of Health Economics 27(3): 531-543.

Vijverberg, W. P. (1986). Consistent Estimates of the Wage Equation when Individuals Choose amoung Income-Earnnings Activities. Southern Economic Journal 52(4): 1028-1042. Vijverberg, W. P. (1993). Educational Investments and Returns for Women and Men in Côte d'Ivoire. The Journal of Human Resources 28(4): 933-974. 


\begin{tabular}{llll}
\hline Death of Mother & 0.09 & 2004 Asset Index & 0.10 \\
Death of Father & $(0.28)$ & & $(1.01)$ \\
& 0.17 & Male & 0.48 \\
Mother Illness/Injury & $(0.38)$ & & $(0.50)$ \\
& 0.17 & Mother's Education & 4.89 \\
Father Illness/Injury & $(0.37)$ & & $(3.58)$ \\
& 0.16 & Father's Education & 5.51 \\
Positive Income Shock before Age 10 & $(0.37)$ & & $(3.97)$ \\
& 0.21 & Age & 21.96 \\
Positive Income Shock between Ages 10 and 14 & $(0.41)$ & & $(1.24)$ \\
& 0.26 & Highest Grade Attained in & 8.27 \\
Positive Income Shock after Age 14 & $(0.44)$ & & $(3.67)$ \\
& 0.51 & Ever Employed Previously & 0.81 \\
Negative Income Shock before Age 10 & $(0.50)$ & & $(0.40)$ \\
Negative Income Shock between Ages 10 and & 0.20 & Age of Entry into Labor & 15.91 \\
\hline
\end{tabular}


Table 2: Proportion of Labor Sectors across Gender

\begin{tabular}{lccc}
\hline & Total & Females & Males \\
$\mathrm{N}=1156$ & $\mathrm{~N}=599$ & $\mathrm{~N}=557$ \\
\hline Unemployed & 0.10 & 0.13 & 0.07 \\
Informal Sector & 0.57 & 0.60 & 0.55 \\
Formal Sector & 0.19 & 0.11 & 0.26 \\
Student & 0.14 & 0.16 & 0.12 \\
\hline
\end{tabular}


Table 3: Individual Characteristics across Labor Sectors

\begin{tabular}{|c|c|c|c|c|}
\hline & Unemployed & $\frac{\text { Informal }}{\text { Sector }}$ & $\frac{\text { Formal }}{\underline{\text { Sector }}}$ & Student \\
\hline "Conscientiousness z-score & $\begin{array}{l}0.16 \\
(1.09)\end{array}$ & $\begin{array}{c}-0.07 * * * \\
(0.98)\end{array}$ & $\begin{array}{c}0.22 * * * \\
(0.88)\end{array}$ & $\begin{array}{c}0.22 * * * \\
(0.90)\end{array}$ \\
\hline Extraversion z-score & $\begin{array}{l}0.15 \\
(1.09)\end{array}$ & $\begin{array}{c}-0.09 * * * \\
(0.96)\end{array}$ & $\begin{array}{c}0.20 * * * \\
(0.88)\end{array}$ & $\begin{array}{c}0.15 * \\
(0.93)\end{array}$ \\
\hline Openness to Experience z-score & $\begin{array}{l}0.16 \\
(1.15)\end{array}$ & $\begin{array}{c}-0.13 * * * \\
(0.95)\end{array}$ & $\begin{array}{c}0.33 * * * \\
(0.88)\end{array}$ & $\begin{array}{c}0.37 * * * \\
(0.93)\end{array}$ \\
\hline Agreeableness z-score & $\begin{array}{l}0.10 \\
(1.10)\end{array}$ & $\begin{array}{c}-0.06^{* * *} \\
(0.96)\end{array}$ & $\begin{array}{c}0.12 * \\
(0.93)\end{array}$ & $\begin{array}{c}0.14 * \\
(0.98)\end{array}$ \\
\hline Neuroticism z-score & $\begin{array}{l}0.06 \\
(1.07)\end{array}$ & $\begin{array}{c}0.08 * * \\
(1.02)\end{array}$ & $\begin{array}{c}-0.13^{* * *} \\
(0.85)\end{array}$ & $\begin{array}{l}-0.03 \\
(1.06)\end{array}$ \\
\hline Aggregate Cognitive Test z-score & $\begin{array}{c}0.35^{* * * *} \\
(0.90)\end{array}$ & $\begin{array}{c}-0.39 * * * \\
(0.91)\end{array}$ & $\begin{array}{c}0.35 * * * \\
(0.88)\end{array}$ & $\begin{array}{c}0.90 * * * \\
(0.70)\end{array}$ \\
\hline Hourly Earnings & $\begin{array}{c}298.01 \\
(1034.81)\end{array}$ & $\begin{array}{c}143.47^{* * *} \\
(909.01)\end{array}$ & $\begin{array}{c}390.96 * * * \\
(1634.79)\end{array}$ & $\begin{array}{l}0.00 \\
(0.00)\end{array}$ \\
\hline 2004 Asset Index & $\begin{array}{c}0.39 * * * \\
(1.18)\end{array}$ & $\begin{array}{c}-0.19 * * * \\
(0.68)\end{array}$ & $\begin{array}{c}0.29 * * * \\
(1.10)\end{array}$ & $\begin{array}{c}0.86 * * * \\
(1.37)\end{array}$ \\
\hline Male & $\begin{array}{c}0.34 * * * \\
(0.48)\end{array}$ & $\begin{array}{l}0.46 \\
(0.50)\end{array}$ & $\begin{array}{c}0.68 * * * \\
(0.47)\end{array}$ & $\begin{array}{c}0.41^{* *} \\
(0.49)\end{array}$ \\
\hline Mother's Education & $\begin{array}{c}6.29 * * * \\
(3.65)\end{array}$ & $\begin{array}{c}3.90 * * * \\
(3.02)\end{array}$ & $\begin{array}{c}5.50 * * * \\
(3.67)\end{array}$ & $\begin{array}{c}7.15^{* * * *} \\
(3.99)\end{array}$ \\
\hline Father's Education & $\begin{array}{c}7.11^{* * *} \\
(4.18)\end{array}$ & $\begin{array}{c}4.45^{* * *} \\
(3.49)\end{array}$ & $\begin{array}{c}6.07 * * \\
(3.87)\end{array}$ & $\begin{array}{c}7.99 * * * \\
(4.16)\end{array}$ \\
\hline Age & $\begin{array}{l}22.10 \\
(1.24)\end{array}$ & $\begin{array}{c}21.90 * \\
(1.23)\end{array}$ & $\begin{array}{c}22.19 * * * \\
(1.22)\end{array}$ & $\begin{array}{c}21.76^{* *} \\
(1.28)\end{array}$ \\
\hline Highest Grade Attained in 2012 & $\begin{array}{c}9.50 * * * \\
(3.15)\end{array}$ & $\begin{array}{c}6.80 * * * \\
(3.18)\end{array}$ & $\begin{array}{c}9.23 * * * \\
(3.27)\end{array}$ & $\begin{array}{c}12.20 * * * \\
(2.67)\end{array}$ \\
\hline Ever Employed Previously & $\begin{array}{c}0.30 * * * \\
(0.46)\end{array}$ & $\begin{array}{c}1.00 * * * \\
(0.00)\end{array}$ & $\begin{array}{c}1.00 * * * \\
(0.00)\end{array}$ & $\begin{array}{c}0.11^{* * * *} \\
(0.31)\end{array}$ \\
\hline Age of Entry into Labor Market & $\begin{array}{c}16.34 \\
(3.51)\end{array}$ & $\begin{array}{c}15.29 * * * \\
(3.51)\end{array}$ & $\begin{array}{c}17.90 * * * \\
(3.49)\end{array}$ & $\begin{array}{c}14.18^{*} \\
(5.02)\end{array}$ \\
\hline Urban & $\begin{array}{c}0.43^{* * *} \\
(0.50)\end{array}$ & $\begin{array}{c}0.15^{* * *} \\
(0.36)\end{array}$ & $\begin{array}{c}0.37 * * * \\
(0.48)\end{array}$ & $\begin{array}{c}0.47 * * * \\
(0.50)\end{array}$ \\
\hline
\end{tabular}


Table 4: Average Marginal Effects on the Likelihood of Selection into each Labor Market Sector

\begin{tabular}{|c|c|c|c|c|c|c|c|c|}
\hline & \multicolumn{2}{|c|}{ Unemployed } & \multicolumn{2}{|c|}{ Informal } & \multicolumn{2}{|c|}{ Formal } & \multicolumn{2}{|c|}{$\underline{\text { Student }}$} \\
\hline & Females & Males & Females & Males & Females & Males & Females & Males \\
\hline Conscientiousness z-score & $\begin{array}{l}-0.006 \\
(0.028)\end{array}$ & $\begin{array}{l}-0.008 \\
(0.025)\end{array}$ & $\begin{array}{l}0.030 \\
(0.041)\end{array}$ & $\begin{array}{l}-0.027 \\
(0.026)\end{array}$ & $\begin{array}{l}-0.009 \\
(0.031)\end{array}$ & $\begin{array}{l}0.018 \\
(0.021)\end{array}$ & $\begin{array}{l}-0.015 \\
(0.02)\end{array}$ & $\begin{array}{l}0.017 \\
(0.025)\end{array}$ \\
\hline Extraversion z-score & $\begin{array}{l}0.010 \\
(0.026)\end{array}$ & $\begin{array}{l}0.018 \\
(0.032)\end{array}$ & $\begin{array}{l}-0.019 \\
(0.038)\end{array}$ & $\begin{array}{l}0.062^{*} \\
(0.033)\end{array}$ & $\begin{array}{l}0.009 \\
(0.037)\end{array}$ & $\begin{array}{c}-0.054+ \\
(0.035)\end{array}$ & $\begin{array}{l}0.000 \\
(0.028)\end{array}$ & $\begin{array}{l}-0.026 \\
(0.027)\end{array}$ \\
\hline Openness to Experience z-score & $\begin{array}{l}0.016 \\
(0.026)\end{array}$ & $\begin{array}{l}-0.001 \\
(0.026)\end{array}$ & $\begin{array}{l}-0.017 \\
(0.032)\end{array}$ & $\begin{array}{l}-0.039 \\
(0.029)\end{array}$ & $\begin{array}{l}0.025 \\
(0.031)\end{array}$ & $\begin{array}{c}0.057 * \\
(0.031)\end{array}$ & $\begin{array}{l}-0.024 \\
(0.023)\end{array}$ & $\begin{array}{l}-0.018 \\
(0.025)\end{array}$ \\
\hline Agreeableness z-score & $\begin{array}{l}-0.020 \\
(0.015)\end{array}$ & $\begin{array}{l}0.021 \\
(0.016)\end{array}$ & $\begin{array}{l}0.032 * \\
(0.018)\end{array}$ & $\begin{array}{c}0.00 \\
(0.023)\end{array}$ & $\begin{array}{c}-0.035^{*} \\
(0.02)\end{array}$ & $\begin{array}{l}-0.008 \\
(0.022)\end{array}$ & $\begin{array}{c}0.023+ \\
(0.015)\end{array}$ & $\begin{array}{l}-0.013 \\
(0.016)\end{array}$ \\
\hline Neuroticism z-score & $\begin{array}{l}-0.004 \\
(0.024)\end{array}$ & $\begin{array}{l}0.016 \\
(0.03)\end{array}$ & $\begin{array}{l}0.003 \\
(0.041)\end{array}$ & $\begin{array}{c}-0.024 \\
(0.03)\end{array}$ & $\begin{array}{l}0.001 \\
(0.035)\end{array}$ & $\begin{array}{l}0.004 \\
(0.029)\end{array}$ & $\begin{array}{c}0.00 \\
(0.017)\end{array}$ & $\begin{array}{l}0.005 \\
(0.025)\end{array}$ \\
\hline Instrumented Cognitive Test z-score & $\begin{array}{l}0.012 \\
(0.046)\end{array}$ & $\begin{array}{l}0.010 \\
(0.039)\end{array}$ & $\begin{array}{c}-0.106^{* *} \\
(0.053)\end{array}$ & $\begin{array}{c}-0.091+ \\
(0.059)\end{array}$ & $\begin{array}{c}0.085^{* *} \\
(0.042)\end{array}$ & $\begin{array}{c}0.070+ \\
(0.053)\end{array}$ & $\begin{array}{l}0.009 \\
(0.035)\end{array}$ & $\begin{array}{l}0.010 \\
(0.034)\end{array}$ \\
\hline Grade & $\begin{array}{c}-0.045^{*} \\
(0.028)\end{array}$ & $\begin{array}{c}-0.045^{*} \\
(0.028)\end{array}$ & $\begin{array}{l}-0.024 \\
(0.026)\end{array}$ & $\begin{array}{l}-0.024 \\
(0.026)\end{array}$ & $\begin{array}{l}0.011 \\
(0.028)\end{array}$ & $\begin{array}{l}0.011 \\
(0.028)\end{array}$ & $\begin{array}{c}0.058^{* *} \\
(0.025)\end{array}$ & $\begin{array}{c}0.058^{* *} \\
(1.025)\end{array}$ \\
\hline Age of Job Entry & $\begin{array}{l}-0.001 \\
(0.002) \\
\end{array}$ & $\begin{array}{l}-0.001 \\
(0.002) \\
\end{array}$ & $\begin{array}{c}-0.020^{* * *} \\
(0.004) \\
\end{array}$ & $\begin{array}{c}-0.020 * * * \\
(1.004) \\
\end{array}$ & $\begin{array}{c}0.024 * * * \\
(0.005) \\
\end{array}$ & $\begin{array}{c}0.024 * * * \\
(0.005) \\
\end{array}$ & $\begin{array}{c}-0.004 * \\
(0.002) \\
\end{array}$ & $\begin{array}{c}-0.004 * \\
(1.002) \\
\end{array}$ \\
\hline
\end{tabular}

Standard errors in parentheses

*** $\mathrm{p}<0.01,{ }^{* *} \mathrm{p}<0.05, * \mathrm{p}<0.1,+\mathrm{p}<0.15$ 
Table 5: Marginal Effects of Personality, Cognition, and Grade on Male and Female Earnings

\begin{tabular}{|c|c|c|c|c|c|c|}
\hline & \multicolumn{2}{|c|}{$\frac{\underline{\text { Formal and }}}{\frac{\underline{\text { Informal Pooled }}}{\text { No Selection }}} \frac{\text { Correction }}{\text { Corren }}$} & \multicolumn{4}{|c|}{ No Selection Correction } \\
\hline & Females & Males & Females & Males & Females & Males \\
\hline Conscientiousness z-score & $\begin{array}{l}0.155 \\
(0.163)\end{array}$ & $\begin{array}{l}0.075 \\
(0.181)\end{array}$ & $\begin{array}{l}0.073 \\
(0.165)\end{array}$ & $\begin{array}{c}0.242+ \\
(0.165)\end{array}$ & $\begin{array}{l}0.100 \\
(0.167)\end{array}$ & $\begin{array}{l}0.294 \\
(0.273)\end{array}$ \\
\hline Extraversion z-score & $\begin{array}{l}0.021 \\
(0.194)\end{array}$ & $\begin{array}{l}-0.029 \\
(0.202)\end{array}$ & $\begin{array}{l}0.005 \\
(0.234)\end{array}$ & $\begin{array}{l}-0.097 \\
(0.230)\end{array}$ & $\begin{array}{l}0.025 \\
(0.208)\end{array}$ & $\begin{array}{l}-0.103 \\
(0.257)\end{array}$ \\
\hline Openness z-score & $\begin{array}{l}0.015 \\
(0.185)\end{array}$ & $\begin{array}{c}-0.247+ \\
(0.158)\end{array}$ & $\begin{array}{l}0.151 \\
(0.182)\end{array}$ & $\begin{array}{c}-0.201 \\
(0.153)\end{array}$ & $\begin{array}{l}0.161 \\
(0.178)\end{array}$ & $\begin{array}{l}-0.192 \\
(0.177)\end{array}$ \\
\hline Agreeableness z-score & $\begin{array}{l}-0.106 \\
(0.130)\end{array}$ & $\begin{array}{c}-0.262+ \\
(0.172)\end{array}$ & $\begin{array}{l}-0.086 \\
(0.145)\end{array}$ & $\begin{array}{c}-0.317 * \\
(0.167)\end{array}$ & $\begin{array}{l}-0.137 \\
(0.179)\end{array}$ & $\begin{array}{c}-0.366^{*} \\
(0.207)\end{array}$ \\
\hline Neuroticism z-score & $\begin{array}{l}0.069 \\
(0.126)\end{array}$ & $\begin{array}{c}0.166+ \\
(0.116)\end{array}$ & $\begin{array}{l}0.144 \\
(0.136)\end{array}$ & $\begin{array}{l}0.053 \\
(0.139)\end{array}$ & $\begin{array}{l}0.100 \\
(0.147)\end{array}$ & $\begin{array}{l}0.021 \\
(0.138)\end{array}$ \\
\hline Cognitive Test Score Aggregate & $\begin{array}{l}-0.101 \\
(0.482)\end{array}$ & $\begin{array}{l}0.071 \\
(0.409)\end{array}$ & $\begin{array}{l}-0.054 \\
(0.581)\end{array}$ & $\begin{array}{c}-0.143 \\
(0.558)\end{array}$ & $\begin{array}{l}-0.020 \\
(0.511)\end{array}$ & $\begin{array}{l}-0.198 \\
(0.577)\end{array}$ \\
\hline Grade & $\begin{array}{l}-0.040 \\
(0.103)\end{array}$ & $\begin{array}{l}-0.050 \\
(0.088)\end{array}$ & $\begin{array}{l}-0.036 \\
(0.101)\end{array}$ & $\begin{array}{c}-0.039 \\
(0.092)\end{array}$ & $\begin{array}{l}-0.093 \\
(0.115)\end{array}$ & $\begin{array}{l}-0.090 \\
(0.096)\end{array}$ \\
\hline Age at First Job & $\begin{array}{c}0.082 * * * \\
(0.027)\end{array}$ & $\begin{array}{l}0.055^{*} \\
(0.029)\end{array}$ & $\begin{array}{c}0.090 * * * \\
(0.028)\end{array}$ & $\begin{array}{l}0.028 \\
(0.029)\end{array}$ & $\begin{array}{c}0.134 * * * \\
(0.039)\end{array}$ & $\begin{array}{l}0.063 \\
(0.046)\end{array}$ \\
\hline \multirow[t]{5}{*}{ Works in Formal Sector } & $0.749 * *$ & $1.395 * * *$ & & & & \\
\hline & $(0.351)$ & $(0.238)$ & & & & \\
\hline & \multicolumn{4}{|c|}{ Formal } & & \\
\hline & \multicolumn{2}{|c|}{$\frac{\text { No Selection }}{\text { Correction }}$} & \multicolumn{2}{|c|}{ Selection Correction } & & \\
\hline & Females & Males & Females & Males & & \\
\hline Conscientiousness z-score & $\begin{array}{l}0.100 \\
(0.167)\end{array}$ & $\begin{array}{l}0.294 \\
(0.273)\end{array}$ & $\begin{array}{c}1.144 * * \\
(0.571)\end{array}$ & $\begin{array}{c}-0.083 \\
(0.374)\end{array}$ & & \\
\hline Extraversion z-score & $\begin{array}{l}0.025 \\
(0.208)\end{array}$ & $\begin{array}{l}-0.103 \\
(0.257)\end{array}$ & $\begin{array}{l}-0.556 \\
(0.581)\end{array}$ & $\begin{array}{c}-0.036 \\
(0.561)\end{array}$ & & \\
\hline Openness z-score & $\begin{array}{l}0.161 \\
(0.178)\end{array}$ & $\begin{array}{l}-0.192 \\
(0.177)\end{array}$ & $\begin{array}{c}-0.806+ \\
(0.503)\end{array}$ & $\begin{array}{l}-0.351 \\
(0.365)\end{array}$ & & \\
\hline Agreeableness z-score & $\begin{array}{l}-0.137 \\
(0.179)\end{array}$ & $\begin{array}{c}-0.366^{*} \\
(0.207)\end{array}$ & $\begin{array}{l}-0.079 \\
(0.393)\end{array}$ & $\begin{array}{l}-0.202 \\
(0.311)\end{array}$ & & \\
\hline Neuroticism z-score & $\begin{array}{l}0.100 \\
(0.147)\end{array}$ & $\begin{array}{l}0.021 \\
(0.138)\end{array}$ & $\begin{array}{c}-0.814^{*} \\
(0.429)\end{array}$ & $\begin{array}{l}0.507 \\
(0.443)\end{array}$ & & \\
\hline Cognitive Test Score Aggregate & $\begin{array}{l}-0.020 \\
(0.511)\end{array}$ & $\begin{array}{l}-0.198 \\
(0.577)\end{array}$ & $\begin{array}{l}-1.744 \\
(1.717)\end{array}$ & $\begin{array}{l}0.599 \\
(1.252)\end{array}$ & & \\
\hline Grade & $\begin{array}{l}-0.093 \\
(0.115)\end{array}$ & $\begin{array}{l}-0.090 \\
(0.096)\end{array}$ & $\begin{array}{l}0.398 \\
(0.355)\end{array}$ & $\begin{array}{l}-0.112 \\
(0.252)\end{array}$ & & \\
\hline Age at First Job & $0.134 * * *$ & 0.063 & 0.023 & 0.043 & & \\
\hline & $(0.039)$ & $(0.046)$ & $(0.146)$ & $(0.125)$ & & \\
\hline
\end{tabular}

${ }_{* * *} \mathrm{p}<0.01,{ }^{* *} \mathrm{p}<0.05,{ }^{*} \mathrm{p}<0.1,+\mathrm{p}<0.15$ 
Figure 1: Male and Female Age of Entry Hazard Curves across Shock Realizations at Mean Trait Levels
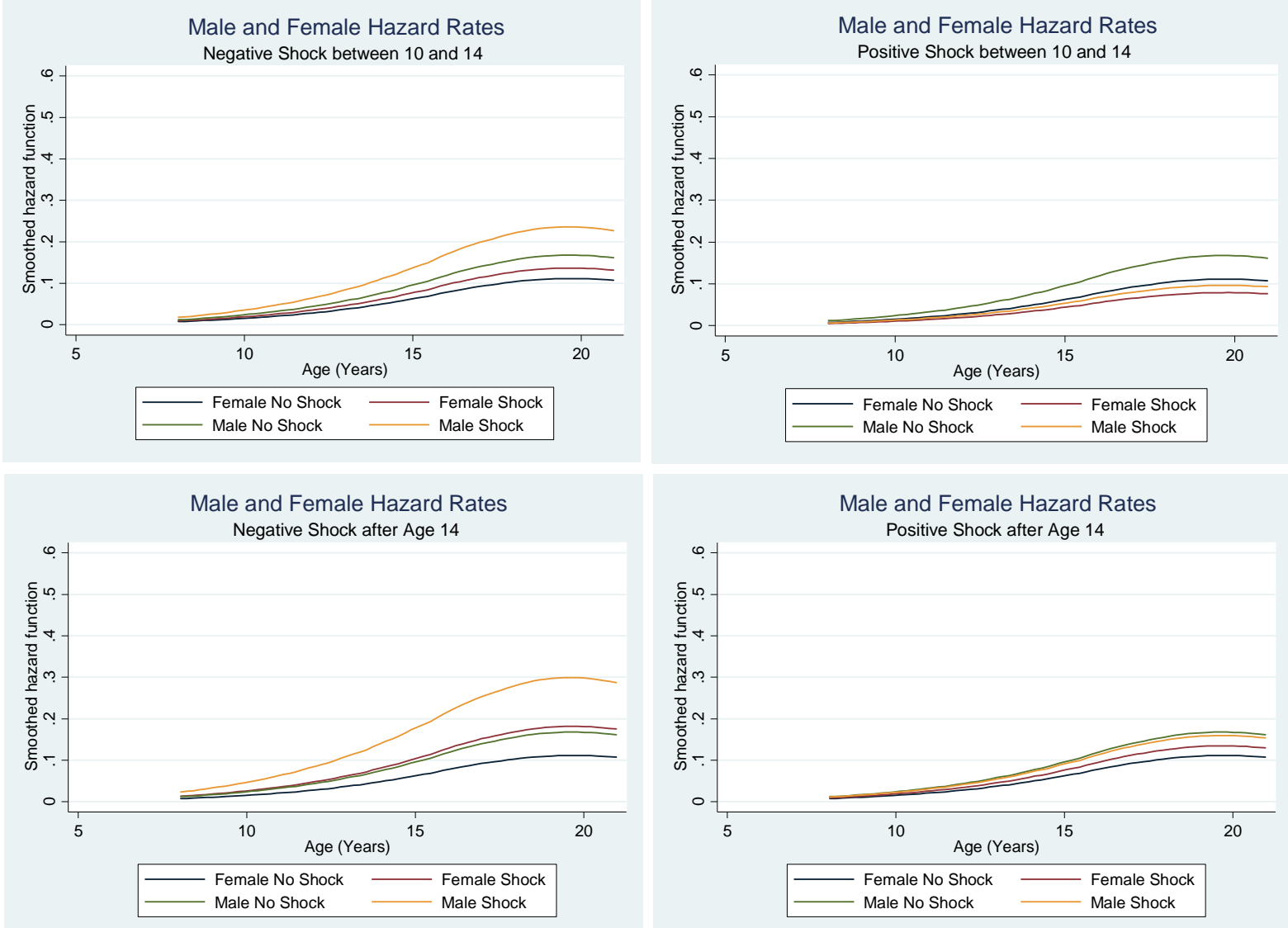

Note: Figures should be viewed in color 
Figure 2: Age of Entry Hazard Curves for Males and Females at High and Low Trait Levels in Event of No Shocks
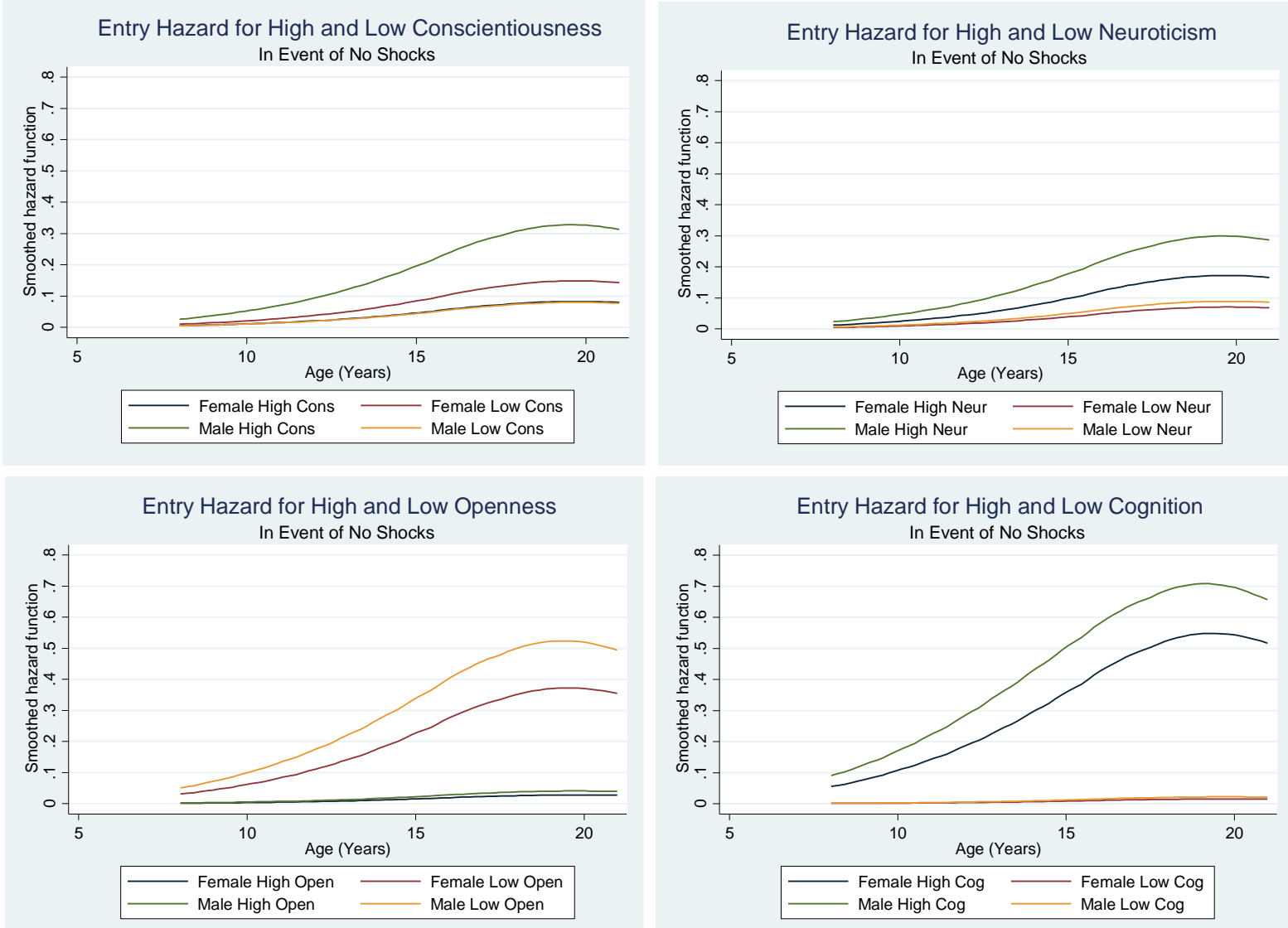

Note: Figures should be viewed in color 
Figure 3: Age of Entry Hazard Curves for Males with High and Low Cognition across Shock Realizations after Age 10
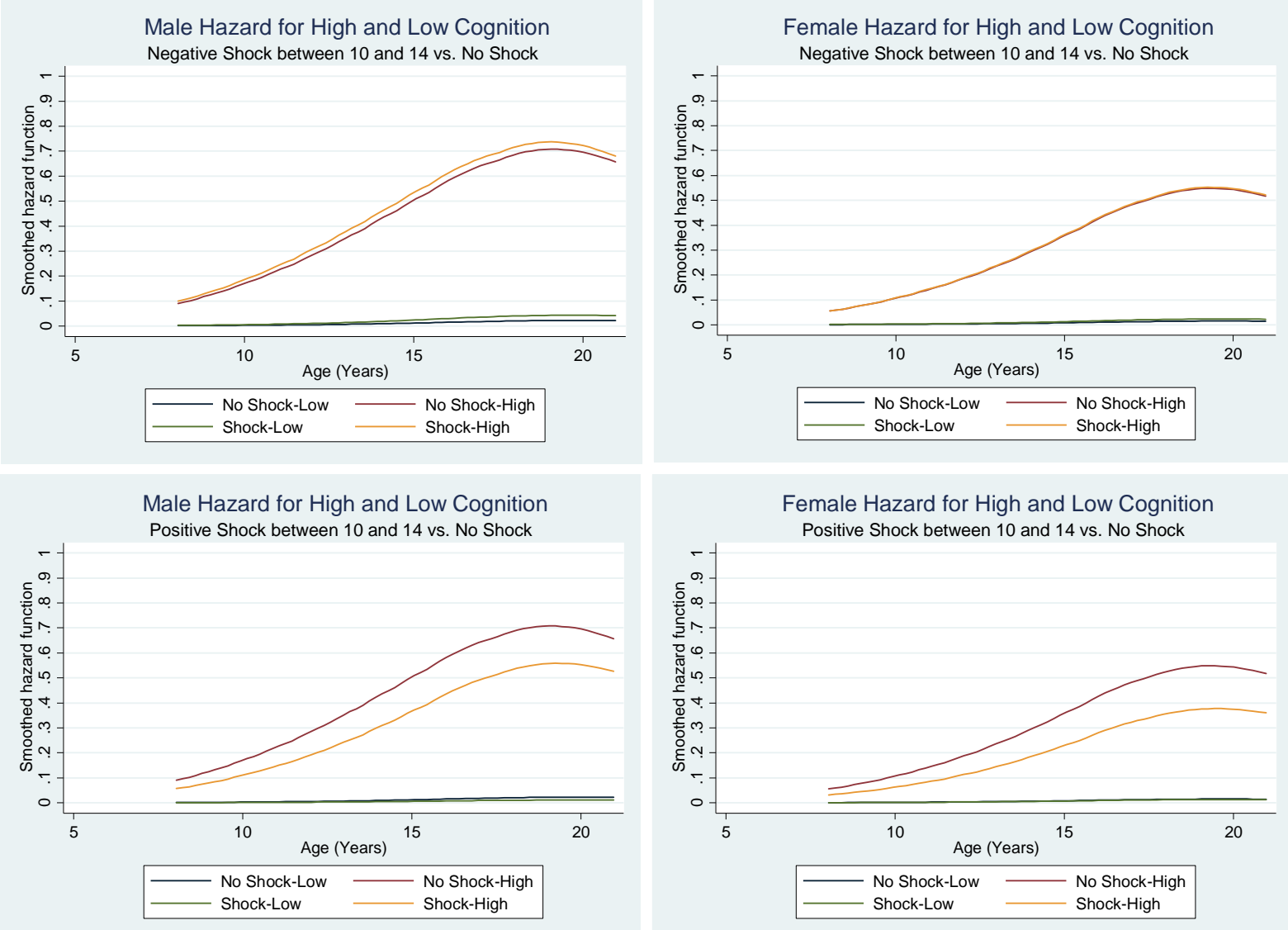

Note: Figures should be viewed in color 
Figure 4: Age of Entry Hazard Curves for Females with High and Low Cognition across Shock Realizations after Age 10
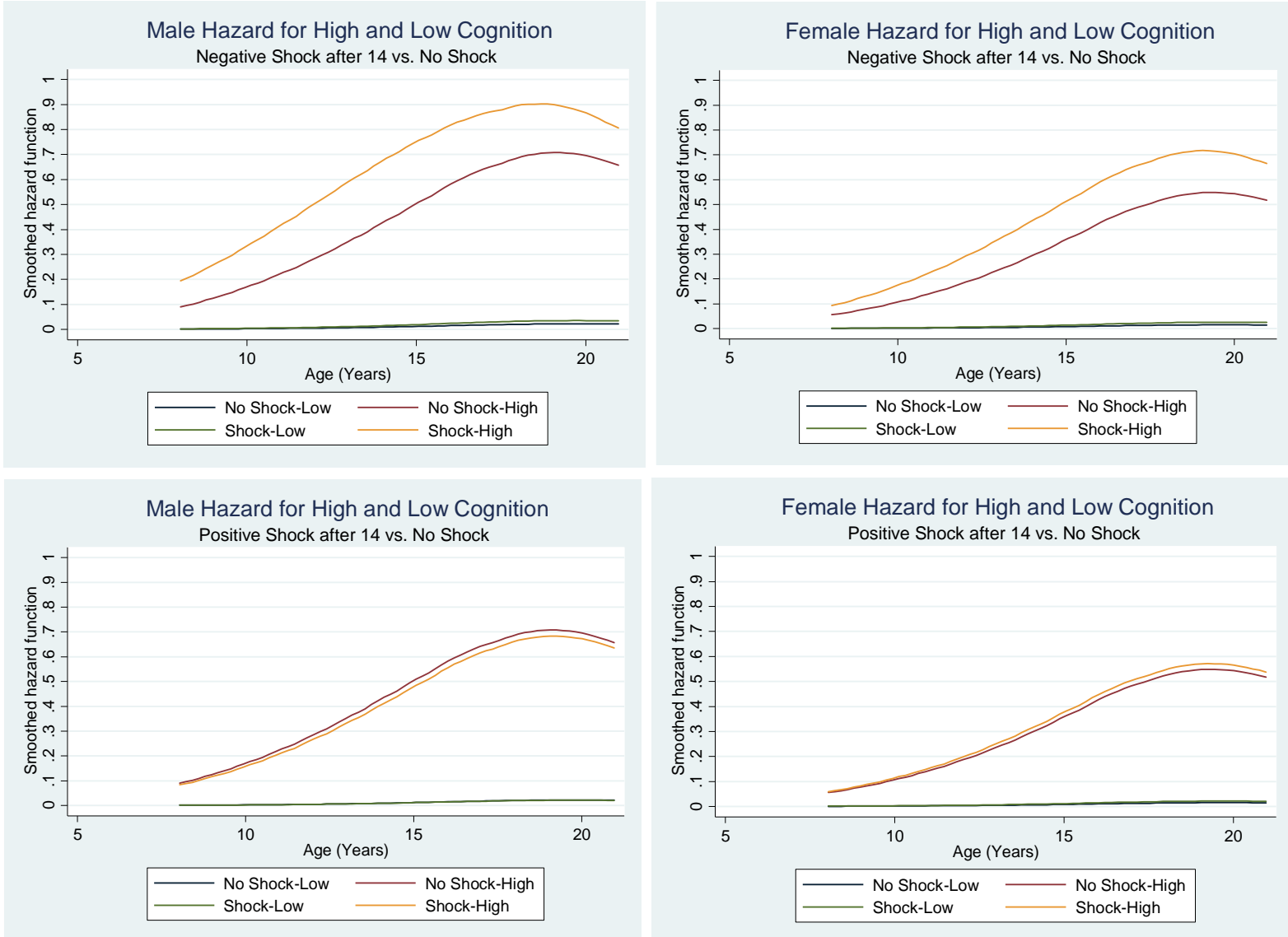

Note: Figures should be viewed in color 
Figure 5: Age of Entry Hazard Curves for Males and Females with High and Low Openness across Shock Realizations after Age 14
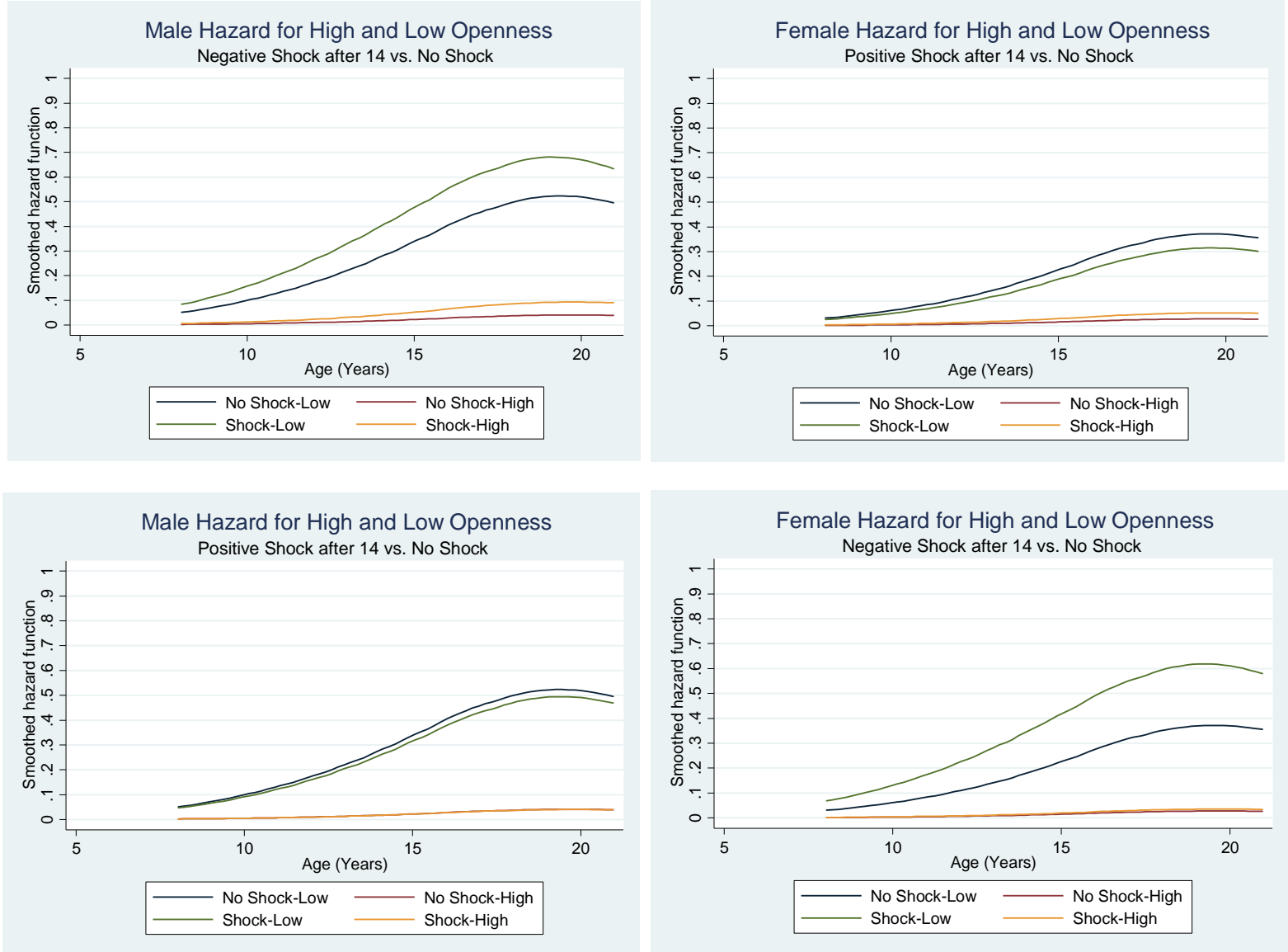

Note: Figures should be viewed in color 
Figure 6: Age of Entry Hazard Curves for Males and Females with High and Low Neuroticism across Shock Realizations after Age 14
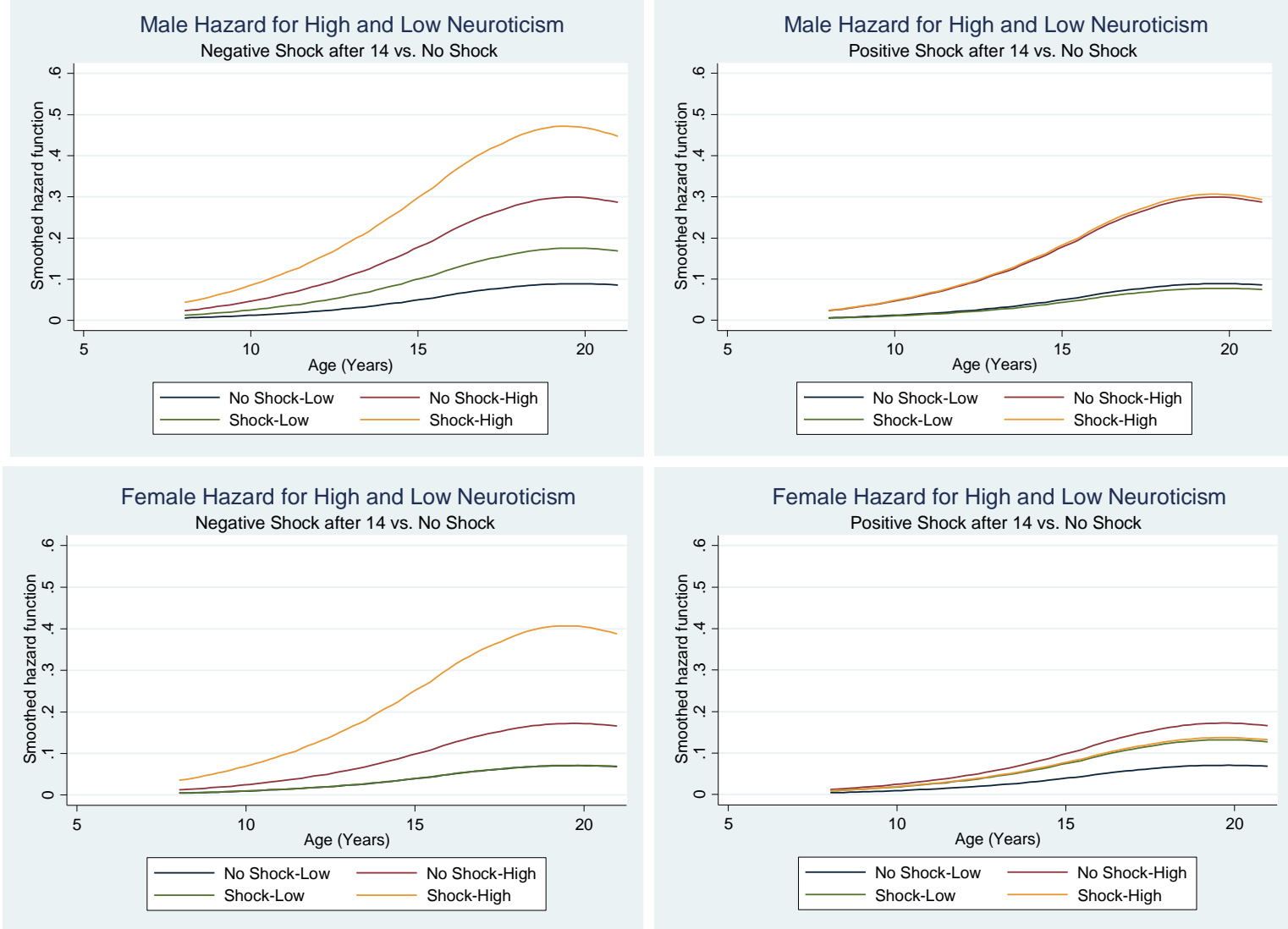

Note: Figures should be viewed in color 
Figure 7: Age of Entry Hazard Curves for Males with High and Low Neuroticism across Positive Shock Realizations between Ages 10 and 14

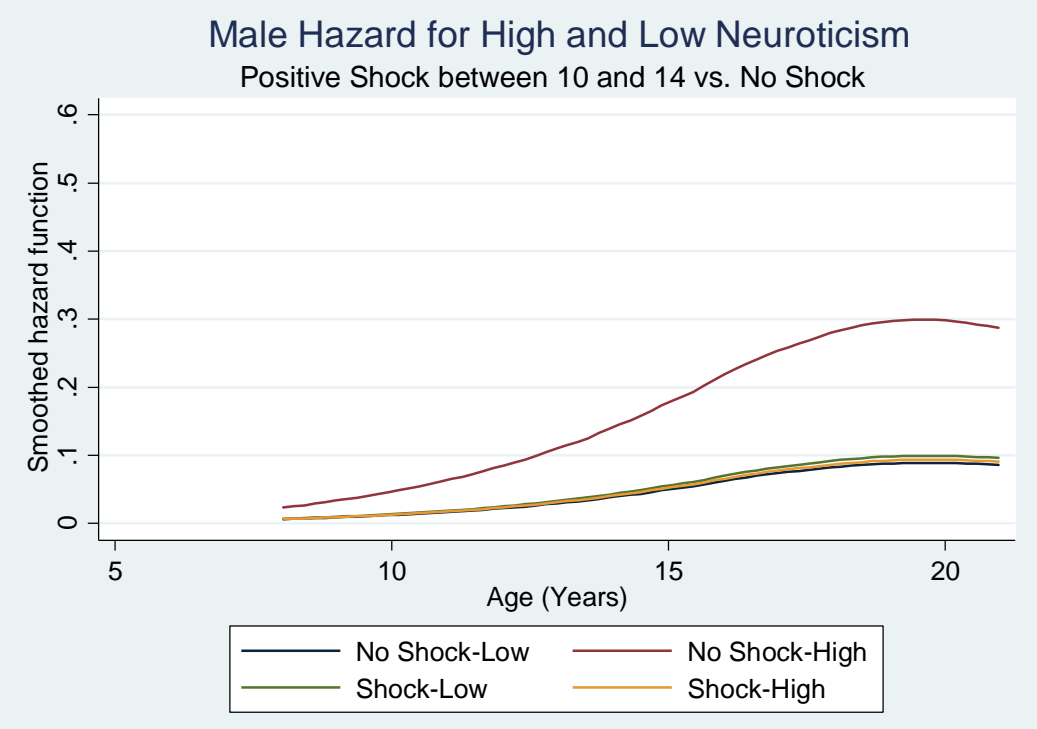

Note: Figures should be viewed in color 
Figure 8: Age of Entry Hazard Curves for Females with High and Low Conscientiousness across Shock Realizations after Age 10
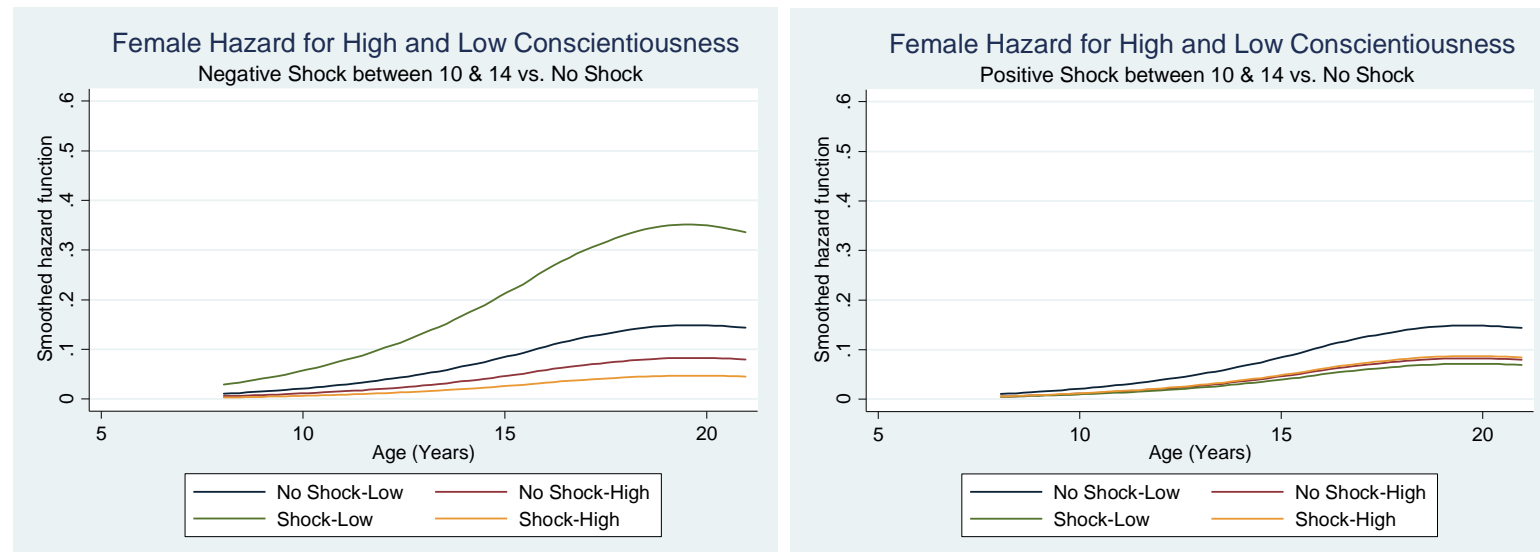

Female Hazard for High and Low Conscientiousness Negative Shock after 14 vs. No Shock

Female Hazard for High and Low Conscientiousness

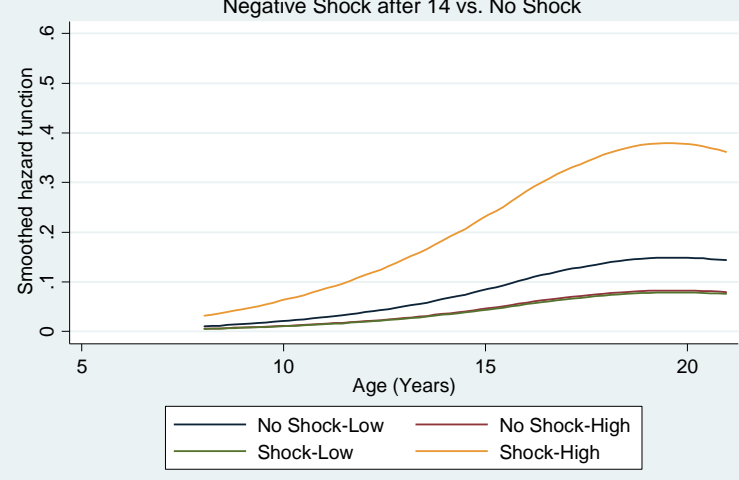
Positive Shock after 14 vs. No Shock

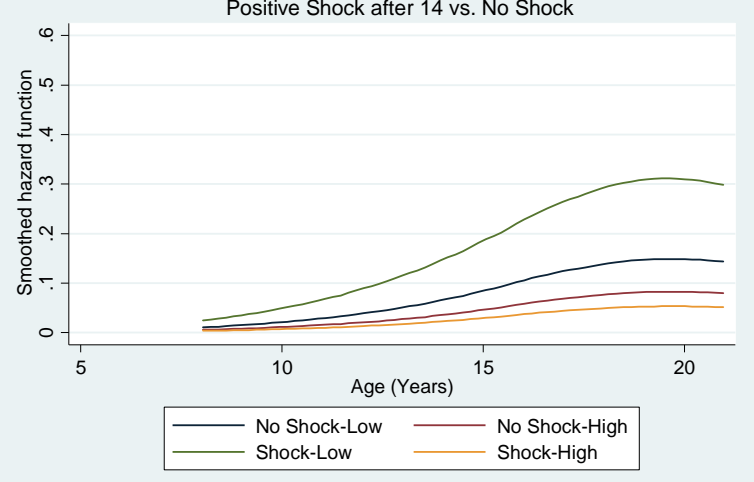

Note: Figures should be viewed in color 
Figure 9: Age of Entry Hazard Curves for Males with High and Low Conscientiousness across Shock Realizations after Age 10
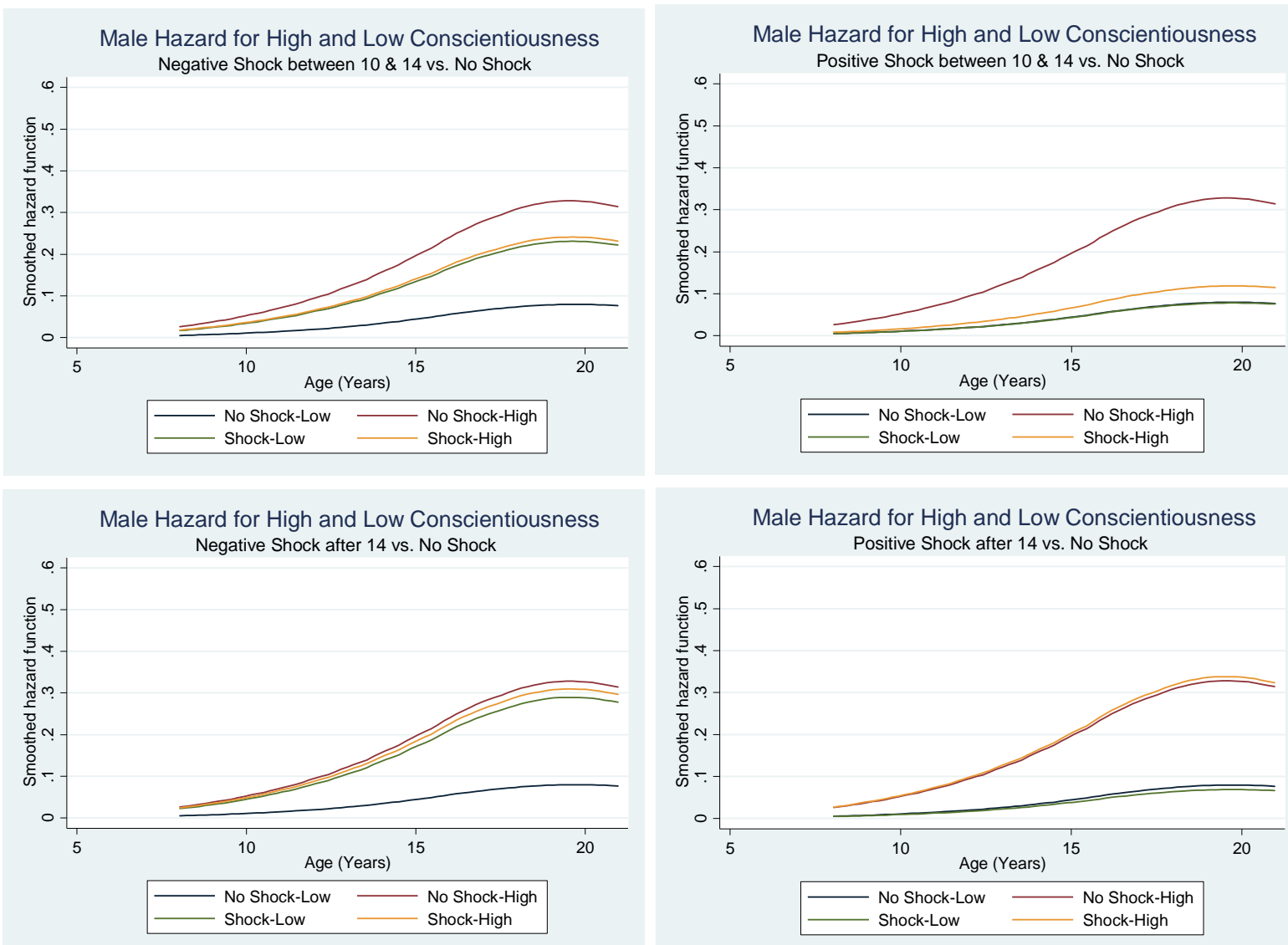

Note: Figures should be viewed in color 


\section{Appendix A: Measurement of Personality}

We model the Big Five Personality Traits as unobserved variables and use confirmatory factor analysis to uncover their latent distributions. By using confirmatory factor analysis, we can estimate the latent joint distribution of our five personality traits using the variance-covariance structure of survey questions designed to measure each trait. Personality traits are then estimated using the following measurement system:

$$
\begin{array}{ll}
Z_{j}^{O}=\mu_{j}^{O}+\lambda_{j}^{O} \theta^{O}+\varepsilon_{j}^{O} & \text { for } j \in\left\{1, \ldots, m_{j}^{O}\right\} \\
Z_{j}^{C}=\mu_{j}^{C}+\lambda_{j}^{C} \theta^{C}+\varepsilon_{j}^{C} & \text { for } j \in\left\{1, \ldots, m_{j}^{C}\right\} \\
Z_{j}^{E}=\mu_{j}^{E}+\lambda_{j}^{E} \theta^{E}+\varepsilon_{j}^{E} & \text { for } j \in\left\{1, \ldots, m_{j}^{E}\right\} \\
Z_{j}^{A}=\mu_{j}^{A}+\lambda_{j}^{A} \theta^{A}+\varepsilon_{j}^{A} & \text { for } j \in\left\{1, \ldots, m_{j}^{A}\right\} \\
Z_{j}^{N}=\mu_{j}^{N}+\lambda_{j}^{N} \theta^{N}+\varepsilon_{j}^{N} & \text { for } j \in\left\{1, \ldots, m_{j}^{N}\right\}
\end{array}
$$

Where $\mathrm{O}$ indexes Openness to Experience, $\mathrm{C}$ indexes Conscientiousness, E indexes Extraversion, A indexes Agreeableness, and N indexes Neuroticism. $Z_{j}^{p}$ is the observed $j^{\text {th }}$ measurement for latent trait $\theta^{p} \cdot m^{p}$ is the number of observed measurements for latent trait $p, p \in\{O, C, E, A, N\}$. To ensure that the model is not under-identified, we normalize $\lambda_{1}^{p}=1$ for all $p \in\{O, C, E, A, N\}$. This simply sets scale and is common practice in factor analysis. We also normalize $E\left[\theta^{p}\right]=0$. Doing so centers the distribution of latent factors over zero and is also common practice. Since the factors do not have any cardinal value, this normalization does not have any implications for how we interpret our results. The $\varepsilon^{\prime} s$ are assumed to be mean zero, are uncorrelated with the factors, and are independent across agents and factors. Using confirmatory factor analysis, we estimate the factor loadings, $\lambda_{j}^{p}$, and predict a personality trait 
factor score for each individual in the sample. We then use the standardized factor scores to estimate their effect school completion, age of labor market entry, and selection into employment sectors. Estimated factor loadings, $\lambda_{j}^{p}$, and the intercepts, $\mu_{j}^{p}$, from the measurement model can be found in Appendix Tables A.6-A.10. 
Table A.1: Openness to Experience Measurements

\begin{tabular}{|c|c|c|c|c|}
\hline & Mean & $\begin{array}{l}\text { Std. } \\
\text { Dev. }\end{array}$ & $\underline{\text { Min }}$ & $\underline{\text { Max }}$ \\
\hline I find the world very interesting & 3.4311 & 1.0660 & 1 & 5 \\
\hline I am never bored & 3.8074 & 0.8355 & 1 & 5 \\
\hline I am proficient in several areas & 3.0190 & 1.0338 & 1 & 5 \\
\hline I am always busy with something interesting & 3.6604 & 0.8602 & 1 & 5 \\
\hline I am interested in many things & 3.1393 & 1.0430 & 1 & 5 \\
\hline In any situation I can find something interesting & 3.1142 & 0.9656 & 1 & 5 \\
\hline I think my life is very interesting & 3.2809 & 0.9649 & 1 & 5 \\
\hline I am very interested in other countries and their cultures & 3.2378 & 1.1360 & 1 & 5 \\
\hline I am not very curious about what is happening in the world & 2.6983 & 1.0739 & 1 & 5 \\
\hline I am interested in very few things & 2.3140 & 0.9426 & 1 & 5 \\
\hline
\end{tabular}


Table A.2 : Conscientiousness Measurements

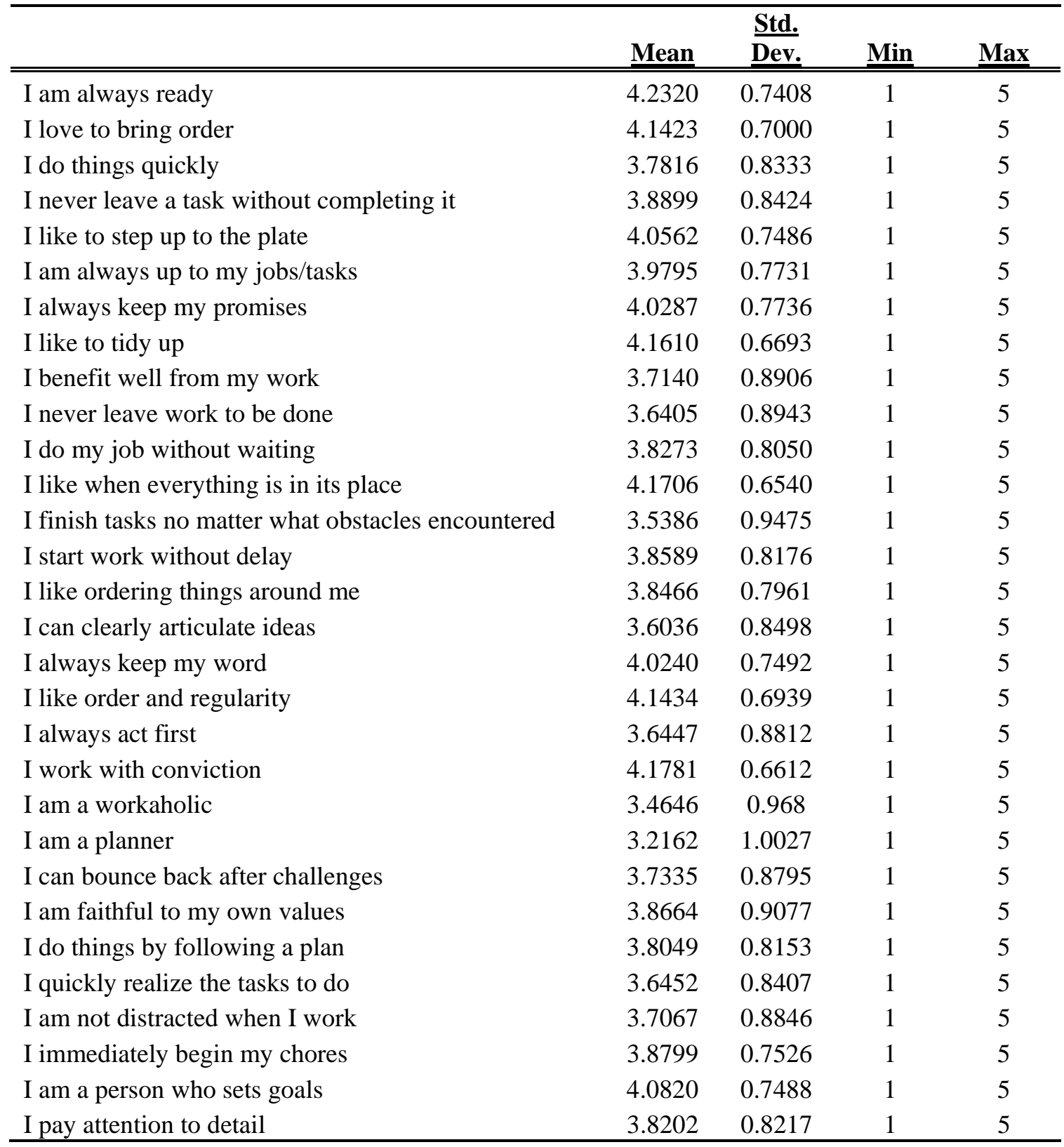


Table A.3: Extraversion Measurements

\begin{tabular}{|c|c|c|c|c|}
\hline & Mean & $\frac{\text { Std. }}{\text { Dev. }}$ & Min & Max \\
\hline I get involved in community/collective activities & 3.9918 & 0.8363 & 1 & 5 \\
\hline I like to animate groups & 3.1517 & 1.0950 & 1 & 5 \\
\hline I like belonging to a group & 3.7278 & 0.9096 & 1 & 5 \\
\hline I can captivate people's attention & 3.1598 & 0.9853 & 1 & 5 \\
\hline I can keep my cool & 3.9450 & 0.7471 & 1 & 5 \\
\hline I take the initiative in conversations & 3.7840 & 0.8354 & 1 & 5 \\
\hline I talk easily & 3.2412 & 1.0591 & 1 & 5 \\
\hline I can clearly articulate ideas & 3.6036 & 0.8498 & 1 & 5 \\
\hline I interact with different people when they are gathered & 3.7458 & 0.8428 & 1 & 5 \\
\hline I am uncomfortable working in a group & 2.1945 & 0.9444 & 1 & 5 \\
\hline I always have something to say & 2.7206 & 0.9702 & 1 & 5 \\
\hline I like to draw attention to myself & 2.8036 & 1.0521 & 1 & 5 \\
\hline I am not usually talkative & 3.1003 & 0.9970 & 1 & 5 \\
\hline I prefer to do it alone & 2.5329 & 1.0009 & 1 & 5 \\
\hline I am not talkative & 3.0592 & 0.9997 & 1 & 5 \\
\hline I have trouble expressing my feelings & 2.6930 & 1.0355 & 1 & 5 \\
\hline I work better when I'm alone & 3.0568 & 1.0799 & 1 & 5 \\
\hline I do not like to take the lead & 3.3175 & 1.0145 & 1 & 5 \\
\hline I wait for others to lead the way & 2.5870 & 1.0475 & 1 & 5 \\
\hline I keep to myself & 3.1567 & 1.0937 & 1 & 5 \\
\hline I do not talk a lot & 3.0439 & 1.0191 & 1 & 5 \\
\hline I rarely associate with others & 2.0334 & 0.8765 & 1 & 5 \\
\hline I try not to attract attention to myself & 2.8640 & 1.1806 & 1 & 5 \\
\hline I'm afraid to draw attention to myself & 2.7013 & 1.0785 & 1 & 5 \\
\hline I leave others to take the initiative & 2.1600 & 0.8988 & 1 & 5 \\
\hline I leave others to decide & 2.2724 & 0.9446 & 1 & 5 \\
\hline I feel comfortable with people & 3.8729 & 0.8385 & 1 & 5 \\
\hline I am a team player & 3.9531 & 0.7876 & 1 & 5 \\
\hline
\end{tabular}


Table A.4: Agreeableness Measurements

\begin{tabular}{|c|c|c|c|c|}
\hline & \multicolumn{3}{|c|}{ Std. } & \multirow[b]{2}{*}{ Max } \\
\hline & Mean & Dev. & Min & \\
\hline I get involved in community/collective activities & 3.9918 & 0.8363 & 1 & 5 \\
\hline I like belonging to a group & 3.7276 & 0.9096 & 1 & 5 \\
\hline I think honesty is the basis of trust & 4.1107 & 0.8364 & 1 & 5 \\
\hline I always keep my word & 4.0240 & 0.7492 & 1 & 5 \\
\hline I respect the decisions of the group & 4.0698 & 0.7066 & 1 & 5 \\
\hline
\end{tabular}


Table A.5: Neuroticism Measurements

\begin{tabular}{lcccc}
\hline & $\underline{\text { Mean }}$ & $\underline{\underline{\text { Dev. }}}$ & $\underline{\text { Min }}$ & $\underline{\text { Max }}$ \\
\hline I have often worried & 2.7822 & 1.0794 & 1 & 5 \\
I am not often worried & 3.1987 & 1.0505 & 1 & 5 \\
I am often sad & 2.2237 & 0.9623 & 1 & 5 \\
I feel hopeless & 2.2168 & 0.9887 & 1 & 5 \\
I have mood swings & 3.7036 & 0.9111 & 1 & 5 \\
I can bounce back after challenges & 3.7335 & 0.8795 & 1 & 5 \\
I have a bad feeling about what is going to happen & 2.2425 & 1.0305 & 1 & 5 \\
I panic easily & 2.2015 & 0.9466 & 1 & 5 \\
I lie to get out of things & 2.0850 & 1.0118 & 1 & 5 \\
I see problems everywhere & 2.4671 & 1.0085 & 1 & 5 \\
I am rarely angry & 3.2019 & 1.1439 & 1 & 5 \\
I get frustrated quickly & 2.2806 & 0.9410 & 1 & 5 \\
I have trouble expressing my feelings & 2.6930 & 1.0355 & 1 & 5 \\
I am a difficult person to understand & 2.8143 & 1.0515 & 1 & 5 \\
I give up easily & 2.0234 & 0.8925 & 1 & 5 \\
I get discouraged easily & 2.0152 & 0.8768 & 1 & 5 \\
I rarely worry & 3.2250 & 0.9958 & 1 & 5 \\
I sometimes feel dishonest & 1.8089 & 0.8451 & 1 & 5 \\
I am easily intimidated & 2.0299 & 0.8768 & 1 & 5 \\
It's often difficult for me to have fun & 2.3705 & 1.0309 & 1 & 5 \\
I exaggerate my troubles & 2.0709 & 0.8706 & 1 & 5 \\
I fear the worst will happen & 2.7825 & 1.1412 & 1 & 5 \\
I am unflappable & 3.2151 & 1.0450 & 1 & 5 \\
I have a lot of fun & 2.9795 & 0.9856 & 1 & 5 \\
I'm consumed by my own problems & 2.2973 & 0.9470 & 1 & 5 \\
\hline
\end{tabular}


Table A.6: Openness to Experience Estimates

\begin{tabular}{llc} 
& \multicolumn{1}{c}{$\lambda_{j}^{p}$} & $\mu_{j}^{p}$ \\
\hline \hline I find the world very interesting & 1.0000 & $3.4310^{* * *}$ \\
I am never bored & $0.4714^{* * *}$ & $3.8080^{* * *}$ \\
I am proficient in several areas & $0.6707^{* * *}$ & $3.0206^{* * *}$ \\
I am always busy with something interesting & $0.7073^{* * *}$ & $3.6624^{* * *}$ \\
I am interested in many things & $0.6845^{* * *}$ & $3.1368^{* * *}$ \\
In any situation I can find something interesting & $0.8995^{* * *}$ & $3.1133^{* * *}$ \\
I think my life is very interesting & $0.7382^{* * *}$ & $3.2813^{* * *}$ \\
I am very interested in other countries and their cultures & $1.1427^{* * *}$ & $3.2372^{* * *}$ \\
I am not very curious about what is happening in the world & $-0.4902^{* * *}$ & $2.6976^{* * *}$ \\
I am interested in very few things & $-0.1742^{* * *}$ & $2.3147^{* * *}$ \\
\hline
\end{tabular}


Table A.7: Conscientiousness Estimates

\begin{tabular}{|c|c|c|}
\hline & $\lambda_{j}^{p}$ & $\mu_{j}^{p}$ \\
\hline I am always ready & 1.0000 & $4.2289 * * *$ \\
\hline I love to bring order & $0.9489 * * *$ & $4.1407^{* * *}$ \\
\hline I do things quickly & $1.2030 * * *$ & $3.7812 * * *$ \\
\hline I never leave a task without completing it & $1.2790 * * *$ & $3.8906^{* * *}$ \\
\hline I like to step up to the plate & $1.3252^{* * *}$ & $4.0532 * * *$ \\
\hline I am always up to my jobs/tasks & $1.4385 * * *$ & $3.9787 * * *$ \\
\hline I always keep my promises & $1.3067 * * *$ & $4.0272 * * *$ \\
\hline I like to tidy up & $1.0557 * * *$ & $4.1591^{* * *}$ \\
\hline I benefit well from my work & $1.3832 * * *$ & $3.7114^{* * *}$ \\
\hline I never leave work to be done & $1.3590 * * *$ & $3.6387 * * *$ \\
\hline I do my job without waiting & $1.3382 * * *$ & $3.8273^{* * *}$ \\
\hline I like when everything is in its place & $0.9487 * * *$ & $4.1697 * * *$ \\
\hline I finish tasks no matter what obstacles encountered & $1.4048 * * *$ & $3.5376 * * *$ \\
\hline I start work without delay & $1.3734 * * *$ & $3.8587 * * *$ \\
\hline I like ordering things around me & $1.1400 * * *$ & $3.8439 * * *$ \\
\hline I can clearly articulate ideas & $1.3056 * * *$ & $3.5985 * * *$ \\
\hline I always keep my word & $1.2625 * * *$ & $4.0219 * * *$ \\
\hline I like order and regularity & $1.1098 * * *$ & $4.1431^{* * *}$ \\
\hline I always act first & $1.1263 * * *$ & $3.6458 * * *$ \\
\hline I work with conviction & $0.9899 * * *$ & $4.1750^{* * *}$ \\
\hline I am a workaholic & $1.3058^{* * *}$ & $3.4624 * * *$ \\
\hline I am a planner & $1.1236^{* * *}$ & $3.2170 * * *$ \\
\hline I can bounce back after challenges & $1.5037 * * *$ & $3.7321 * * *$ \\
\hline I am faithful to my own values & $1.2373 * * *$ & $3.8622 * * *$ \\
\hline I do things by following a plan & $1.3231^{* * *}$ & $3.8025^{* * *}$ \\
\hline I quickly realize the tasks to do & $1.2905^{* * *}$ & $3.6452 * * *$ \\
\hline I am not distracted when I work & $1.0688 * * *$ & $3.7067 * * *$ \\
\hline I immediately begin my chores & $1.2344 * * *$ & $3.8817 * * *$ \\
\hline I am a person who sets goals & $1.2342 * * *$ & $4.0816^{* * *}$ \\
\hline I pay attention to detail & $1.1054 * * *$ & $3.8196 * * *$ \\
\hline
\end{tabular}


Table A.8: Extroversion Estimates

\begin{tabular}{lll} 
& $\lambda_{j}^{p}$ & $\mu_{j}^{p}$ \\
\hline \hline I get involved in community/collective activities & 1.0000 & $3.9923^{* * *}$ \\
I like to animate groups & $0.9976^{* * *}$ & $3.1530^{* * *}$ \\
I like belonging to a group & $1.0798^{* * *}$ & $3.7271^{* * *}$ \\
I can captivate people's attention & $0.8997^{* * *}$ & $3.1607^{* * *}$ \\
I can keep my cool & $0.8390^{* * *}$ & $3.9468^{* * *}$ \\
I take the initiative in conversations & $1.0952^{* * *}$ & $3.7844^{* * *}$ \\
I talk easily & $0.7552^{* * *}$ & $3.2392^{* * *}$ \\
I can clearly articulate ideas & $0.9967 * * *$ & $3.6060^{* * *}$ \\
I interact with different people when they are gathered & $1.0291^{* * *}$ & $3.7460^{* * *}$ \\
I am uncomfortable working in a group & $-0.7069^{* * *}$ & $2.1955^{* * *}$ \\
I always have something to say & $0.5207^{* * *}$ & $2.7212^{* * *}$ \\
I like to draw attention to myself & $0.7325^{* * *}$ & $2.8021^{* * *}$ \\
I am not usually talkative & $-0.4272^{* * *}$ & $3.1010^{* * *}$ \\
I prefer to do it alone & $-0.2628^{* * *}$ & $2.5346^{* * *}$ \\
I am not talkative & $-0.5708^{* * *}$ & $3.0602^{* * *}$ \\
I have trouble expressing my feelings & $-0.6399^{* * *}$ & $2.6929^{* * *}$ \\
I work better when I'm alone & 0.0865 & $3.0561^{* * *}$ \\
I do not like to take the lead & $-0.1796^{* * *}$ & $3.3207^{* * *}$ \\
I wait for others to lead the way & $-0.3261^{* * *}$ & $2.5883^{* * *}$ \\
I keep to myself & $-0.1505^{* *}$ & $3.1559^{* * *}$ \\
I do not talk a lot & $-0.5989^{* * *}$ & $3.0443^{* * *}$ \\
I rarely associate with others & $-0.7581^{* * *}$ & $2.0307^{* * *}$ \\
I try not to attract attention to myself & $-0.6578^{* * *}$ & $2.8641^{* * *}$ \\
I'm afraid to draw attention to myself & $-0.6918^{* * *}$ & $2.6988^{* * *}$ \\
I leave others to take the initiative & $-0.8393^{* * *}$ & $2.1577^{* * *}$ \\
I leave others to decide & $-0.7280^{* * *}$ & $2.2705^{* * *}$ \\
I feel comfortable with people & $0.8178^{* * *}$ & $3.8748^{* * *}$ \\
I am a team player & $0.9104^{* * *}$ & $3.9545^{* * *}$ \\
\hline & &
\end{tabular}


Table A.9: Agreeableness Estimates

\begin{tabular}{lll} 
& \multicolumn{1}{c}{$\lambda_{j}^{p}$} & \multicolumn{1}{c}{$\mu_{j}^{p}$} \\
\hline \hline I get involved in community/collective activities & 1.0000 & $3.9924^{* * *}$ \\
I like belonging to a group & $0.9792^{* * *}$ & $3.7273^{* * *}$ \\
I think honesty is the basis of trust & $0.5626^{* * *}$ & $4.1097^{* * *}$ \\
I always keep my word & $0.6772^{* * *}$ & $4.0240^{* * *}$ \\
I respect the decisions of the group & $0.6460^{* * *}$ & $4.0698^{* * *}$ \\
\hline
\end{tabular}


Table A.10: Neuroticism Estimates

\begin{tabular}{lcc} 
& $\lambda_{j}^{p}$ & $\mu_{j}^{p}$ \\
\hline \hline I have often worried & 1.0000 & $2.7825^{* * *}$ \\
I am not often worried & $-0.5230^{* * *}$ & $3.1974^{* * *}$ \\
I am often sad & $1.0921^{* * *}$ & $2.4965^{* * *}$ \\
I feel hopeless & $1.1355^{* * *}$ & $2.2169^{* * *}$ \\
I have mood swings & $0.2514^{* * *}$ & $3.7021^{* * *}$ \\
I can bounce back after challenges & $-0.4762^{* * *}$ & $3.7305^{* * *}$ \\
I have a bad feeling about what is going to happen & $0.7088^{* * *}$ & $2.2470^{* * *}$ \\
I panic easily & $1.0688^{* * *}$ & $2.2045^{* * *}$ \\
I lie to get out of things & $0.5988^{* * *}$ & $2.0857^{* * *}$ \\
I see problems everywhere & $0.9497^{* * *}$ & $2.4675^{* * *}$ \\
I am rarely angry & -0.0347 & $3.2033^{* * *}$ \\
I get frustrated quickly & $0.9652^{* * *}$ & $2.2825^{* * *}$ \\
I have trouble expressing my feelings & $0.9433^{* * *}$ & $2.6950^{* * *}$ \\
I am a difficult person to understand & $0.7272^{* * *}$ & $2.8174^{* * *}$ \\
I give up easily & $1.0426^{* * *}$ & $2.0266^{* * *}$ \\
I get discouraged easily & $1.1387^{* * *}$ & $2.0165^{* * *}$ \\
I rarely worry & $-0.1413^{* * *}$ & $3.2287^{* * *}$ \\
I sometimes feel dishonest & $0.9316^{* * *}$ & $1.8085^{* * *}$ \\
I am easily intimidated & $0.9783^{* * *}$ & $2.0307^{* * *}$ \\
It's often difficult for me to have fun & $0.7225^{* * *}$ & $2.3729^{* * *}$ \\
I exaggerate my troubles & $0.8541^{* * *}$ & $2.0751^{* * *}$ \\
I fear the worst will happen & $1.1304^{* * *}$ & $2.7843^{* * *}$ \\
I am unflappable & $-0.3405^{* * *}$ & $3.2122^{* * *}$ \\
I have a lot of fun & $-0.1185^{* *}$ & $2.9775^{* * *}$ \\
I'm consumed by my own problems & $1.0307^{* * *}$ & $2.2991^{* * *}$ \\
\hline & & \\
\hline
\end{tabular}


Table A.11: Correlation Matrix of Personality Traits and Cognitive Test Score

\begin{tabular}{|c|c|c|c|c|c|c|}
\hline & $\begin{array}{c}\text { Openness to } \\
\text { Experience } \\
\text { z-score }\end{array}$ & $\begin{array}{c}\text { Conscientiousness } \\
\text { z-score }\end{array}$ & $\begin{array}{c}\text { Extroversion } \\
\text { z-score }\end{array}$ & $\begin{array}{l}\text { Agreeableness } \\
\text { z-score }\end{array}$ & $\begin{array}{l}\text { Neuroticism } \\
\text { z-score }\end{array}$ & $\begin{array}{c}\text { Aggregate } \\
\text { Math/French } \\
\text { z-score }\end{array}$ \\
\hline Openness to Experience z-score & 1 & & & & & \\
\hline Conscientiousness z-score & $0.66^{* * *}$ & 1 & & & & \\
\hline Extroversion z-score & $0.63^{* * *}$ & $0.75^{* * *}$ & 1 & & & \\
\hline Agreeableness z-score & $0.52 * * *$ & $0.72 * * *$ & $0.75^{* * *}$ & 1 & & \\
\hline Neuroticism z-score & $-0.17 * * *$ & $-0.34 * * *$ & $-0.44 * * *$ & $-0.28 * * *$ & 1 & \\
\hline Aggregate Math/French z-score & $0.23 * * *$ & $0.14^{* * *}$ & $0.18 * * *$ & $0.09 * * *$ & $-0.13 * * *$ & 1 \\
\hline
\end{tabular}

${ }^{* * *} \mathrm{p}<0.01,{ }^{* *} \mathrm{p}<0.05,{ }^{*} \mathrm{p}<0.1$ 


\section{Appendix B: Additional Tables}

Table B.1: First-Stage Prediction for Grade Attainment and Cognitive Test Scores

\begin{tabular}{|c|c|c|}
\hline & Grade & Cognitive Test Sc \\
\hline Conscientiousness z-score & $\begin{array}{c}-0.1285 \\
(0.133)\end{array}$ & $\begin{array}{c}-0.0789 * * \\
(0.039)\end{array}$ \\
\hline Extraversion z-score & $\begin{array}{l}-0.0433 \\
(0.145)\end{array}$ & $\begin{array}{l}-0.0150 \\
(0.040)\end{array}$ \\
\hline Openness to Experience z-score & $\begin{array}{c}0.6090^{* * *} \\
(0.109)\end{array}$ & $\begin{array}{c}0.1695 * * * \\
(0.032)\end{array}$ \\
\hline Agreeableness z-score & $\begin{array}{l}0.1130 \\
(0.127)\end{array}$ & $\begin{array}{l}0.0227 \\
(0.035)\end{array}$ \\
\hline Neuroticism z-score & $\begin{array}{c}-0.2386 * * * \\
(0.089)\end{array}$ & $\begin{array}{c}-0.0954 * * * \\
(0.024)\end{array}$ \\
\hline Male & $\begin{array}{l}-0.2196 \\
(0.159)\end{array}$ & $\begin{array}{l}-0.0027 \\
(0.044)\end{array}$ \\
\hline Mother's Highest Grade & $\begin{array}{c}0.1913^{* * *} \\
(0.027)\end{array}$ & $\begin{array}{c}0.0467 * * * \\
(0.008)\end{array}$ \\
\hline Father's Highest Grade & $\begin{array}{c}0.1969 * * * \\
(0.027)\end{array}$ & $\begin{array}{c}0.0382 * * * \\
(0.007)\end{array}$ \\
\hline 2004 Household Asset Index & $\begin{array}{c}0.5857 * * * \\
(0.123)\end{array}$ & $\begin{array}{c}0.1971 * * * \\
(0.031)\end{array}$ \\
\hline 2012 Household Nonlabor Income & $\begin{array}{l}0.0001 \\
(0.000)\end{array}$ & $\begin{array}{l}0.0000 \\
(0.000)\end{array}$ \\
\hline 2004 Household Nonlabor Income & $\begin{array}{c}0.0000^{* * *} \\
(0.000)\end{array}$ & $\begin{array}{c}0.0000 * * * \\
(0.000)\end{array}$ \\
\hline 2004 Household Size & $\begin{array}{c}0.1042 * \\
(0.058)\end{array}$ & $\begin{array}{c}0.0415^{* * * *} \\
(0.015)\end{array}$ \\
\hline Number of Kids $<17$ yrs in 2004 & $\begin{array}{c}-0.2464 * * * \\
(0.073)\end{array}$ & $\begin{array}{c}-0.0703 * * * \\
(0.019)\end{array}$ \\
\hline 2004 Primary School Facilities Quality Index & $\begin{array}{c}0.3871^{* *} \\
(0.154)\end{array}$ & $\begin{array}{c}0.1398 * * * \\
(0.040)\end{array}$ \\
\hline $\begin{array}{l}2004 \text { Distance between Town Center and Primary } \\
\text { School }\end{array}$ & $\begin{array}{l}-0.0304 \\
(0.067)\end{array}$ & $\begin{array}{l}0.0079 \\
(0.022)\end{array}$ \\
\hline 2004 Primary School Participation in Nutrition Program & $\begin{array}{l}-0.0856 \\
(0.165)\end{array}$ & $\begin{array}{l}0.0722 \\
(0.045)\end{array}$ \\
\hline 2004 Private School in Community & $\begin{array}{l}0.2161 \\
(0.210)\end{array}$ & $\begin{array}{l}-0.0492 \\
(0.053)\end{array}$ \\
\hline 2004 Community Health Index & $\begin{array}{c}-0.2113^{*} \\
(0.125)\end{array}$ & $\begin{array}{l}0.0119 \\
(0.037)\end{array}$ \\
\hline 2004 Community Infrastructure Index & $\begin{array}{c}0.3943^{* *} \\
(0.162)\end{array}$ & $\begin{array}{l}0.1497 * * * \\
(0.049)\end{array}$ \\
\hline 2004 Remoteness Index & $\begin{array}{c}-0.3996 * * * \\
(0.085)\end{array}$ & $\begin{array}{l}-0.1045 * * * \\
(0.024)\end{array}$ \\
\hline Formal Account a Primary Savings Method & $-0.5210 *$ & $-0.2454 * * *$ \\
\hline
\end{tabular}




\begin{tabular}{|c|c|c|}
\hline & $(0.284)$ & $(0.077)$ \\
\hline Bank is a Primary Source for Large Loans & $\begin{array}{c}0.3399+ \\
(0.219)\end{array}$ & $\begin{array}{c}0.2161^{* * *} \\
(0.065)\end{array}$ \\
\hline Urban & $\begin{array}{c}-0.4625 \\
(0.355)\end{array}$ & $\begin{array}{c}-0.2920 * * * \\
(0.087)\end{array}$ \\
\hline 2012 Community Infrastructure Index & $\begin{array}{c}-0.2398 \\
(0.187)\end{array}$ & $\begin{array}{c}-0.0928 * \\
(0.050)\end{array}$ \\
\hline 2012 Access to Secondary School & $\begin{array}{c}0.5080 * * \\
(0.219)\end{array}$ & $\begin{array}{c}0.3326 * * * \\
(0.059)\end{array}$ \\
\hline Death of Mother & $\begin{array}{c}-0.1516 \\
(0.288)\end{array}$ & $\begin{array}{c}0.1506 * \\
(0.087)\end{array}$ \\
\hline Death of Father & $\begin{array}{l}-0.0401 \\
(0.223)\end{array}$ & $\begin{array}{l}0.0094 \\
(0.061)\end{array}$ \\
\hline Mother Illness/Injury & $\begin{array}{c}-0.5805^{* * *} \\
(0.221)\end{array}$ & $\begin{array}{c}-0.1040^{*} \\
(0.063)\end{array}$ \\
\hline Father Illness/Injury & $\begin{array}{l}0.2357 \\
(0.221)\end{array}$ & $\begin{array}{l}0.0701 \\
(0.062)\end{array}$ \\
\hline Positive Income Shock before Age 10 & $\begin{array}{c}0.3549+ \\
(0.235)\end{array}$ & $\begin{array}{l}0.0789 \\
(0.067)\end{array}$ \\
\hline Positive Income Shock between Ages 10 and 14 & $\begin{array}{l}0.1852 \\
(0.204)\end{array}$ & $\begin{array}{l}0.1046 * \\
(0.058)\end{array}$ \\
\hline Positive Income Shock after Age 14 & $\begin{array}{l}-0.0567 \\
(0.183)\end{array}$ & $\begin{array}{c}-0.0528 \\
(0.049)\end{array}$ \\
\hline Negative Income Shock before Age 10 & $\begin{array}{c}-0.1938 \\
(0.221)\end{array}$ & $\begin{array}{l}-0.0230 \\
(0.062)\end{array}$ \\
\hline Negative Income Shock between Ages 10 and 14 & $\begin{array}{l}-0.1271 \\
(0.200)\end{array}$ & $\begin{array}{c}-0.0827+ \\
(0.055)\end{array}$ \\
\hline Negative Income Shock after Age 14 & $\begin{array}{c}-0.4772^{* *} \\
(0.197)\end{array}$ & $\begin{array}{l}-0.0577 \\
(0.055)\end{array}$ \\
\hline Constant & $\begin{array}{c}7.3887^{* * * *} \\
(0.503)\end{array}$ & $\begin{array}{c}-0.3869 * * * \\
(0.143)\end{array}$ \\
\hline
\end{tabular}

Robust standard errors in parentheses

*** $\mathrm{p}<0.01,{ }^{* *} \mathrm{p}<0.05,{ }^{*} \mathrm{p}<0.1,+\mathrm{p}<0.15$ 
Table B.2: Hazard of Age of Entry into the Labor Market

\begin{tabular}{|c|c|c|}
\hline & No IV & IV \\
\hline \multirow[t]{2}{*}{ Conscientiousness z-score } & $-0.3241 * *$ & -0.1594 \\
\hline & $(0.159)$ & $(0.184)$ \\
\hline \multirow[t]{2}{*}{ Extraversion z-score } & -0.0630 & -0.0883 \\
\hline & $(0.157)$ & $(0.161)$ \\
\hline \multirow[t]{2}{*}{ Openness to Experience z-score } & 0.0044 & -0.7191 \\
\hline & $(0.130)$ & $(0.523)$ \\
\hline \multirow[t]{2}{*}{ Agreeableness z-score } & $0.2615^{*}$ & 0.1809 \\
\hline & $(0.152)$ & $(0.168)$ \\
\hline \multirow[t]{2}{*}{ Neuroticism z-score } & -0.0839 & 0.2423 \\
\hline & $(0.108)$ & $(0.231)$ \\
\hline \multirow[t]{2}{*}{ Aggregate Cognitive Test z-score } & $-0.2204 * *$ & $2.0425 *$ \\
\hline & $(0.112)$ & $(1.048)$ \\
\hline \multirow[t]{2}{*}{ Cognitive Test First-Stage Predicted Residual } & & $-2.2867 * *$ \\
\hline & & $(1.047)$ \\
\hline \multirow[t]{2}{*}{ Highest Grade Attained } & $-0.0882 * * *$ & 0.5275 \\
\hline & $(0.016)$ & $(0.631)$ \\
\hline \multirow[t]{2}{*}{ Grade First-Stage Predicted Residual } & & -0.6127 \\
\hline & & $(0.630)$ \\
\hline \multirow[t]{2}{*}{ Positive Income Shock before Age 10} & $0.4009 * *$ & 0.0692 \\
\hline & $(0.171)$ & $(0.346)$ \\
\hline \multirow[t]{2}{*}{ Positive Income Shock between Ages 10 and 14} & -0.0046 & -0.3665 \\
\hline & $(0.140)$ & $(0.263)$ \\
\hline \multirow{2}{*}{ Positive Income Shock after Age 14} & 0.1346 & $0.2074+$ \\
\hline & $(0.125)$ & $(0.132)$ \\
\hline \multirow[t]{2}{*}{ Negative Income Shock before Age 10} & 0.0870 & 0.2511 \\
\hline & $(0.151)$ & $(0.228)$ \\
\hline \multirow[t]{2}{*}{ Negative Income Shock between Ages 10 and 14} & -0.0605 & 0.2240 \\
\hline & $(0.149)$ & $(0.233)$ \\
\hline \multirow[t]{2}{*}{ Negative Income Shock after Age 14} & 0.1379 & $0.5452+$ \\
\hline & $(0.139)$ & $(0.352)$ \\
\hline \multirow[t]{2}{*}{ Death of Mother } & 0.0761 & -0.1445 \\
\hline & $(0.123)$ & $(0.164)$ \\
\hline \multirow[t]{2}{*}{ Death of Father } & 0.0837 & 0.0354 \\
\hline & $(0.094)$ & $(0.097)$ \\
\hline \multirow[t]{2}{*}{ Mother Illness/Injury } & -0.0334 & 0.4395 \\
\hline & $(0.101)$ & $(0.388)$ \\
\hline \multirow[t]{2}{*}{ Father Illness/Injury } & -0.0514 & -0.4549 \\
\hline & $(0.100)$ & $(0.319)$ \\
\hline Individual and Household Controls & $\mathrm{X}$ & $\mathrm{X}$ \\
\hline 2004 and 2012 Community Controls & $\mathrm{X}$ & $\mathrm{X}$ \\
\hline Regional Dummies & $\mathrm{X}$ & $\mathrm{X}$ \\
\hline Interactions of Income Shocks with Personality and Cognition & $\mathrm{X}$ & $\mathrm{X}$ \\
\hline Interactions of Male with Personality and Cognition & $\mathrm{X}$ & $\mathrm{X}$ \\
\hline Interactions of Male with Income Shocks & $\mathrm{X}$ & $\mathrm{X}$ \\
\hline \multicolumn{3}{|l|}{ Interaction of Male with Income Shocks with Personality and } \\
\hline Cognition & $\mathrm{X}$ & $\mathrm{X}$ \\
\hline
\end{tabular}

Standard errors in parentheses

*** $\mathrm{p}<0.01, * * \mathrm{p}<0.05, * \mathrm{p}<0.1,+\mathrm{p}<0.15$ 
Table B.3: $\chi^{2}$ Tests Statistics on Joint Significance of Trait and Shock Coefficients with Interactions

\begin{tabular}{lcc}
\hline & Males & Females \\
\cline { 2 - 3 }$\chi^{2}(14)$ & $\chi^{2}(7)$ \\
\hline \hline Conscientiousness & $20.70^{*}$ & 10.07 \\
Extraversion & $33.36^{* * *}$ & $15.79^{* *}$ \\
Openness to Experience & $22.68^{*}$ & $12.29^{*}$ \\
Agreeableness & $25.78^{* *}$ & $15.62^{* *}$ \\
Neuroticism & $22.50^{*}$ & 11.11 \\
Instrumented Cognition Scores & $28.56^{* * *}$ & $12.88^{*}$ \\
\hline Shocks & & \\
\hline Positive Shock before 10 & 8.35 & 2.55 \\
Positive Shock between 10 and 14 & $27.63^{* * *}$ & $15.29^{* *}$ \\
Positive Shock after 14 & 12.98 & 10.35 \\
Negative Shock before 10 & 16.99 & $12.12^{*}$ \\
Negative Shock between 10 and 14 & $22.75^{*}$ & 9.46 \\
Negative Shock after 14 & 18.00 & 10.28 \\
\hline
\end{tabular}

Standard errors in parentheses

*** $\mathrm{p}<0.01,{ }^{* *} \mathrm{p}<0.05,{ }^{*} \mathrm{p}<0.1$ 
Table B.4: Estimated Multinomial Logistic Coefficients for Selection into Labor Market Sectors

\begin{tabular}{|c|c|c|c|c|}
\hline & Unemployed & Informal Sector & $\frac{\text { Formal }}{\text { Sector }}$ & Student \\
\hline \multirow[t]{2}{*}{ Conscientiousness z-score } & -0.3286 & 0.1629 & Base & -0.5503 \\
\hline & $(0.461)$ & $(0.297)$ & Outcome & $(0.514)$ \\
\hline \multirow[t]{2}{*}{ Extraversion z-score } & 0.1528 & -0.1315 & & 0.0818 \\
\hline & $(0.523)$ & $(0.321)$ & & $(0.578)$ \\
\hline \multirow[t]{2}{*}{ Openness to Experience z-score } & -0.2584 & -0.2710 & & $-0.7795+$ \\
\hline & $(0.442)$ & $(0.263)$ & & $(0.501)$ \\
\hline \multirow[t]{2}{*}{ Agreeableness z-score } & -0.1069 & -0.0012 & & -0.0877 \\
\hline & $(0.404)$ & $(0.262)$ & & $(0.455)$ \\
\hline \multirow[t]{2}{*}{ Neuroticism z-score } & 0.2491 & $0.4054 * *$ & & $0.7909 * *$ \\
\hline & $(0.288)$ & $(0.188)$ & & $(0.317)$ \\
\hline \multirow[t]{2}{*}{ Aggregate Cognitive Test z-score } & -0.3218 & $-1.0619 * *$ & & -0.2307 \\
\hline & $(0.783)$ & $(0.431)$ & & $(0.923)$ \\
\hline \multirow[t]{2}{*}{ Cognitive Test First-Stage Predicted Residual } & -0.1462 & 0.2631 & & 0.3321 \\
\hline & $(0.767)$ & $(0.408)$ & & $(0.899)$ \\
\hline \multirow[t]{2}{*}{ Highest Grade Attained } & -0.1465 & -0.1537 & & $1.2225^{* *}$ \\
\hline & $(0.445)$ & $(0.237)$ & & $(0.512)$ \\
\hline \multirow[t]{2}{*}{ Grade First-Stage Predicted Residual } & 0.1008 & 0.1066 & & $-0.9186^{*}$ \\
\hline & $(0.442)$ & $(0.237)$ & & $(0.505)$ \\
\hline \multirow[t]{2}{*}{ Never Employed } & 0.8711 & -0.1100 & & 0.7912 \\
\hline & (42.533) & $(50.050)$ & & $(42.533)$ \\
\hline \multirow{2}{*}{ Ever-Employed X Age at First Job } & $-0.1404 * *$ & $-0.1690 * * *$ & & $-0.3169 * * *$ \\
\hline & $(0.060)$ & $(0.030)$ & & $(0.081)$ \\
\hline \multirow[t]{2}{*}{ Male X Conscientiousness } & 0.3882 & -0.3417 & & 1.0177 \\
\hline & $(0.695)$ & $(0.372)$ & & $(0.791)$ \\
\hline \multirow[t]{2}{*}{ Male X Extraversion } & 0.1024 & $0.6193+$ & & -0.5041 \\
\hline & $(0.749)$ & $(0.407)$ & & $(0.862)$ \\
\hline \multirow[t]{2}{*}{ Male X Openness } & -0.5427 & -0.1643 & & -0.3752 \\
\hline & $(0.516)$ & $(0.292)$ & & $(0.598)$ \\
\hline \multirow[t]{2}{*}{ Male X Neuroticism } & 0.1566 & $-0.3567+$ & & $-0.8098 *$ \\
\hline & $(0.403)$ & $(0.236)$ & & $(0.473)$ \\
\hline \multirow[t]{2}{*}{ Male X Agreeableness } & 0.7170 & -0.0896 & & 0.6649 \\
\hline & $(0.647)$ & $(0.341)$ & & $(0.737)$ \\
\hline \multirow[t]{2}{*}{ Male X Cognition } & 0.5096 & $0.4043^{*}$ & & 0.5521 \\
\hline & $(0.417)$ & $(0.236)$ & & $(0.545)$ \\
\hline \multirow[t]{2}{*}{ Constant } & 0.2272 & $4.2429 *$ & & -5.8085 \\
\hline & $(4.264)$ & $(2.269)$ & & $(4.793)$ \\
\hline Individual and Household Controls & $\mathrm{X}$ & $\mathrm{X}$ & & $\mathrm{X}$ \\
\hline 2004 and 2012 Community Controls & $\mathrm{X}$ & $\mathrm{X}$ & & $\mathrm{X}$ \\
\hline Regional Dummies & $\mathrm{X}$ & $\mathrm{X}$ & & $\mathrm{X}$ \\
\hline Observations & 1,156 & 1,156 & 1,156 & 1,156 \\
\hline
\end{tabular}

Standard errors in parentheses

${ }^{* * *} \mathrm{p}<0.01,{ }^{* *} \mathrm{p}<0.05,{ }^{*} \mathrm{p}<0.1,+\mathrm{p}<0.15$ 


\section{Appendix C: Additional Figures}

Figure C.1: Male and Female Age of Entry Hazard Curves across Shock Realizations before Age 10
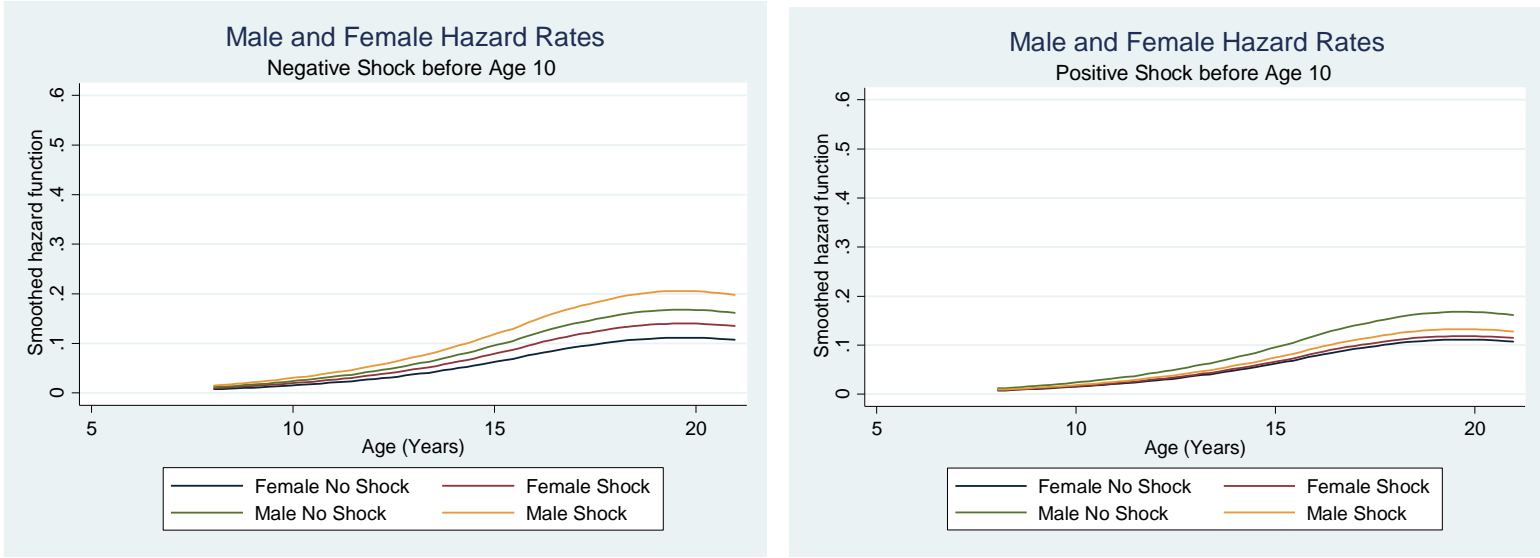
Figure C.2: Age of Entry Hazard Curves for Males and Females with High and Low Agreeableness and Extraversion in the Event of No Shocks
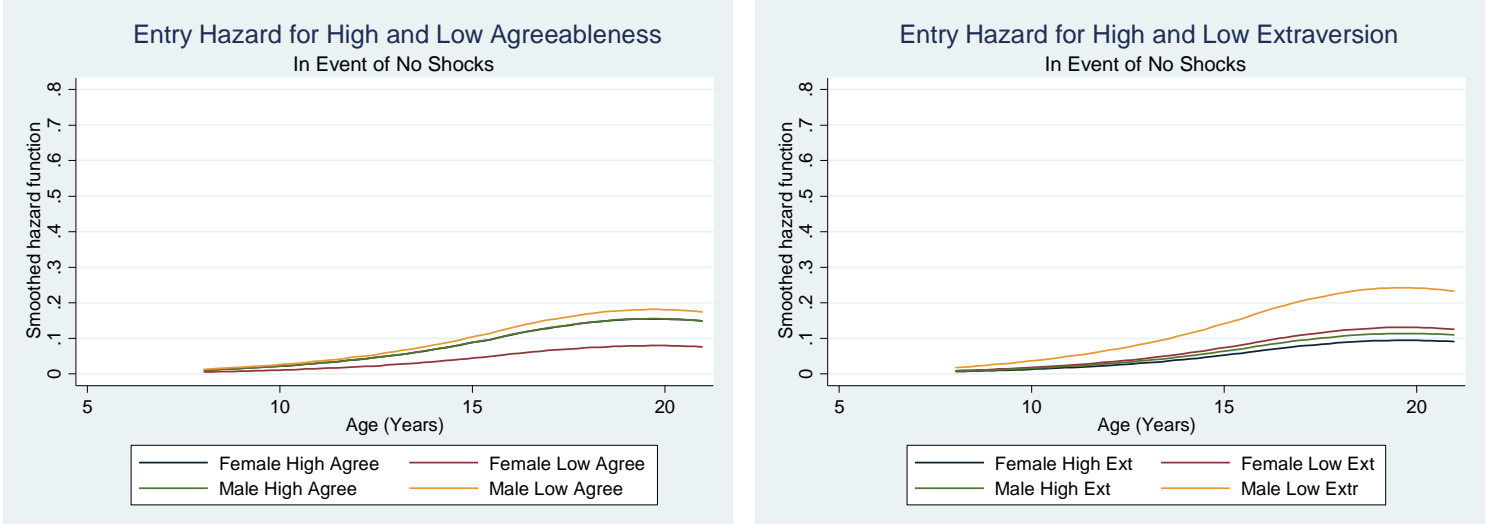
Figure C.3: Age of Entry Hazard Curves for Males and Females with High and Low Cognition across Early Shock Realizations
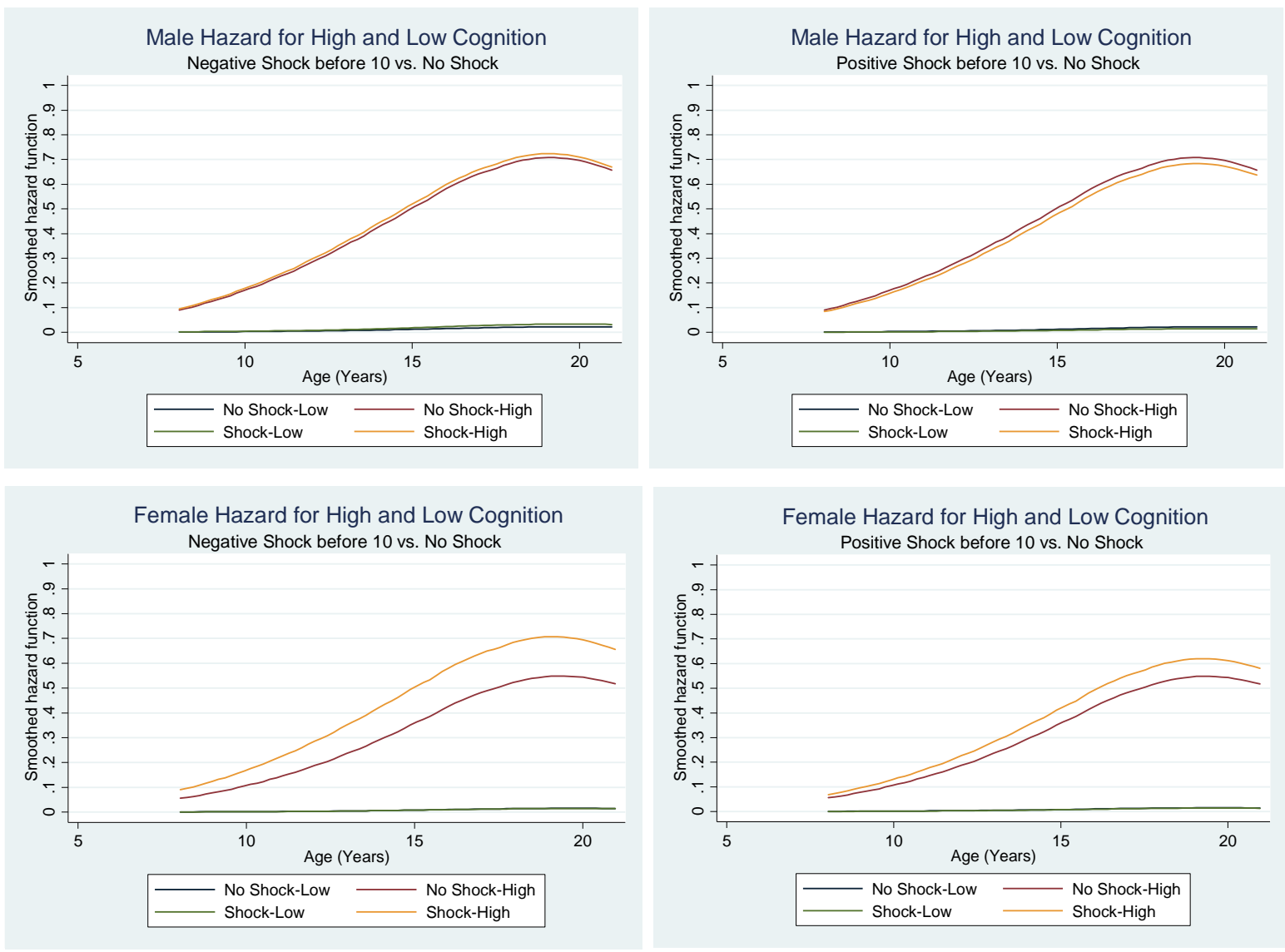
Figure C.4: Age of Entry Hazard Curves for Males with High and Low Openness across Early Shock Realizations
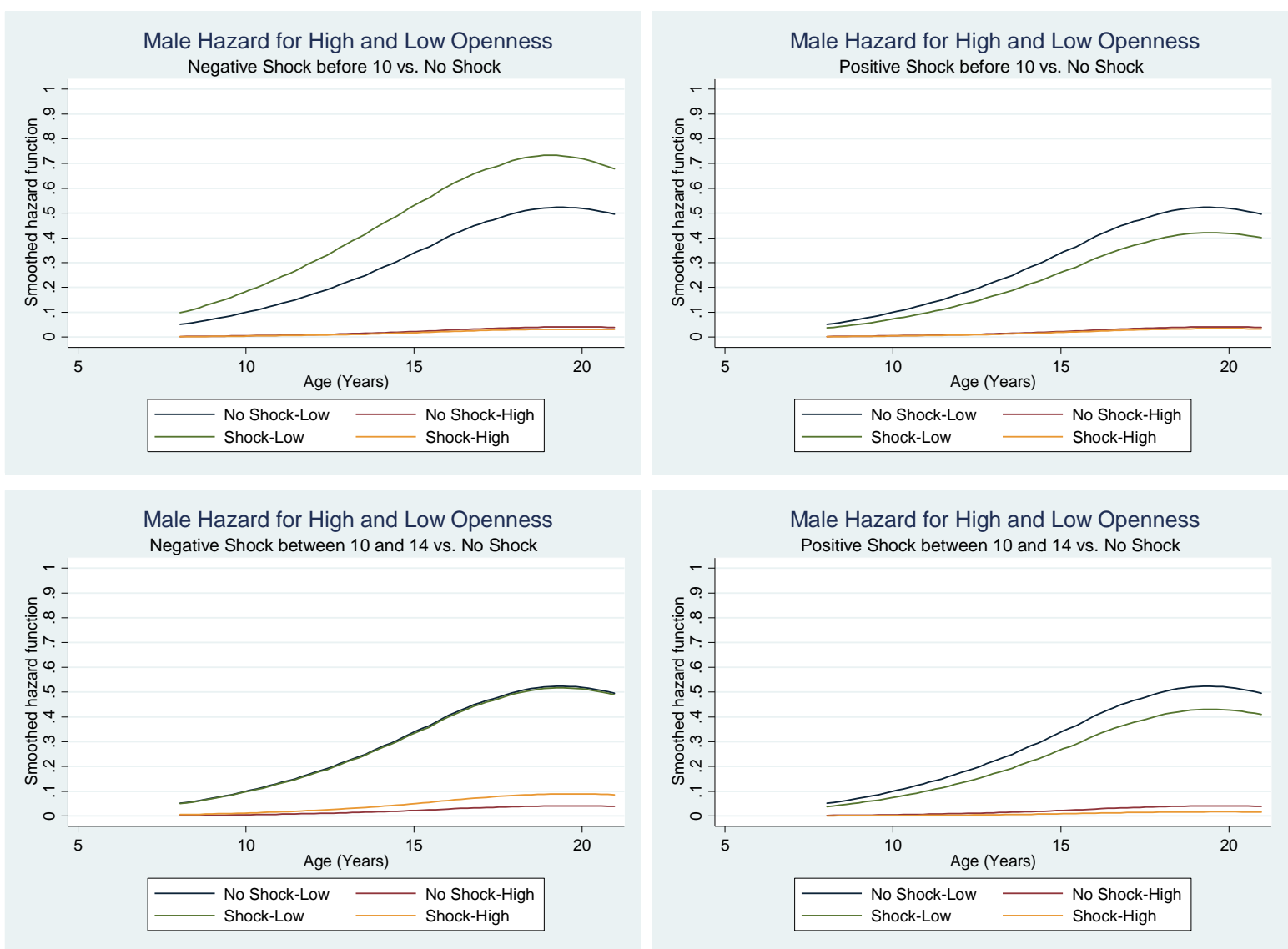
Figure C.5: Age of Entry Hazard Curves for Females with High and Low Openness across Early Shock Realizations
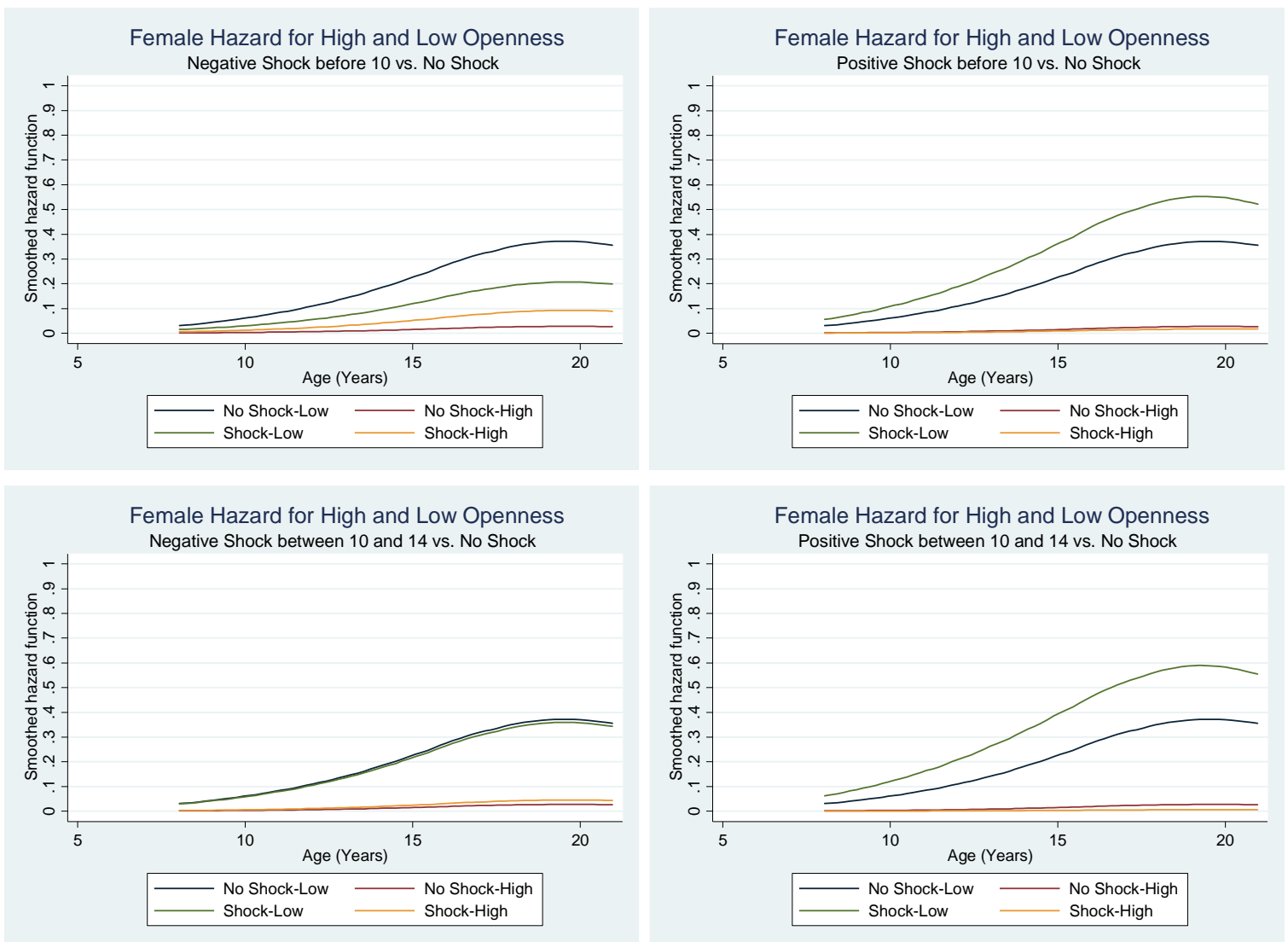
Figure C.6: Age of Entry Hazard Curves for Males with High and Low Neuroticism across Early Shock Realizations
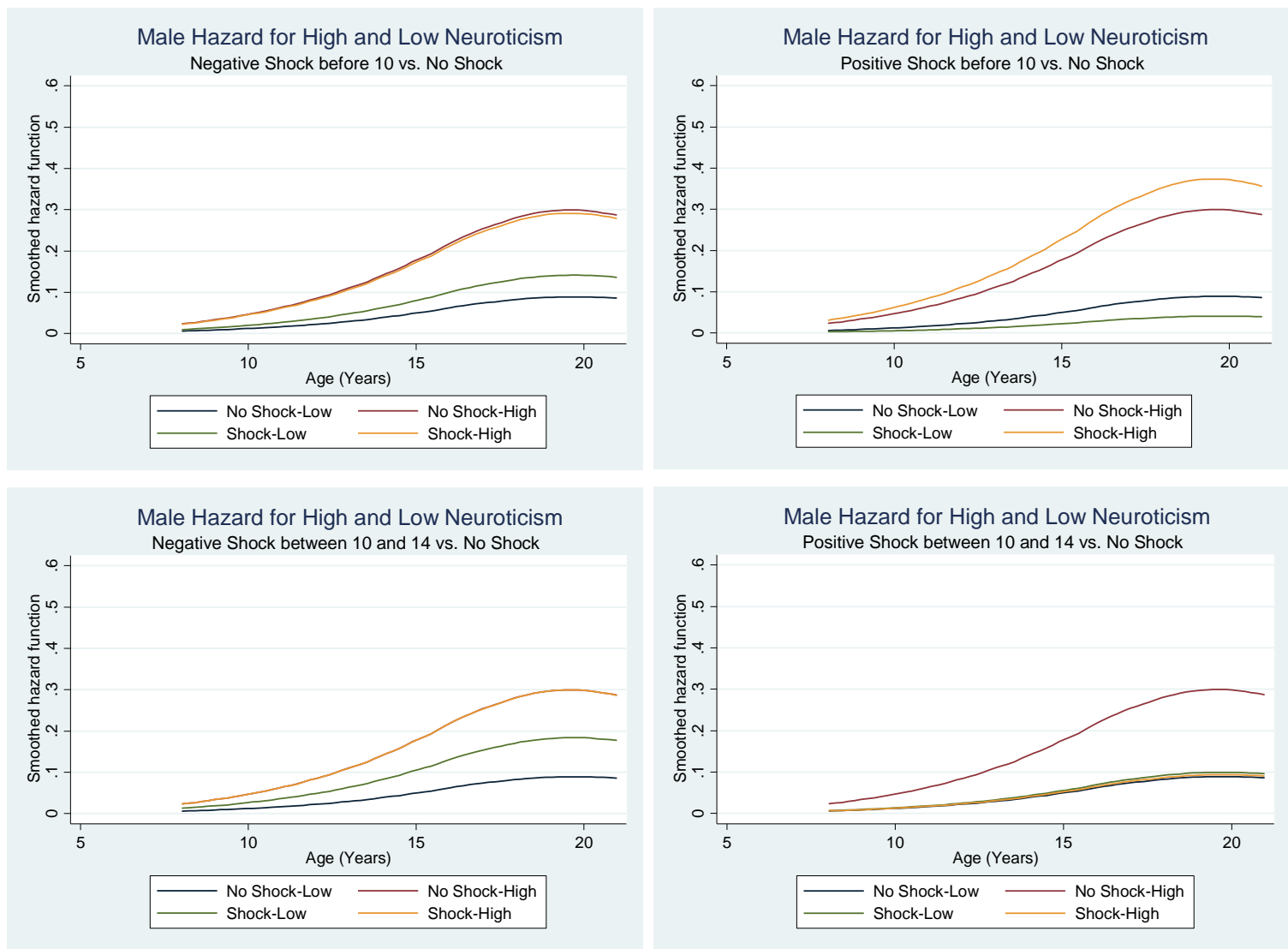
Figure C.7: Age of Entry Hazard Curves for Females with High and Low Neuroticism across Early Shock Realizations
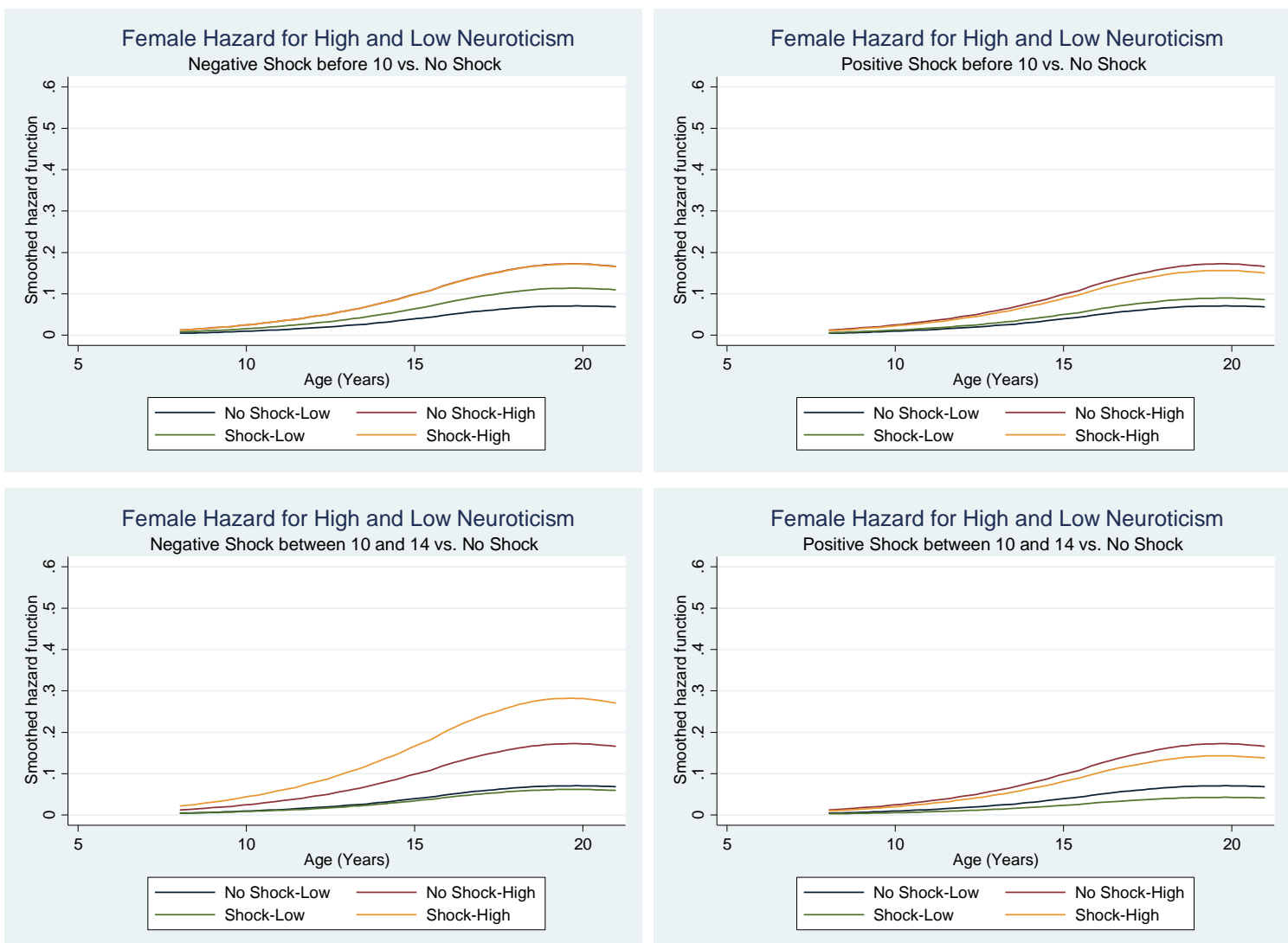
Figure C.8: Age of Entry Hazard Curves for Males and Females with High and Low Conscientiousness across Early Shock Realizations
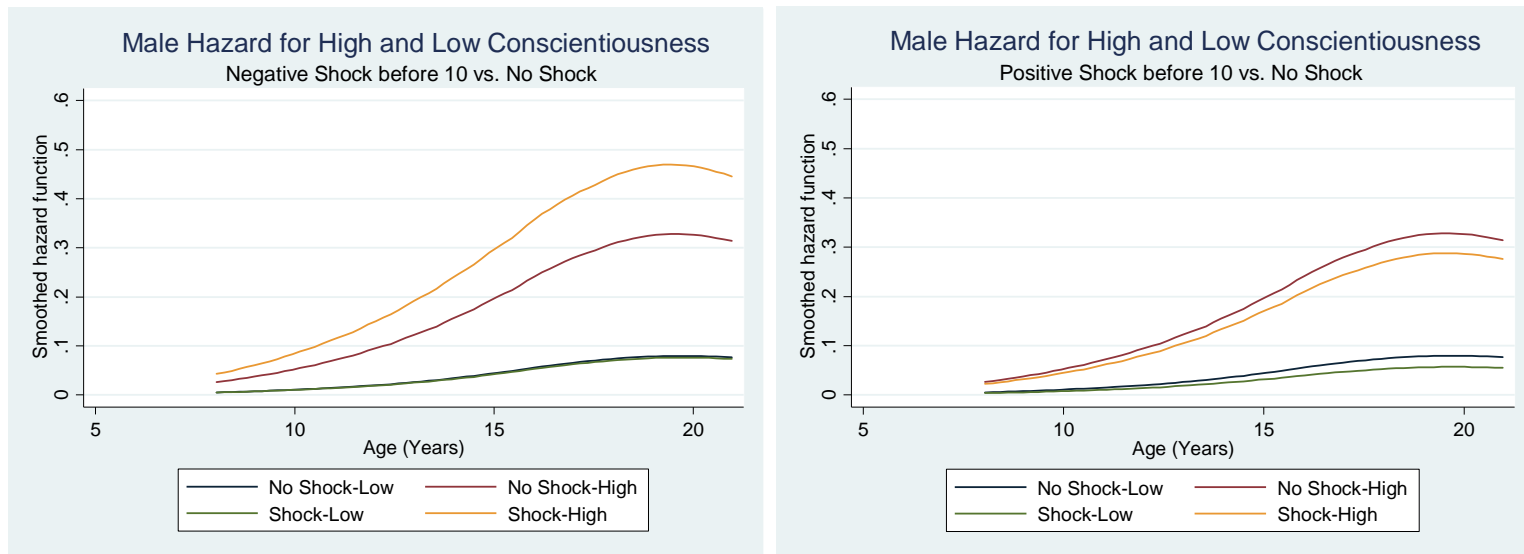

Female Hazard for High and Low Conscientiousness Negative Shock before 10 vs. No Shock

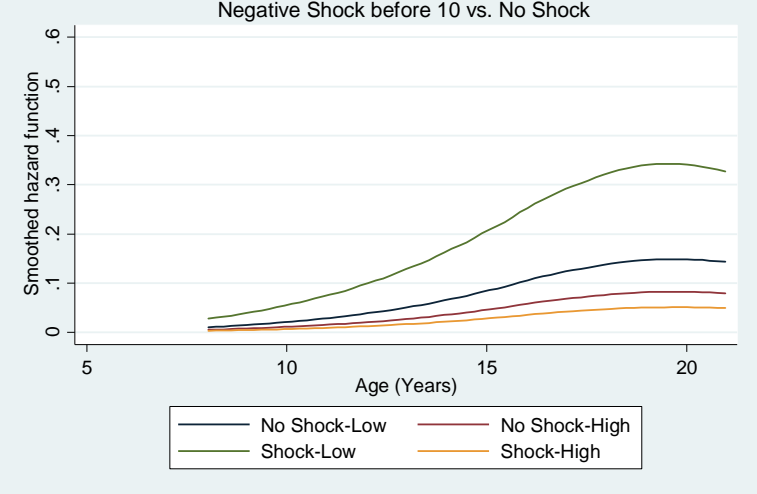

Female Hazard for High and Low Conscientiousness Positive Shock before 10 vs. No Shock

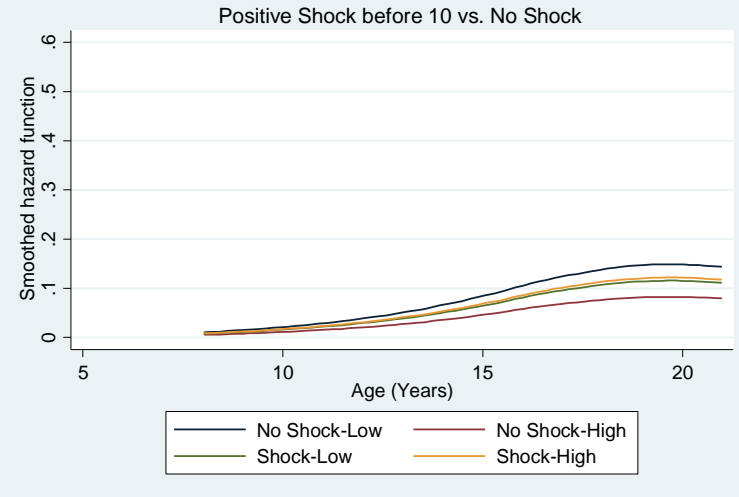


Figure C.9: Age of Entry Hazard Curves for Males with High and Low Extraversion across All Shock Realizations
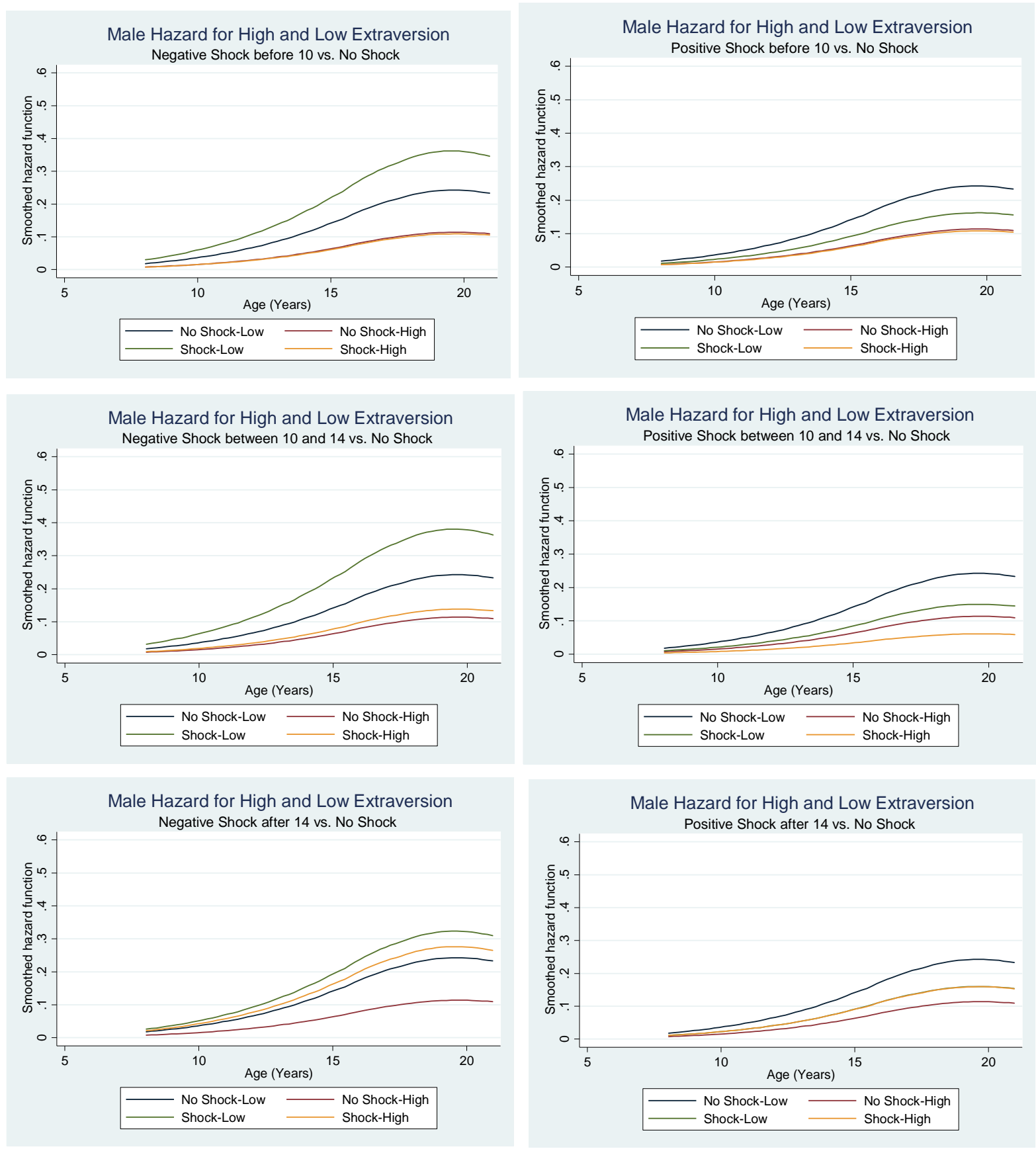
Figure C.10: Age of Entry Hazard Curves for Females with High and Low Extraversion across All Shock Realizations
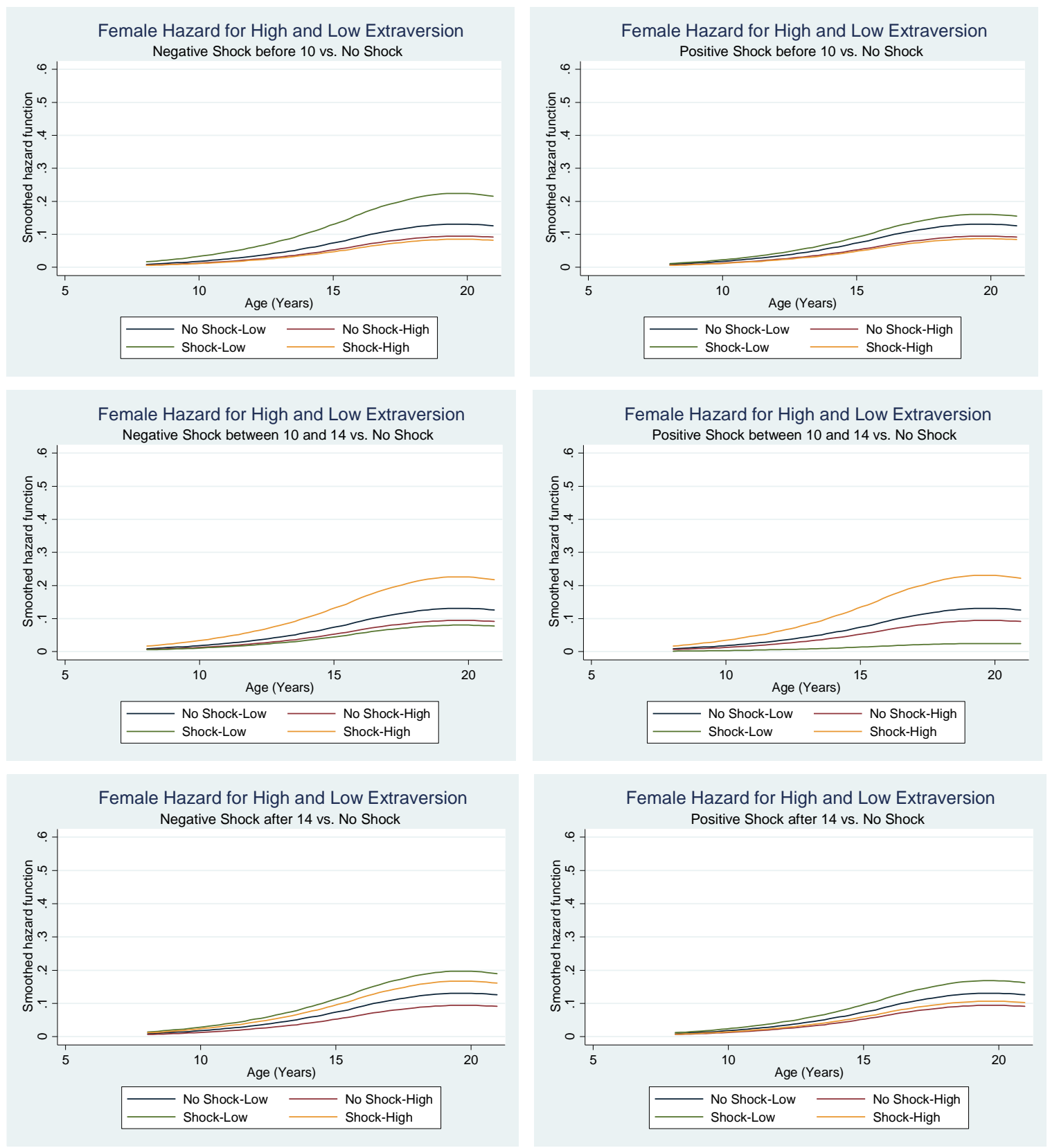
Figure C.11: Age of Entry Hazard Curves for Males with High and Low Agreeableness across All Shock Realizations
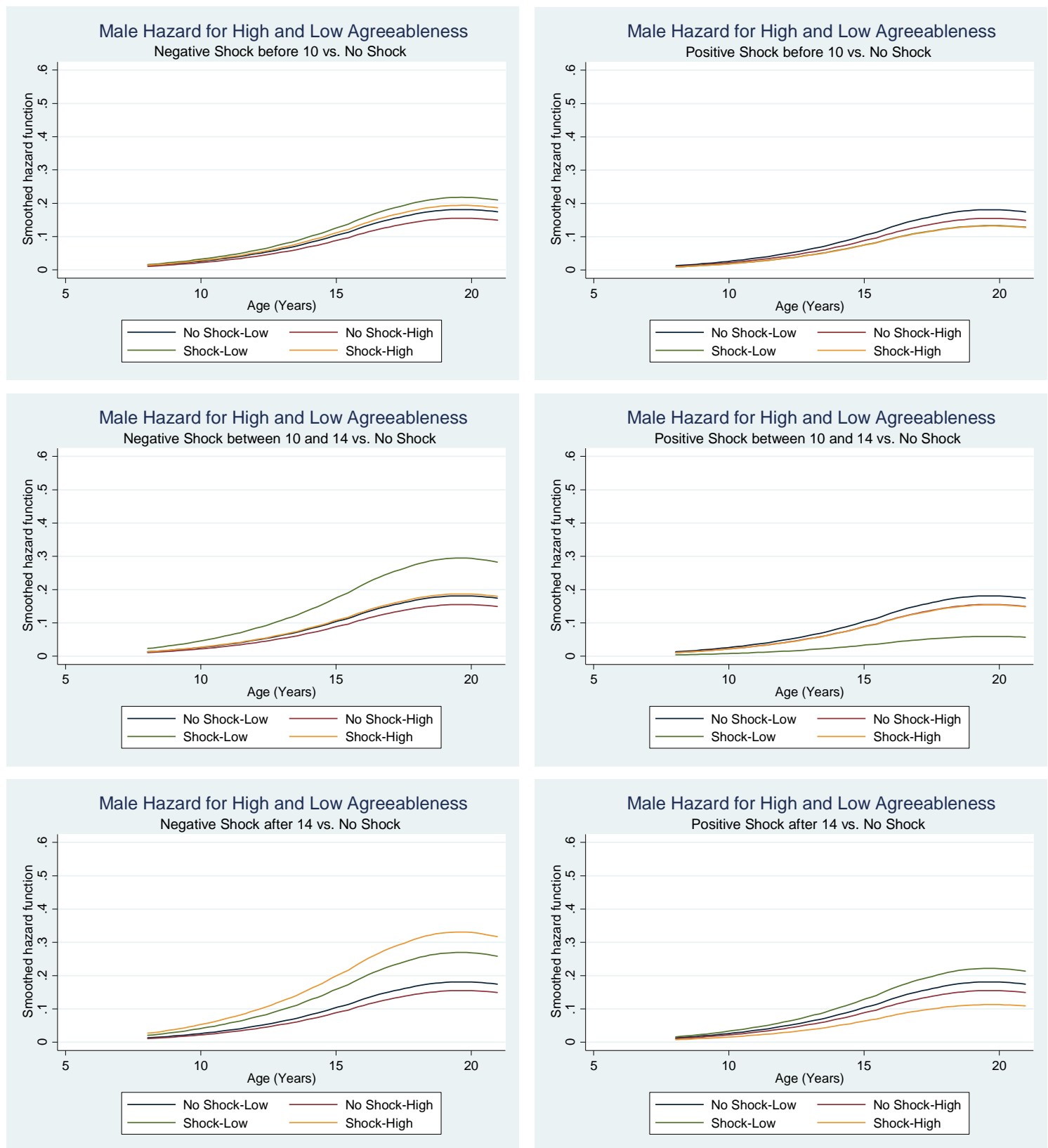
Figure C.12: Age of Entry Hazard Curves for Females with High and Low Agreeableness across All Shock Realizations
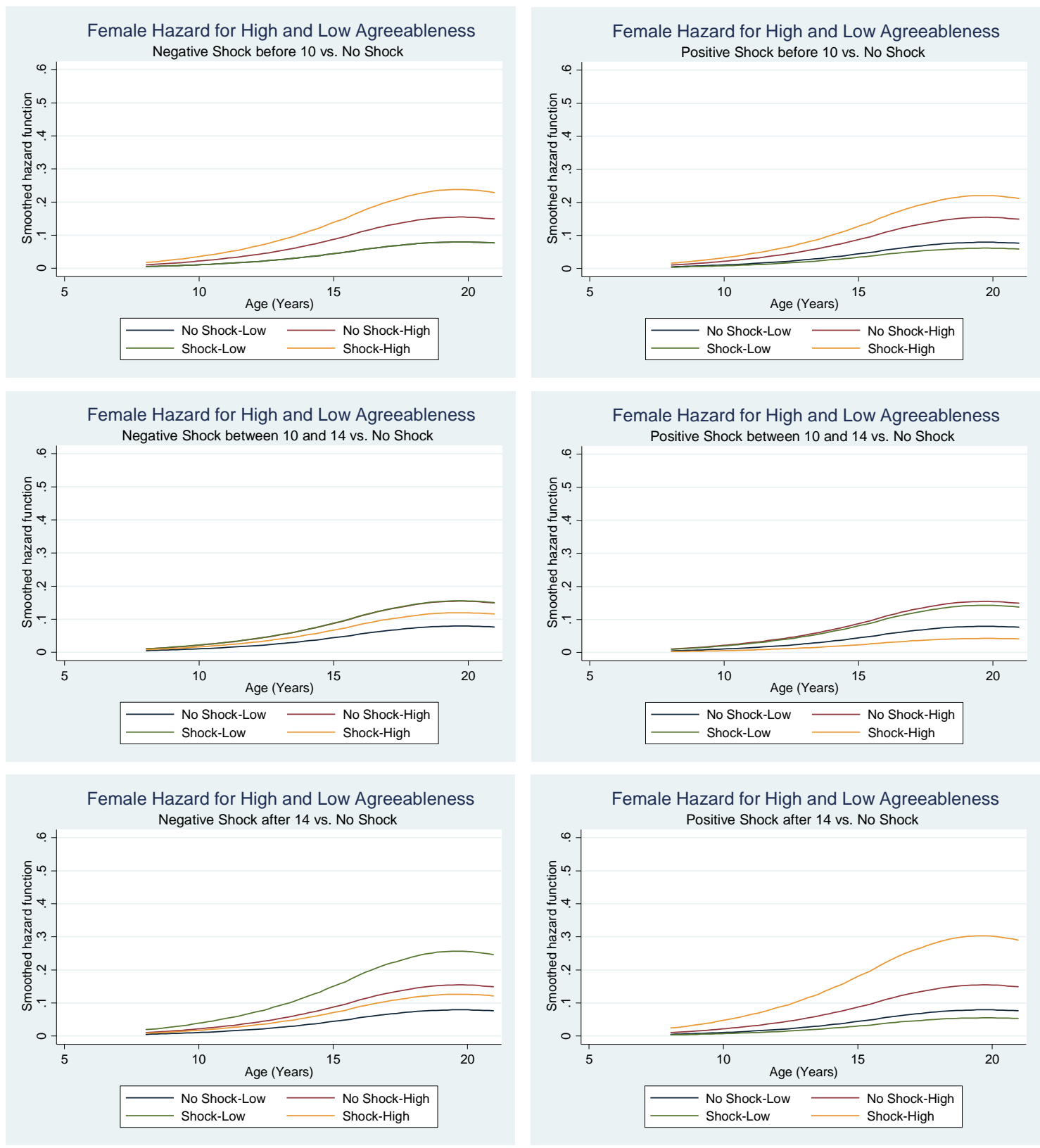
The Role of Personality, Cognition, and Shocks in Determining Labor Outcomes of Young Adults in Madagascar

\title{
Web Appendix
}

\author{
David E. Sahn \\ Cornell University \\ Forschungsinstitut zur Zukunft der Arbeit (IZA) \\ Kira M. Villa \\ Economics Department, \\ University of New Mexico
}


Table 1: Estimated Hazard Coefficients on Age of Entry with and without Controls

\begin{tabular}{lccccc}
\hline & $(1)$ & $(2)$ & $(3)$ & $(4)$ & $(5)$ \\
\hline \hline & & & & & \\
Conscientiousness Zscore & -0.0761 & -0.0634 & -0.0416 & -0.0427 & -0.0331 \\
& $(0.058)$ & $(0.061)$ & $(0.062)$ & $(0.062)$ & $(0.103)$ \\
Extraversion Zscore & -0.0450 & 0.0146 & 0.0242 & -0.0035 & -0.0074 \\
& $(0.059)$ & $(0.059)$ & $(0.060)$ & $(0.060)$ & $(0.065)$ \\
Openness to Experience Zscore & $-0.1661^{* * *}$ & -0.0474 & -0.0904 & -0.0926 & -0.3476 \\
& $(0.046)$ & $(0.053)$ & $(0.061)$ & $(0.064)$ & $(0.466)$ \\
Agreeableness Zscore & 0.0698 & 0.0415 & 0.0380 & 0.0449 & 0.0371 \\
& $(0.052)$ & $(0.054)$ & $(0.055)$ & $(0.055)$ & $(0.080)$ \\
Neuroticism Zscore & -0.0422 & -0.0032 & 0.0204 & 0.0296 & 0.1626 \\
& $(0.037)$ & $(0.039)$ & $(0.043)$ & $(0.044)$ & $(0.190)$ \\
Individual and Household & & & & & $\mathrm{X}$ \\
Controls & & $\mathrm{X}$ & $\mathrm{X}$ & $\mathrm{X}$ & $\mathrm{X}$ \\
2004 Community Controls & & & & $\mathrm{X}$ & $\mathrm{X}$ \\
2012 Community Controls & & & & $\mathrm{X}$ & $\mathrm{X}$ \\
Provence Dummies & 1,175 & 1,175 & 1,175 & 1,175 & 1,175 \\
\hline Observations & & & & & \\
\hline Standard errors in parentheses & & & & & \\
*** $\mathrm{p}<0.01, * * \mathrm{p}<0.05,{ }^{*} \mathrm{p}<0.1$ & & & & &
\end{tabular}

Individual and household controls include instrumented cognitive test score, instrumented grade, gender, 2004 household asset index, 2004 and 2012 nonlabor income, mother's and father's education, 2004 household size, number of children under 17 in the household in 2004, and the eight household-level shock variables. Community controls from 2004 include a health services index, and physical infrastructure index, a remoteness index, an indicator for whether one of the top three methods of savings is with a formal account, and an indicator for whether one of the top three sources of a large loan was with a bank. Community controls from 2012 include an urban indicator, a physical infrastructure index, and an indicator for whether a secondary school was accessible. 
Table 2: Multinomial Logit Coefficients on Selection into Unemployment with and without Controls

\begin{tabular}{lccccc}
\hline & $(1)$ & $(2)$ & $(3)$ & $(4)$ & $(5)$ \\
\hline \hline Conscientiousness Zscore & -0.0201 & -0.4207 & -0.4690 & -0.4385 & -0.3969 \\
& $(0.255)$ & $(0.496)$ & $(0.449)$ & $(0.600)$ & $(0.674)$ \\
Extraversion Zscore & 0.3243 & 0.2472 & 0.1929 & 0.0956 & 0.1171 \\
& $(0.253)$ & $(0.558)$ & $(0.420)$ & $(0.556)$ & $(0.514)$ \\
& -0.1915 & -0.1564 & -0.1233 & -0.2536 & -0.2955 \\
Openness to Experience Zscore & $(0.227)$ & $(0.483)$ & $(0.422)$ & $(0.583)$ & $(0.645)$ \\
& 0.1558 & 0.2062 & 0.1773 & 0.2176 & 0.2401 \\
Neuroticism Zscore & $(0.177)$ & $(0.252)$ & $(0.277)$ & $(0.333)$ & $(0.366)$ \\
& -0.0811 & -0.1044 & -0.0526 & 0.0095 & -0.0364 \\
Agreeableness Zscore & $(0.234)$ & $(0.504)$ & $(0.444)$ & $(0.537)$ & $(0.571)$ \\
Individual and Household & & & & & \\
Controls & & $\mathrm{X}$ & $\mathrm{X}$ & $\mathrm{X}$ & $\mathrm{X}$ \\
2004 Community Controls & & & $\mathrm{X}$ & $\mathrm{X}$ & $\mathrm{X}$ \\
2012 Community Controls & & & & $\mathrm{X}$ & $\mathrm{X}$ \\
Provence Dummies & $\mathrm{X}$ & $\mathrm{X}$ & $\mathrm{X}$ & $\mathrm{X}$ & $\mathrm{X}$ \\
Male Interacted with Personality & $\mathrm{X}$ & 1,156 & 1,156 & 1,156 & 1,156 \\
\hline Observations & 1,675 & & & & \\
\hline Standard errors in parentheses & & & & &
\end{tabular}

Individual and household controls include instrumented cognitive test score, instrumented grade, age at first job, gender, 2004 household asset index, 2004 and 2012 nonlabor income, mother's and father's education, 2004 household size, number of children under 17 in the household in 2004, and the eight household-level shock variables. Community controls from 2004 include a health services index, and physical infrastructure index, a remoteness index, an indicator for whether one of the top three methods of savings is with a formal account, and an indicator for whether one of the top three sources of a large loan was with a bank. Community controls from 2012 include an urban indicator, a physical infrastructure index, and an indicator for whether a secondary school was accessible. 
Table 3: Multinomial Logit Coefficients on Selection into Informal Employment with and without Controls

\begin{tabular}{lccccc}
\hline & $(1)$ & $(2)$ & $(3)$ & $(4)$ & $(5)$ \\
\hline \hline Conscientiousness Zscore & -0.1384 & 0.0446 & 0.0737 & 0.0862 & 0.1107 \\
& $(0.216)$ & $(0.312)$ & $(0.343)$ & $(0.264)$ & $(0.348)$ \\
Extraversion Zscore & 0.0602 & -0.2019 & -0.2120 & -0.1927 & -0.1590 \\
& $(0.209)$ & $(0.319)$ & $(0.309)$ & $(0.369)$ & $(0.383)$ \\
Openness to Experience Zscore & $-0.4498^{* *}$ & -0.1705 & -0.2574 & -0.2588 & -0.3013 \\
& $(0.184)$ & $(0.216)$ & $(0.277)$ & $(0.275)$ & $(0.339)$ \\
Neuroticism Zscore & $0.2621^{*}$ & $0.3403^{* *}$ & $0.3630^{*}$ & $0.3703^{* *}$ & $0.3957 * *$ \\
& $(0.146)$ & $(0.161)$ & $(0.186)$ & $(0.181)$ & $(0.200)$ \\
Agreeableness Zscore & 0.2285 & 0.1535 & 0.1288 & 0.0882 & 0.0606 \\
Individual and Household & $(0.225)$ & $(0.338)$ & $(0.321)$ & $(0.282)$ & $(0.289)$ \\
Controls & & & & & $\mathrm{X}$ \\
2004 Community Controls & & $\mathrm{X}$ & $\mathrm{X}$ & $\mathrm{X}$ & $\mathrm{X}$ \\
2012 Community Controls & & & $\mathrm{X}$ & $\mathrm{X}$ & $\mathrm{X}$ \\
Provence Dummies & & & & $\mathrm{X}$ & $\mathrm{X}$ \\
Male Interacted with Personality & $\mathrm{X}$ & $\mathrm{X}$ & $\mathrm{X}$ & $\mathrm{X}$ & $\mathrm{X}$ \\
\hline Observations & 1,675 & 1,156 & 1,156 & 1,156 & 1,156 \\
\hline
\end{tabular}

Standard errors in parentheses

*** $\mathrm{p}<0.01, * * \mathrm{p}<0.05, * \mathrm{p}<0.1$

Individual and household controls include instrumented cognitive test score, instrumented grade, age at first job, gender, 2004 household asset index, 2004 and 2012 nonlabor income, mother's and father's education, 2004 household size, number of children under 17 in the household in 2004, and the eight household-level shock variables. Community controls from 2004 include a health services index, and physical infrastructure index, a remoteness index, an indicator for whether one of the top three methods of savings is with a formal account, and an indicator for whether one of the top three sources of a large loan was with a bank. Community controls from 2012 include an urban indicator, a physical infrastructure index, and an indicator for whether a secondary school was accessible. 
Table 4: Multinomial Logit Coefficients on Selection into Student with and without Controls

\begin{tabular}{lccccc}
\hline & $(1)$ & $(2)$ & $(3)$ & $(4)$ & $(5)$ \\
\hline \hline Conscientiousness Zscore & -0.0924 & -0.6674 & -0.6088 & -0.6189 & -0.6148 \\
& $(0.231)$ & $(0.588)$ & $(0.526)$ & $(0.577)$ & $(0.691)$ \\
Extraversion Zscore & 0.0300 & 0.1281 & 0.1059 & 0.0441 & 0.0405 \\
& $(0.304)$ & $(0.608)$ & $(0.574)$ & $(0.701)$ & $(0.727)$ \\
Openness to Experience Zscore & $0.3878^{*}$ & -0.0383 & -0.2264 & -0.3548 & -0.8131 \\
& $(0.210)$ & $(0.471)$ & $(0.408)$ & $(0.598)$ & $(0.684)$ \\
Neuroticism Zscore & 0.2147 & $0.5432 * *$ & $0.6271^{* *}$ & $0.6512^{*}$ & $0.7809 * *$ \\
& $(0.153)$ & $(0.277)$ & $(0.305)$ & $(0.350)$ & $(0.394)$ \\
Agreeableness Zscore & 0.0474 & -0.0731 & -0.0597 & 0.0349 & -0.0157 \\
Individual and Household & $(0.289)$ & $(0.538)$ & $(0.527)$ & $(0.474)$ & $(0.598)$ \\
Controls & & & & & \\
2004 Community Controls & & $\mathrm{X}$ & $\mathrm{X}$ & $\mathrm{X}$ & $\mathrm{X}$ \\
2012 Community Controls & & & $\mathrm{X}$ & $\mathrm{X}$ & $\mathrm{X}$ \\
Provence Dummies & & & & $\mathrm{X}$ & $\mathrm{X}$ \\
Male Interacted with Personality & $\mathrm{X}$ & $\mathrm{X}$ & $\mathrm{X}$ & $\mathrm{X}$ & $\mathrm{X}$ \\
\hline Observations & 1,675 & 1,156 & 1,156 & 1,156 & 1,156 \\
\hline Standard errors in parentheses & & & & & \\
${ }^{* * *} \mathrm{p}<0.01, * * \mathrm{p}<0.05, * \mathrm{p}<0.1$ & & & & &
\end{tabular}

Individual and household controls include instrumented cognitive test score, instrumented grade, age at first job, gender, 2004 household asset index, 2004 and 2012 nonlabor income, mother's and father's education, 2004 household size, number of children under 17 in the household in 2004, and the eight household-level shock variables. Community controls from 2004 include a health services index, and physical infrastructure index, a remoteness index, an indicator for whether one of the top three methods of savings is with a formal account, and an indicator for whether one of the top three sources of a large loan was with a bank. Community controls from 2012 include an urban indicator, a physical infrastructure index, and an indicator for whether a secondary school was accessible. 
Table 5: Personality Coefficients for Informal Sector Earnings with and without Controls

\begin{tabular}{lcccc}
\hline & $(1)$ & $(2)$ & $(3)$ & $(4)$ \\
\hline \hline Conscientiousness Zscore & 0.1680 & -0.0134 & 0.1074 & 0.1260 \\
& $(0.168)$ & $(0.177)$ & $(0.152)$ & $(0.192)$ \\
Extraversion Zscore & -0.0682 & 0.0147 & 0.0327 & 0.0059 \\
& $(0.243)$ & $(0.266)$ & $(0.203)$ & $(0.221)$ \\
Openness to Experience Zscore & 0.1051 & $0.2645^{*}$ & 0.1162 & 0.1742 \\
& $(0.147)$ & $(0.151)$ & $(0.165)$ & $(0.208)$ \\
Neuroticism & 0.1750 & 0.0710 & 0.1607 & 0.0989 \\
& $(0.137)$ & $(0.097)$ & $(0.118)$ & $(0.143)$ \\
Agreeableness & -0.0663 & -0.0920 & -0.1135 & -0.1413 \\
& $(0.171)$ & $(0.153)$ & $(0.166)$ & $(0.153)$ \\
Individual and Household & & & & \\
Controls & & $\mathrm{X}$ & $\mathrm{X}$ & $\mathrm{X}$ \\
2004 Community Controls & & & $\mathrm{X}$ & $\mathrm{X}$ \\
2012 Community Controls & & & & $\mathrm{X}$ \\
Male Interacted with Personality & $\mathrm{X}$ & $\mathrm{X}$ & $\mathrm{X}$ & $\mathrm{X}$ \\
Male Interacted with Cognition & & $\mathrm{X}$ & $\mathrm{X}$ & $\mathrm{X}$ \\
Male Interacted with Grade & & $\mathrm{X}$ & $\mathrm{X}$ & $\mathrm{X}$ \\
Selection Correction Terms & $\mathrm{X}$ & $\mathrm{X}$ & $\mathrm{X}$ & $\mathrm{X}$ \\
\hline Observations & 748 & 748 & 748 & 748 \\
\hline Standard errors in parentheses & & & & \\
*** p<0.01, ** p<0.05, * p $<0.1$ & & & &
\end{tabular}

Individual and household controls include instrumented cognitive test score, instrumented grade, age at first job, gender, 2004 household asset index, 2004 and 2012 nonlabor income, mother's and father's education, 2004 household size, number of children under 17 in the household in 2004, and the eight household-level shock variables. Community controls from 2004 include a health services index, and physical infrastructure index, a remoteness index, an indicator for whether one of the top three methods of savings is with a formal account, and an indicator for whether one of the top three sources of a large loan was with a bank. Community controls from 2012 include an urban indicator, a physical infrastructure index, and an indicator for whether a secondary school was accessible. 
Table 6: Personality Coefficients for Formal Sector Earnings with and without Controls

\begin{tabular}{|c|c|c|c|c|}
\hline & (1) & (2) & (3) & (4) \\
\hline Conscientiousness Zscore & $\begin{array}{c}1.1695^{* *} \\
(0.569)\end{array}$ & $\begin{array}{c}1.0378^{*} \\
(0.638)\end{array}$ & $\begin{array}{c}0.9448 \\
(0.748)\end{array}$ & $\begin{array}{c}1.1427^{*} \\
(0.684)\end{array}$ \\
\hline Extraversion Zscore & $\begin{array}{c}-0.6977 \\
(0.613)\end{array}$ & $\begin{array}{c}-0.3433 \\
(0.583)\end{array}$ & $\begin{array}{c}-0.0720 \\
(0.614)\end{array}$ & $\begin{array}{c}-0.5663 \\
(0.771)\end{array}$ \\
\hline Openness to Experience Zscore & $\begin{array}{c}-1.0654^{* *} \\
(0.466)\end{array}$ & $\begin{array}{c}-0.9455^{*} \\
(0.545)\end{array}$ & $-1.1682 * *$ & $\begin{array}{c}-0.7884 \\
(0.600)\end{array}$ \\
\hline Neuroticism Zscore & $\begin{array}{c}-0.3699 \\
(0.311)\end{array}$ & $\begin{array}{c}-0.5288 \\
(0.374)\end{array}$ & $\begin{array}{c}-0.4287 \\
(0.364)\end{array}$ & $\begin{array}{c}-0.8294 * * \\
(0.415)\end{array}$ \\
\hline Agreeableness Zscore & $\begin{array}{c}0.0441 \\
(0.436)\end{array}$ & $\begin{array}{c}0.0334 \\
(0.503)\end{array}$ & $\begin{array}{c}-0.0559 \\
(0.390)\end{array}$ & $\begin{array}{c}-0.0812 \\
(0.460)\end{array}$ \\
\hline Individual and Household & & & & \\
\hline Controls & & $\mathrm{X}$ & $\mathrm{X}$ & $\mathrm{X}$ \\
\hline 2004 Community Controls & & & $\mathrm{X}$ & $\mathrm{X}$ \\
\hline 2012 Community Controls & & & & $\mathrm{X}$ \\
\hline Male Interacted with Personality & $\mathrm{X}$ & $\mathrm{X}$ & $\mathrm{X}$ & $\mathrm{X}$ \\
\hline Male Interacted with Cognition & & $\mathrm{X}$ & $\mathrm{X}$ & $\mathrm{X}$ \\
\hline Male Interacted with Grade & & $\mathrm{X}$ & $\mathrm{X}$ & $\mathrm{X}$ \\
\hline Selection Correction Terms & $\mathrm{X}$ & $\mathrm{X}$ & $\mathrm{X}$ & $\mathrm{X}$ \\
\hline Observations & 227 & 227 & 227 & 227 \\
\hline
\end{tabular}

Individual and household controls include instrumented cognitive test score, instrumented grade, age at first job, gender, 2004 household asset index, 2004 and 2012 nonlabor income, mother's and father's education, 2004 household size, number of children under 17 in the household in 2004, and the eight household-level shock variables. Community controls from 2004 include a health services index, and physical infrastructure index, a remoteness index, an indicator for whether one of the top three methods of savings is with a formal account, and an indicator for whether one of the top three sources of a large loan was with a bank. Community controls from 2012 include an urban indicator, a physical infrastructure index, and an indicator for whether a secondary school was accessible. 